Aus der Abteilung Vegetative Physiologie und Pathophysiologie (Prof. Dr. med. G. Burckhardt) im Zentrum Physiologie und Pathophysiologie der Medizinischen Fakultät der Universität Göttingen

\title{
Interaktion der Organische-Anionen-Transporter 1 und 3 mit Dicarboxylaten
}

\author{
INAUGURAL-DISSERTATION \\ zur Erlangung des Doktorgrades für Zahnheilkunde \\ der Medizinischen Fakultät \\ der Georg-August-Universität zu Göttingen \\ vorgelegt von \\ Marcel Kaufhold \\ aus \\ Mühlhausen/ Thüringen
}

Göttingen 2013 
I. Berichterstatter: PD Dr. rer. nat. W. Krick

II. Berichterstatter/-in:

III. Berichterstatter/-in:

Tag der mündlichen Prüfung: 


\section{Inhaltsverzeichnis}

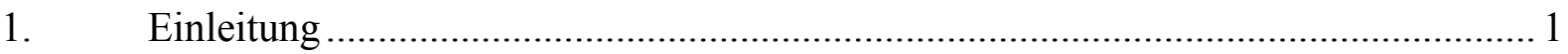

1.1. Die SLC22-Transporter-Familie ..................................................................... 3

1.2. Der Organische-Anionen-Transporter 1 (OAT1)................................................. 3

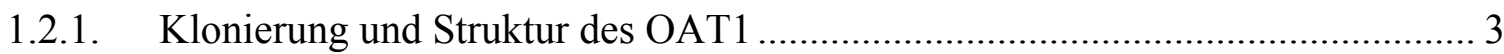

1.2.2. Immunhistochemie und Gewebeverteilung des OAT1 .................................. 4

1.2.3. Substrate und Substratbindung des OAT1 ..................................................... 4

1.3. Der Organische-Anionen-Transporter 3 (OAT3) .................................................. 7

1.3.1. Klonierung und Struktur des OAT3 ........................................................... 7

1.3.2. Immunhistochemie und Gewebeverteilung des OAT3 ................................... 7

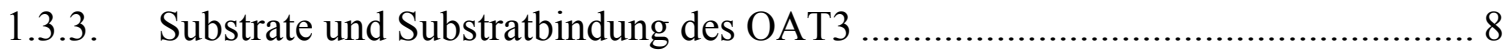

1.4. Weitere Mitglieder der Familie der Organische-Anionen-Transporter ..................... 9

1.5. Dicarboxylate und die $\mathrm{Na}^{+}$-Dicarboxylat-Cotransporter .................................... 10

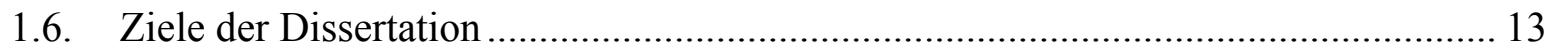

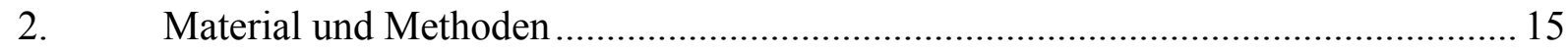

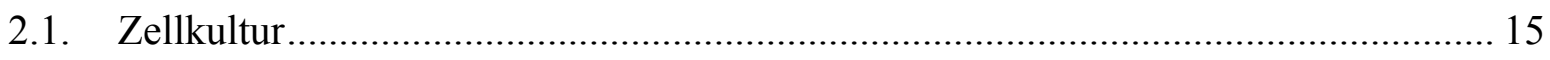

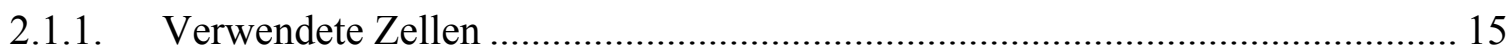

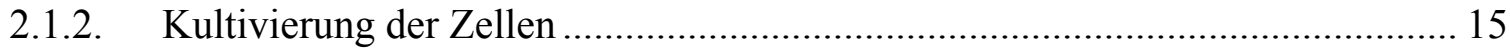

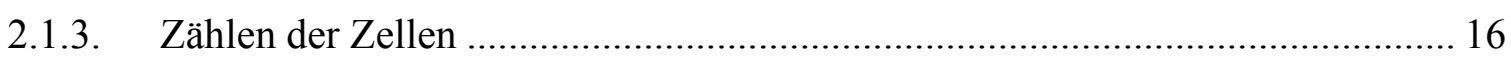

2.1.4. Aussäen der stabil-transfizierten Zellen in 24-Loch-Platten .............................. 16

2.2. Messung der Aufnahme radioaktiv markierter Substrate in die Zellen .................... 16

2.2.1. Vorbereitung der Zellen und Herstellung der Transportlösungen ..................... 16

2.2.2. Transportmessung mit radioaktiv markierten Substraten................................. 17

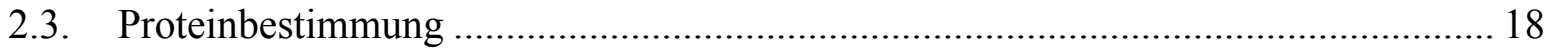

2.4. Zusammensetzung der Kulturmedien und Lösungen............................................ 19

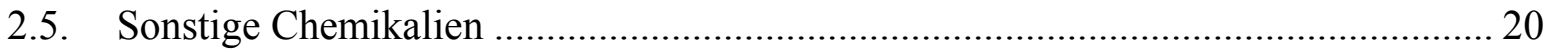

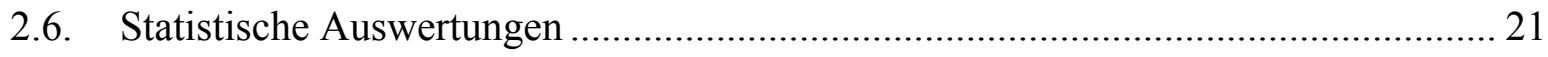

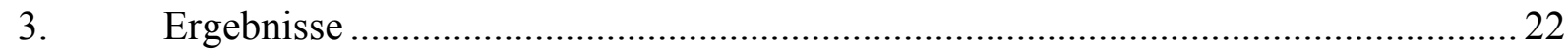


3.1. Zeitabhängigkeit des Organische-Anionen-Transports in hOAT1- und hOAT3-

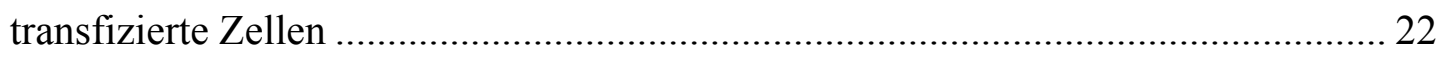

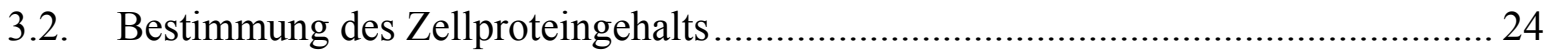

3.3. Bestimmung der unspezifischen Substrataufnahme und Substratbindung ................ 25

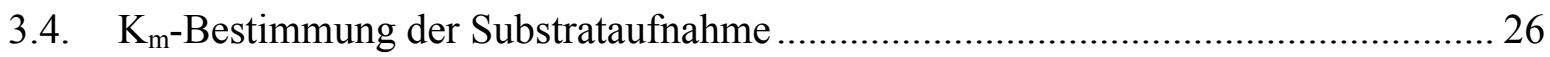

3.5. Bestimmung der $\mathrm{IC}_{50}$ - und $\mathrm{K}_{\mathrm{i}}$-Werte für die Substrattransporte durch hOAT1 und hOAT3

3.6. Bestimmung der $\mathrm{IC}_{50}$-Werte der Dicarboxylate für den PAH-Transport durch

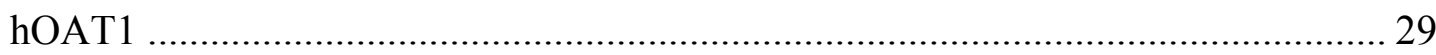

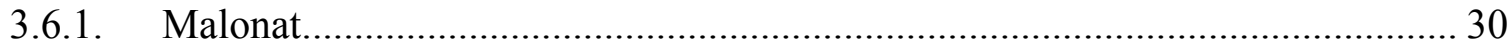

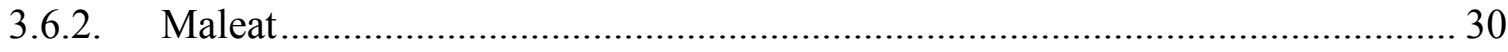

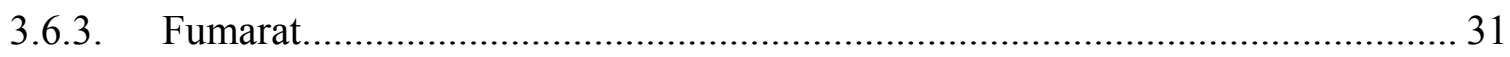

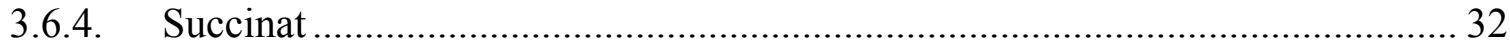

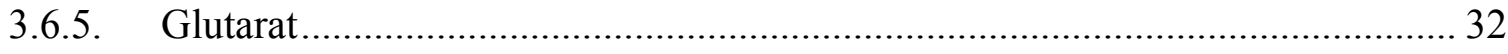

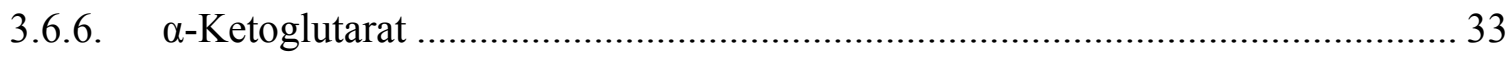

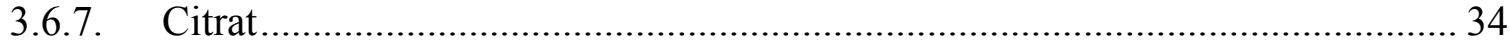

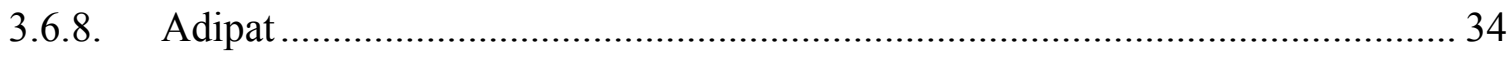

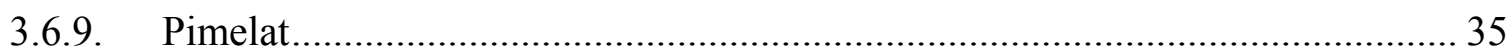

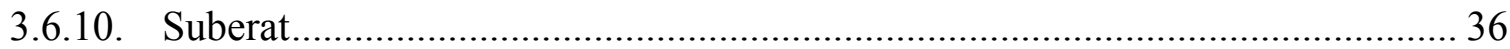

3.7. Bestimmung der $\mathrm{K}_{\mathrm{i}}$-Werte von zwei Dicarboxylaten für den PAH-Transport durch

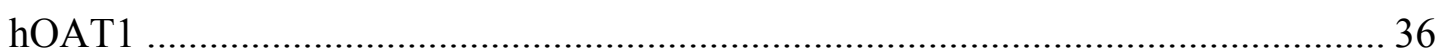

3.7.1. $\quad \mathrm{K}_{\mathrm{i}}$-Wert von Glutarat für den PAH-Transport durch hOAT1 …....................... 37

3.7.2. $\quad \mathrm{K}_{\mathrm{i}}$-Wert von $\alpha$-Ketoglutarat für den PAH-Transport durch hOAT1 …............... 37

3.8. Bestimmung der $\mathrm{IC}_{50}$-Werte der Dicarboxylate für den Östronsulfat-Transport

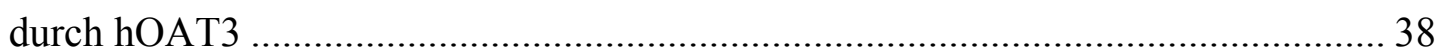

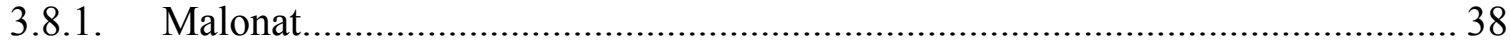

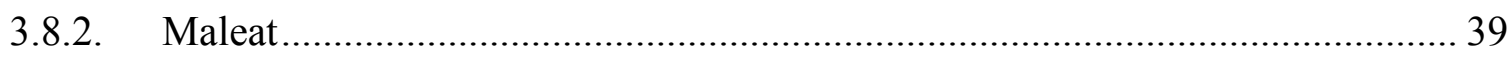

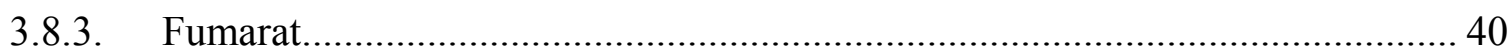

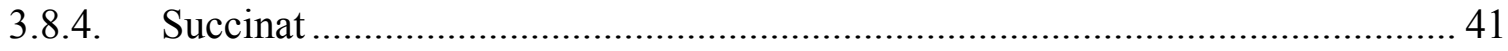

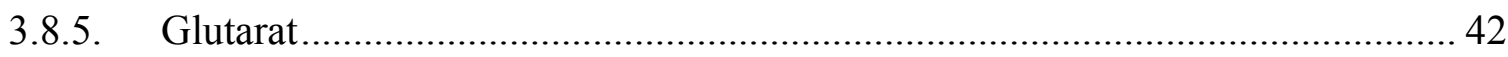

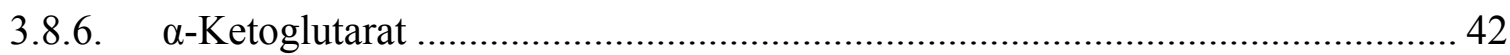




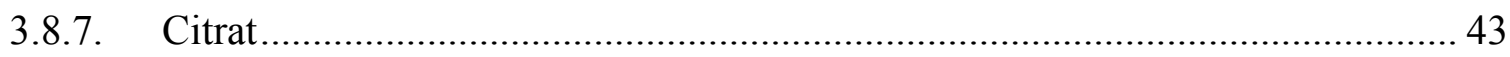

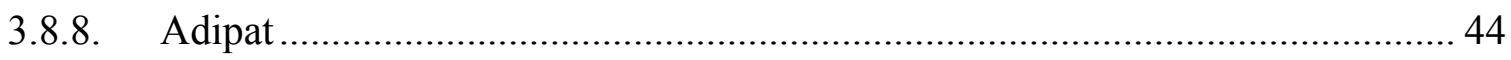

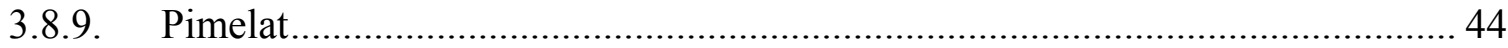

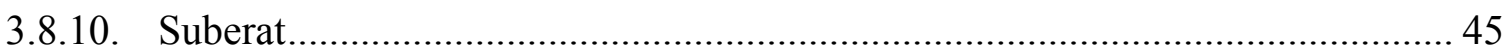

3.9. Bestimmung der $\mathrm{K}_{\mathrm{i}}$-Werte von zwei Dicarboxylaten für den Östronsulfat-

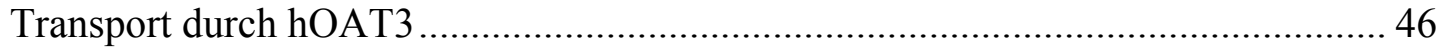

3.9.1. $\mathrm{K}_{\mathrm{i}}$-Wert von Glutarat für den Östronsulfat-Transport durch hOAT3 ................ 46

3.9.2. $\mathrm{K}_{\mathrm{i}}$-Wert von $\alpha$-Ketoglutarat für den Östronsulfat-Transport durch hOAT3 ...... 47

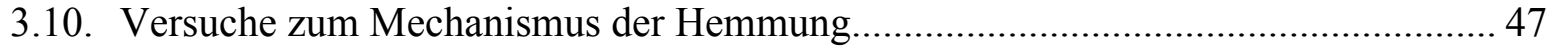

3.10.1. Messung der ${ }^{3} \mathrm{H}-\mathrm{PAH}-\mathrm{Aufnahme}$ durch hOAT1 in An- und Abwesenheit von

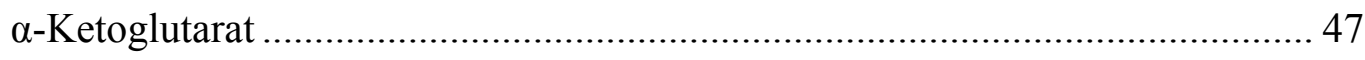

3.10.2. Messung der ${ }^{3} \mathrm{H}$-Östronsulfat-Aufnahme durch hOAT3 in An- und

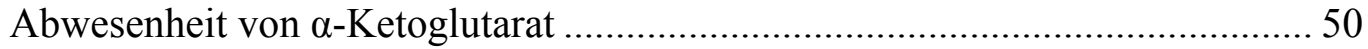

3.11. Zusammenfassung der gemessenen $\mathrm{IC}_{50}$ - und $\mathrm{K}_{\mathrm{i}}-$ Werte........................................ 52

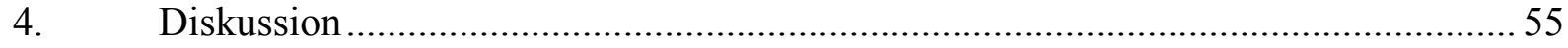

4.1. Bestimmung der spezifischen Substrataufnahme durch hOAT1 und hOAT3 .......... 55

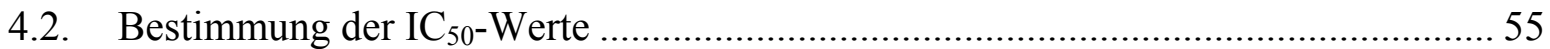

4.3. Bestimmung des $\mathrm{K}_{\mathrm{m}}$-Wertes des PAH- und Östronsulfat-Transports ...................... 57

4.4. $\mathrm{K}_{\mathrm{i}}$-Bestimmung und Hemmmechanismen ........................................................... 58

4.5. $\mathrm{IC}_{50}$-Werte der Hemmung von hOAT1 und hOAT3 durch die Dicarboxylate........... 63

4.6. Die Bindungstasche der Dicarboxylate in den Organische-Anionen-Transportern... 66

4.7. Physiologie des Dicarboxylat- und Organische-Anionen-Transports durch hOAT1

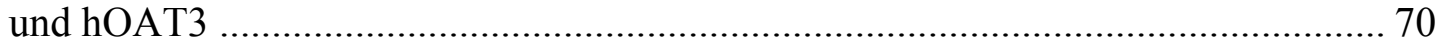

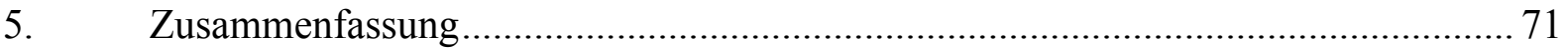

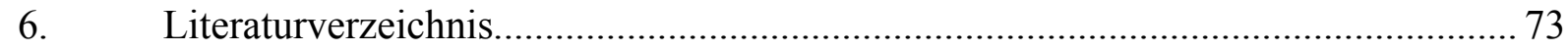

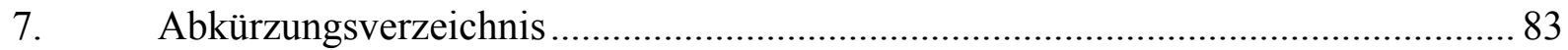




\section{1. $\quad$ Einleitung}

Im menschlichen Körper gibt es viele verschiedene Substanzen, die in die Gruppe der organischen Anionen oder organischen Kationen gehören, und daher beim physiologischen pH-Wert von 7,4 eine oder mehrere elektrische Ladungen haben. Darunter sind viele Stoffwechselendprodukte, Pharmaka und auch Pflanzeninhaltsstoffe. Die Ausscheidung dieser potentiell schädlichen Stoffe erfolgt über die Nieren oder mit der Galle über die Leber.

Die Nieren bestehen aus Nierenrinde und Nierenmark. Nephrone sind die Funktionseinheiten der Niere und setzen sich aus einem Glomerulus mit Bowman-Kapsel und einem Tubulussystem zusammen. Das Tubulussystem ist in mehrere Abschnitte gegliedert: proximaler Tubulus, Henle-Schleife und distaler Tubulus, der in ein Sammelrohr mündet. In den Glomeruli wird der Primärharn filtriert, dessen Zusammensetzung sich beim Durchlauf durch das Tubulussystem durch Sekretions- und Resorptionsvorgänge noch ändert, bevor er als endgültiger Harn ausgeschieden wird (SCHMIDT et al. 2005).

Die Ausscheidung organischer Anionen und Kationen erfolgt in den humanen Nieren zum einen durch Filtration, zum anderen können einige organische Ionen auch noch zusätzlich sezerniert werden. Bei der Sekretion werden die organischen Anionen über die basolaterale Membran aus dem Blut in die proximalen Tubuluszellen aufgenommen und über die apikale Membran ins Lumen der proximalen Tubuli abgegeben. Durch diese zusätzliche Sekretion können also z.B. toxische Substanzen oder auch Pharmaka schneller ausgeschieden werden. Auf der anderen Seite können sich aber auch z.B. zwei gleichzeitig eingenommene Pharmaka durch die gleichzeitige Interaktion mit dem Sekretionssystem gegenseitig in ihrer Ausscheidung behindern, wodurch es zu erhöhten Plasmakonzentrationen dieser Pharmaka mit eventuell schädlichen Wirkungen kommen kann (RIZWAN und BURCKHARDT G 2007).

ULLRICH et al. haben durch in vivo Untersuchungen mit perfundierten Rattennieren ein „PAH-Transport-System“ identifiziert (ULLRICH et al. 1987a, ULLRICH et al. 1987b), das neben der Modellsubstanz para-Aminohippurat (PAH) auch verschiedene andere organische Anionen über die basolaterale Membran in die Zellen der proximalen Tubuli aufnimmt. Weitere Untersuchungen an isolierten Membranvesikeln aus der basolateralen Membran der proximalen Tubuli führten zu dem Modell, dass die Aufnahme von PAH ein tertiär aktiver Transport ist (SHIMADA et al. 1987, PRITCHARD 1988). Die organischen Anionen werden gegen ihren elektrochemischen Potentialgradienten in die Zellen aufgenommen, im Austausch gegen intrazelluläre organische Anionen, die die Zelle entlang ihres elektrochemischen Gradienten verlassen. Diese intrazellulären Anionen sind wahrscheinlich Dicarboxylate, die 
über einen $\mathrm{Na}^{+}$-gekoppelten Cotransporter in die Zelle aufgenommen und akkumuliert werden. Der hierfür benötigte einwärts gerichtete $\mathrm{Na}^{+}$-Gradient wird durch die $\mathrm{Na}^{+} / \mathrm{K}^{+}$ATPase aufrechterhalten, die die $\mathrm{Na}^{+}$-Ionen wieder aus der Zelle heraustransportiert. Die aufgenommenen organischen Anionen werden dann über die luminale Membran in das Lumen der proximalen Tubuli sezerniert (BURCKHARDT G et al. 2001).

Bei diesen Prozessen spielen Membrantransporter die entscheidende Rolle. Mittlerweile sind mehrere Transporter für organische Anionen in den proximalen Tubuli identifiziert und kloniert worden (Abb. 1) (BURCKHARDT G und KOEPSELL 2008).

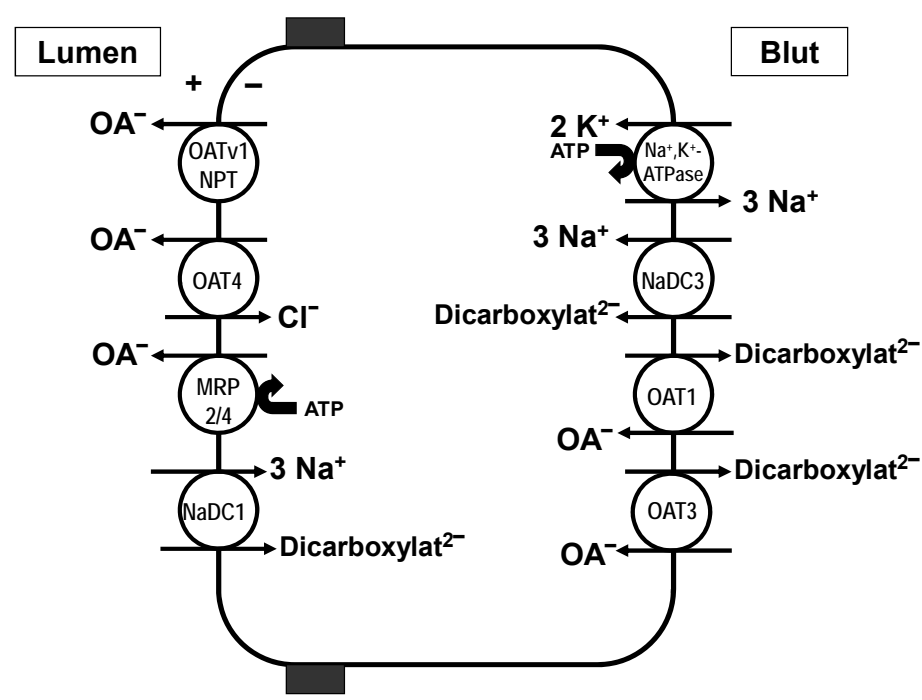

Abb. 1: Schematische Darstellung des Transports organischer Anionen in den proximalen Tubuluszellen der menschlichen Niere

Dargestellt sind die Transporter $\mathrm{OAT}_{\mathrm{v} 1}(\mathrm{NPT}), \mathrm{OAT} 4$, MRP 2 und 4, sowie NaDC1 in der apikalen Membran und die Transporter OAT1, OAT3 und NaDC3 sowie die Na/K-ATPase in der basolateralen Membran

So besteht das „PAH-Transport-System“ für die Aufnahme von PAH und anderen organischen Anionen aus mindestens zwei verschiedenen Transportern: Organische-AnionenTransporter 1 und 3 (OAT1 und OAT3), die eine ähnliche aber nicht identische Substratselektivität haben. Die Aufnahme der Dicarboxylate über die basolaterale Membran kann über den $\mathrm{Na}^{+}$-Dixcarboxylat-Cotransporter $\mathrm{NaDC} 3$ erfolgen. Die Sekretion der organischen Anionen über die apikale Membran in das Tubuluslumen erfolgt über verschiedene Transporter wie die ATP-abhängigen MRP2 und 4, über den Austauscher OAT4 und auch über den Uniporter $\mathrm{OAT}_{\mathrm{v}} 1$. 


\subsection{Die SLC22-Transporter-Familie}

OAT1 und OAT3 gehören aufgrund ihrer Aminosäuresequenz zur Familie der SLC22Transporter (solute carrier 22) (KOEPSELL und ENDOU 2004). Die humane Genfamilie besteht aus mindestens 22 Mitgliedern, darunter die Organische-Kationen-Transporter, der Organische-Zwitterion/Kation-Transporter und der Carnitin-Transporter. OAT1 und OAT3 bilden mit weiteren Organische-Anionen-Transportern und dem URAT1 die Unterfamilie der Organische-Anionen-Transporter. Funktionell charakterisiert sind von dieser Unterfamilie noch OAT2, OAT4, OAT7 und OAT10 (BURCKHARDT G und BURCKHARDT BC 2011). In der vorliegenden Arbeit wurden von den Mitgliedern der SLC22-Familie nur hOAT1 und hOAT3 untersucht.

\subsection{Der Organische-Anionen-Transporter 1 (OAT1)}

\subsubsection{Klonierung und Struktur des OAT1}

Der OAT1 wurde 1997 erstmals aus der Rattenniere (rOat1) von zwei unabhängigen Gruppen kloniert (SWEET et al. 1997, SEKINE et al. 1997). Der OAT1 der Maus (mOAT) wurde im gleichen Jahr von LOPEZ-NIETO et al. kloniert und als Novel Kidney Transporter (NKT) bezeichnet (LOPEZ-NIETO et al. 1997). Die Klonierung des OATs aus der Flunder erfolgte ebenfalls 1997 (WOLFF et al. 1997). Ein Jahr später gelang es den humanen OAT1 zu klonieren (REID et al. 1998, HOSOYAMADA et al. 1999; RACE et al. 1999, LU et al. 1999, CIHLAR et al. 1999).

Das Gen für den hOAT1 (SLC22A6) liegt zusammen mit dem Gen für den hOAT3 auf dem Chromosom 11. Das hOAT1-Protein besteht aus 550 Aminosäuren (Isoform hOAT1-2). Eine längere Splice-Variante mit 563 Aminosäuren wird weniger exprimiert (Isoform OAT1-1). Außerdem gibt es noch zwei weitere Splice-Varianten, die nicht aktiv sind (BAHN et al. 2000, 2004).

Wie alle OATs besteht der OAT1 aus $12 \alpha$-helikalen Transmembrandomänen (TMD) mit sechs extrazellulären und fünf intrazellulären Schleifen, wie in Abb. 2 dargestellt.

Die große extrazelluläre Schleife zwischen TMD1 und TMD2 hat 3 bis $5 \mathrm{~N}$ Glykosylierungsstellen. Eine weitere relativ große Schleife befindet sich intrazellulär zwischen TMD6 und TMD7 mit mehreren Phosphorylierungsstellen. Die Carboxy- und Aminoenden sind beide intrazellulär (RIZWAN und BURCKHARDT G 2007). 


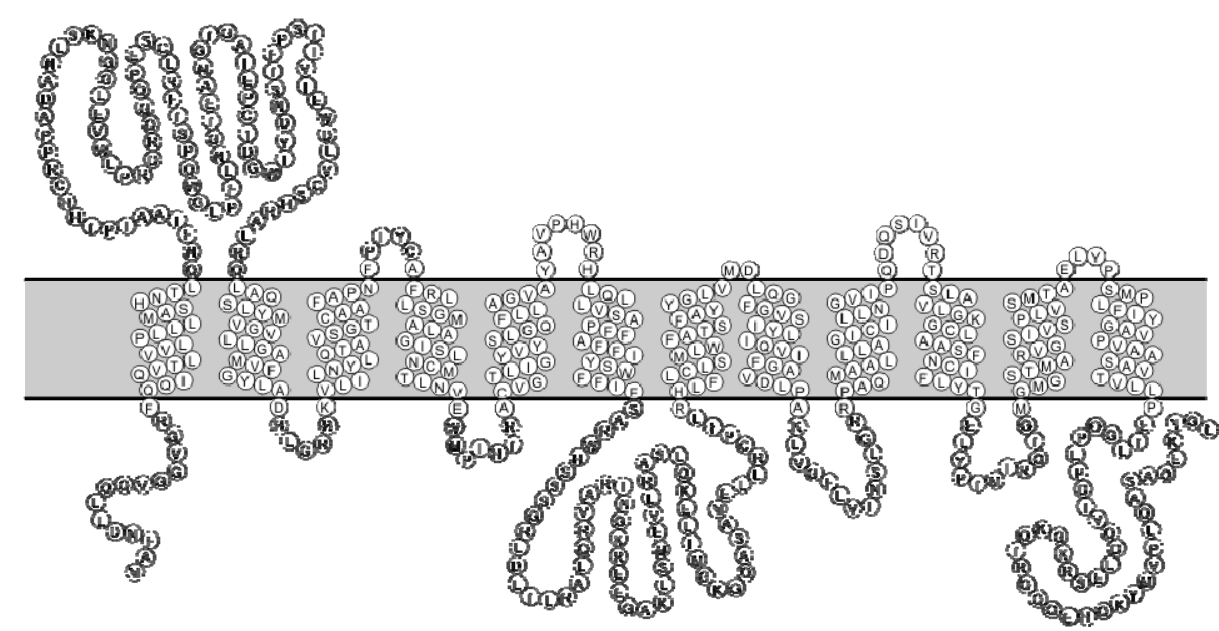

Abb. 2: Modell des hOAT1 mit 12 Transmembrandomänen

Das Aminoende ist links, das Carboxyende rechts, die extrazelluläre Seite ist oben, die intrazelluläre Seite unten. Die 1. Transmembrandomäne ist links, die 12. rechts.

\subsubsection{Immunhistochemie und Gewebeverteilung des OAT1}

OAT1 wird vor allem in den Nieren exprimiert. Immunhistochemisch wurde der OAT1 beim Menschen in der basolateralen Membran der proximalen Nierentubuluszelle nachgewiesen (HOSOYAMADA et al. 1999, MOTOHASHI et al. 2002). Daneben wurde auch im Gehirn und in den Nebennieren die OAT1-Expression gezeigt. mRNA des OAT1 wurde auch noch in mehreren anderen Geweben gefunden (BURCKHARDT G und BURCKHARDT BC 2011).

\subsubsection{Substrate und Substratbindung des OAT1}

Da der OAT1 eine breite Substratspezifität hat, interagiert er mit einer Vielzahl von Substanzen. Als klassisches Substrat für den OAT1 gilt para-Aminohippurat (PAH). PAH kann für die Bestimmung des renalen Plasmaflusses genutzt werden, da PAH durch glomeruläre Filtration und durch die zusätzliche Sekretion in den proximalen Tubuli bei einem Durchlauf durch die Nieren praktisch vollständig ausgeschieden wird. Wegen seiner hohen Affinität zum OAT1 wird für gewöhnlich PAH als Substrat bei Transportstudien an OAT1 verwendet. Daneben ist noch für eine große Anzahl anderer Substanzen eine Interaktion mit OAT1 bzw. dem „PAH-Transport-System“ nachgewiesen worden. Bei diesen Studien wurde entweder direkt der Transport der betreffenden Substanz oder die Hemmung des PAH-Transportes durch diese Substanz gemessen (BURCKHARDT BC und BURCKHARDT G 2003, RIZWAN und BURCKHARDT G 2007, BURCKHARDT G und BURCKHARDT BC 2011). Endogene Substrate des OAT1, deren Transport durch OAT1 gezeigt wurde, sind z.B. Stoffwechselprodukte wie Urat und $\alpha$-Ketoglutarat, Signaltransduktionssubstanzen wie cGMP 
und cAMP, Hormone wie Prostaglandin $\mathrm{E}_{2}$ und $\mathrm{F}_{2 \alpha}$ sowie Vitamine wie Folat. Für andere endogene Substanzen wurde zumindest nachgewiesen, dass sie den PAH-Transport durch OAT1 hemmen: darunter die Purinmetabolite Xanthin und Hypoxanthin, die Hormone Corticosteron und Dehydroepiandrosteronsulfat, das Vitamin Nicotinsäure und saure Metabolite von Neurotransmittern und Tryptophan.

Eine OAT1-knock-out-Maus ist gesund und hat eine normale glomeruläre Filtrationsrate. Allerdings ist die Ausscheidung von verschiedenen Metaboliten wie z.B. 3-Hydroxybutyrat. 4-Hydroxyphenylbutyrat und N-Acetylaspartat verringert, was darauf hindeutet, dass diese Stoffwechselprodukte normalerweise durch OAT1 sezerniert werden. Auch die PAHClearance ist erniedrigt (ERALY et al. 2006).

Zu den Pharmaka, für die eine Interaktion mit OAT1 nachgewiesen wurden, gehören z.B. Antibiotika wie Penicilline und Tetracycline, antivirale Medikamente, nichtsteroidaleantiinflammatorische Pharmaka wie z.B. Acetylsalicylsäure, Diuretika, ACE-Hemmer, Histamin-H2-Antagonisten, Statine und Urikosurika (RIZWAN und BURCKHARDT G 2007).

Vor allem die systematischen Untersuchungen von ULLRICH (1999) liefern Hinweise darauf, welche Strukturen ein Substrat haben muss, um an das „PAH-Transport-System“ der proximalen Tubuli, also an OAT1 und OAT3, binden zu können. Danach muss ein Substrat eine hydrophobe Domäne mit einer Länge von 400 bis 1000 pm haben. Eine negative Ladung erhöht die Affinität, allerdings werden auch Substanzen ohne eine vollständige elektrische Ladung gebunden. Ebenso werden Substrate akzeptiert mit zwei negativen Ladungen und einer hydrophoben Domäne zwischen den beiden Ladungen. Die Bindung erfolgt also wahrscheinlich über hydrophobe Wechselwirkungen und über die Bindung von negativ geladenen Gruppen an positiv geladene Aminosäuren des Transporters (BURCKHARDT BC und BURCKHARDT G 2003, SRIMAROENG 2008).

Mit Mutagenese-Studien wurde versucht, mehr Informationen über die Bindung der Substrate an die Organische-Anionen-Transporter zu erhalten: welche Aminosäuren der Transporter bilden die Bindungstasche und sind damit an der Bindung und am Transport der Substrate beteiligt?

Durch solche Studien wurde gezeigt, dass im OAT1 der Flunder (fOAT1) die Aminosäuren Lys394 (s. Abb. 3) in Transmembrandomäne 8 (TMD 8) und Arg478 in TMD 11 wichtig für die Dicarboxylatbindung sind, und Arg478 auch bei der PAH-Bindung eine Rolle spielt. Die Mutation der Aminosäure His34 in TMD 1 resultierte in einer Abnahme von $\mathrm{v}_{\max }$ des PAHTransports ohne eine Änderung der Affinität (WOLFF et al. 2001). 


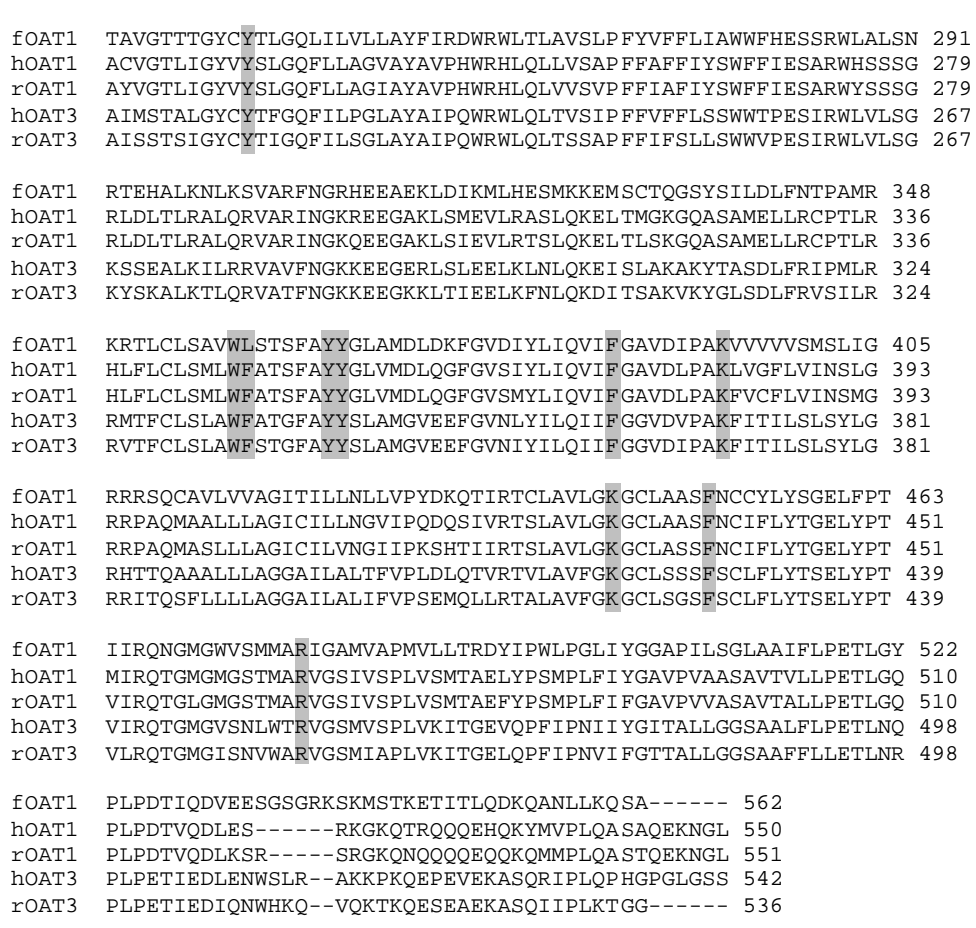

Abb. 3: Alignment von Teilsequenzen von OAT1 und OAT3 aus verschiedenen Spezies. Die im Text erwähnten Aminosäuren sind grau hinterlegt.

Eine wichtige Rolle beim PAH-Transport spielt auch Thr36 in der 1. TMD des hOAT1 (HONG et al. 2004). Ebenso sind offensichtlich die Aminosäuren Tyr230 in der 5. TMD sowie Lys431 und Phe438 in der 10. TMD des hOAT1 an der Substratbindung beteiligt (PERRY et al. 2006). Die Aminosäure Arg466 in der 11. TMD des hOAT1, die der Aminosäure Arg478 im Flunder-OAT1 entspricht, ist in die Bindung von Dicarboxylaten involviert (RIZWAN et al. 2007). Andere Mutagenese-Experimente deuten darauf hin, dass in der Transmembrandomäne 7 des hOAT1 die beiden aromatischen Aminosäuren Tyr353 und Tyr354 über Wasserstoff-Bindungen an der Bindung von PAH beteiligt sind (HONG et al. 2007). Eine Röntgenstrukturanalyse der Organische-Anionen-Transporter gibt es bisher nicht. 2006 publizierten PERRY et al. aber ein Strukturmodell, das auf Homologien des hOAT1 mit dem Glycerol-3-phosphat-Transporter (GlpT) aus E. coli beruht, von dem eine Kristallstruktur bekannt ist, und der mehrere ähnliche Sequenzmotive wie hOAT1 hat. Nach diesem Modell bilden die Transmembrandomänen 5, 7, 8, 10 und 11 eine $830 \AA^{3}$ große Höhlung, die die Bindungstasche enthält. An der Öffnung der Tasche ist die Aminosäure Arg466 lokalisiert. Die Bindungstasche ist weiter umgeben von z.B. den basischen Aminosäuren Lys382 (TMD 8) und Lys431 (TMD 10) und den aromatischen Aminosäuren Tyr230 (TMD 5), Tyr353, Tyr354 (TMD 7) und Phe438 (TMD10). 


\subsection{Der Organische-Anionen-Transporter 3 (OAT3)}

\subsubsection{Klonierung und Struktur des OAT3}

Der OAT3 wurde zunächst aus der Ratte (rOAT3) (KUSUHARA et al. 1999) und aus der Maus (mOAT3 oder roct) (BRADY et al. 1999) kloniert. 2001 erfolgte dann die Klonierung des humanen hOAT3 aus den Nieren (CHA et al. 2001).

Wie die anderen Mitglieder hat auch der hOAT3 12 putative Transmembranhelices mit einer großen extra- und einer großen intrazellulären Schleife (Abb. 4). Auch hier hat die intrazelluläre Schleife wie beim OAT1 mehrere Phosphorylierungsstellen für verschiedene Proteinkinasen (RIZWAN und BURCKHARDT G 2007).

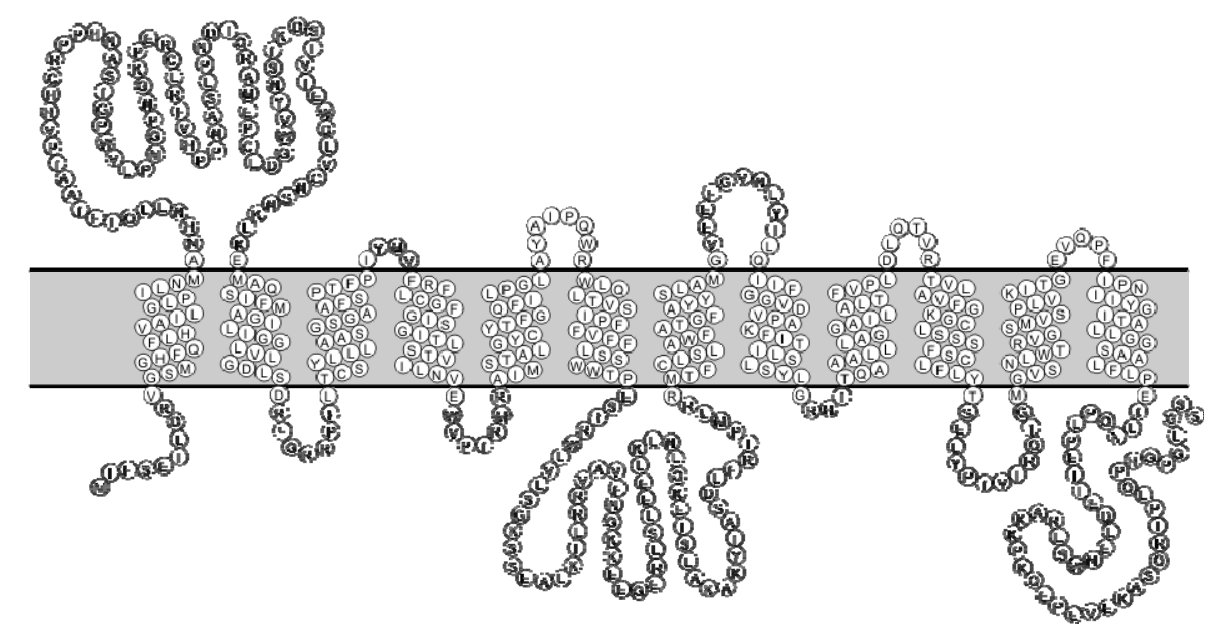

Abb. 4: Modell des hOAT3 mit 12 Transmembrandomänen

Das Aminoende ist links, das Carboxyende rechts, die extrazelluläre Seite ist oben, die intrazelluläre Seite unten. Die 1. Transmembrandomäne ist links, die 12. rechts.

\subsubsection{Immunhistochemie und Gewebeverteilung des OAT3}

Immunhistochemisch wurde der OAT3 in der basolateralen Membran der proximalen Tubuli der humanen Nieren (CHA et al. 2001) nachgewiesen, in der Ratte (HASEGAWA et al. 2002, KOJIMA et al. 2002, LJUBOJEVIC et al. 2007) auch noch in anderen Abschnitten der Nephrone.

In den humanen Nieren ist mehr OAT3-mRNA als mRNA von anderen OATs gemessen worden (MOTOHASHI et al. 2002). Das deutet darauf hin, dass der hOAT3 wahrscheinlich der am stärksten in den humanen Nieren exprimierte Organische-Anionen-Transporter ist. Außerdem wurde hOAT3 auch im Plexus choroideus und in cerebralen Kapillaren immunhistochemisch nachgewiesen (ALEBOYEH et al. 2003). 
Die Anwesenheit von mRNA des OAT3 wurde auch in verschiedenen anderen Organen wie Leber und Nebennieren belegt (BURCKHARDT G und BURCKHARDT BC 2011).

\subsubsection{Substrate und Substratbindung des OAT3}

Der OAT3 transportiert eine Vielzahl organischer Anionen. Wie der OAT1 hat auch der OAT3 eine breite Substratspezifität. Teilweise überlappen sich die Substratspezifitäten mit denen des OAT1, sie sind aber nicht identisch. Der OAT3 transportiert eher voluminösere und lipophilere Substrate als der OAT1. Östronsulfat ist ein Substrat mit einer sehr hohen Affinität, das daher auch meist für die Untersuchungen des Transports durch OAT3 benutzt wird.

Der OAT3 transportiert verschiedene endogene Substanzen wie cAMP, Cortisol, Prostaglandin E2, konjugierte Hormone wie Dehydroepiandrosteronsulfat, Östronsulfat und Östradiol-17ß-glucuronid sowie Taurocholat und Urat. Die Hemmung des OAT3-Transports ist außerdem nachgewiesen worden für Cholat und verschiedene saure NeurotransmitterMetabolite. OAT3 interagiert auch mit einer Reihe von Pharmaka wie z.B. Antibiotika, antiviralen Substanzen, Histamin-H2-Antagonisten, Diuretika und nichtsteroidalenantiinflammatorischen Medikamenten (RIZWAN und BURCKHARDT G 2007, BURCKHARDT G und BURCKHARDT BC 2011).

Eine OAT3-knock-out-Maus entwickelt sich normal. Experimentell war die Aufnahme von Östronsulfat und PAH in Nierenschnitte der Maus sowie die Aufnahme von Fluorescein in Zellen des Plexus choroideus erniedrigt (SWEET et al. 2002).

Auch im OAT3 wurden Aminosäuren mutiert, mit dem Ziel, so mehr über die Substratbindungsstellen zu erfahren. FENG et al. haben 2001 im OAT3 aus der Ratte die positiven Aminosäuren Lys370 in der 8. TMD, die im Flunder-OAT1 Lys394 entspricht, und die Aminosäure Arg454 in der 11. TMD, die den Aminosäuren Arg478 im fOAT1 und Arg466 im hOAT1 entspricht, mutiert. Der PAH- und Östronsulfat-Transport durch diese Mutanten war deutlich erniedrigt. Offensichtlich sind für den Transport dieser organischen Anionen positive Ladungen an den Positionen 370 und 454 des rOAT3 nötig. 2002 zeigte dieselbe Arbeitsgruppe (FENG et al. 2002), dass die aromatischen Aminosäuren Trp334, Phe335, Tyr341 und Tyr342 in der 7.TMD und Phe362 in der 8. TMD des rOAT3 wichtig für den PAH-Transport sind, weniger für den Östronsulfat-Transport.

Nach Mutation von Lys419, in der 10. TMD des hOAT3, wurde kein Glutarat mehr transportiert und die PAH-Transportaktivität erniedrigt. Mutationen von Tyr218 in der 5.TMD zeigten, dass diese Aminosäure wahrscheinlich an der PAH- und Östronsulfat-Bindung beteiligt ist (PERRY et al. 2006, SRIMAROENG et al. 2008). 


\subsection{Weitere Mitglieder der Familie der Organische-Anionen- Transporter}

Neben OAT1 und OAT3 hat die Genfamilie der Organische-Anionen-Transporter (OAT) noch mehrere andere Mitglieder, von denen einige schon näher charakterisiert sind.

OAT2 ist zuerst 1994 aus der Rattenleber kloniert worden (SIMONSON et al. 1994). mRNA wurde vor allem in der Leber, weniger in den Nieren und anderen Organen nachgewiesen (SIMONSON et al. 1994, SEKINE et al. 1998a). In humanen Nieren wurde OAT2 immunhistochemisch in der basolateralen Membran der proximalen Tubuli nachgewiesen, in Ratte und Maus dagegen in der apikalen Membran der proximalen Tubuli und der Sammelrohre (ENOMOTO et al. 2002a, KOJIMA et al. 2002, LJUBOJEVIC et al. 2007). Der Transportmechanismus von OAT2 ist immer noch unklar. Er interagiert in Transportstudien mit einer Vielzahl organischer Anionen (BURCKHARDT G und BURCKHARDT BC 2011).

OAT4 ist bisher nur beim Menschen nachgewiesen worden und wurde 2000 von CHA et al. kloniert. mRNA wurde in den Nieren, der Placenta und den Nebennieren nachgewiesen (CHA et al. 2000, ASIF et al. 2005). Immunhistochemisch wurde die Expression des hOAT4 in den Nieren in der apikalen Membran der proximalen Tubuli gezeigt (BABU et al. 2002). Dort kann OAT4 organische Anionen aus der Zelle im Austausch gegen Chloridionen sezernieren oder auch organische Anionen aus dem Lumen in die Tubuluszellen im Austausch gegen Dicarboxylate aufnehmen (HAGOS et al. 2007). Auch für OAT4 ist die Interaktion mit einer Vielzahl organischer Anionen nachgewiesen worden (BURCKHARDT G und BURCKHARDT BC 2011).

OAT5 bis OAT10 sind zwar kloniert, aber bisher weniger ausführlich funktionell charakterisiert bzw. nicht beim Menschen nachgewiesen worden (BURCKHARDT G und BURCKHARDT BC 2011).

Der Transporter URAT1, der ebenfalls der Familie der Organische-Anionen-Transporter angehört, wurde 2002 kloniert (ENOMOTO et al. 2002b). Histochemische Untersuchungen zeigten, dass er in der apikalen Membran der proximalen Tubuli lokalisiert ist (ANZAI et al. 2004, HOSOYAMADA et al. 2004). Hier resorbiert URAT1 wahrscheinlich Urat (ENOMOTO et al. 2002b). 


\subsection{Dicarboxylate und die $\mathrm{Na}^{+}$-Dicarboxylat-Cotransporter}

Organische Anionen werden physiologisch in den Nieren wahrscheinlich durch OAT1 und OAT3 im Austausch gegen intrazelluläre Dicarboxylate in die Zellen der proximalen Tubuli aufgenommen (SHIMADA et al. 1987, PRITCHARD 1988). Dicarboxylate fallen zum einen im Stoffwechsel an, zum anderen können Dicarboxylate durch die $\mathrm{Na}^{+}$-Dicarboxylat-Cotransporter NaDC1 und NaDC3 in die Zellen der proximalen Tubuli aufgenommen werden. NaDC1 und NaDC3 gehören zur SLC13 Familie der Sulfat- und Carboxylat-Transporter (PAJOR 2006, BURCKHARDT G und KOEPSELL 2008). Angetrieben wird der Transport der Dicarboxylate in die Zelle gegen ihren elektrochemischen Gradienten durch den gleichzeitigen Cotransport von $3 \mathrm{Na}^{+}$-Ionen. Der humane NaDC1 wurde 1996 kloniert (PAJOR 1996). NaDC1 ist in der apikalen Membran der proximalen Tubuli der Nieren und des Dünndarms nachgewiesen worden (PAJOR und SUN 1996, SEKINE et al. 1998b). Er resorbiert hier Dicarboxylate aus dem Lumen. NaDC1 transportiert vor allem Citrat und C4Dicarboxylate des Citrat-Zyklus. Er hat eine geringere Affinität gegenüber Succinat als der NaDC3 (PAJOR 2006). Der humane NaDC3 wurde im Jahr 2000 kloniert (WANG H et al. 2000). Der NADC3 hat eine breitere Gewebeverteilung als der NaDC1. Er ist in der basolateralen Membran der proximalen Tubuli lokalisiert (HENTSCHEL et al. 2003), mRNA ist aber auch in Leber, Gehirn und Placenta nachgewiesen worden (CHEN et al. 1999, KEKUDA et al. 1999). NaDC3 bindet neben Succinat und anderen Dicarboxylaten des Citrat-Zyklus auch substituierte Dicarboxylate. In den Nieren resorbiert er Dicarboxylate aus dem Plasma in die proximalen Tubuli-Zellen (PAJOR 2006). Diese Dicarboxylate stehen dann den Organische-Anionen-Transportern OAT1 und OAT3 zum Austausch gegen organische Anionen zur Verfügung. In der vorliegenden Arbeit sollten die Interaktionen verschiedener Dicarboxylate mit den Organische-Anionen-Transportern OAT1 und OAT3 untersucht werden.

Die Abb. 5 zeigt die Struktur der in dieser Arbeit getesteten Dicarboxylate.

Dicarboxylate sind Anionen der Dicarbonsäuren, organische Säuren mit zwei Carboxygruppen. Malonat ist das Dianion der Malonsäure oder Propandisäure und mit drei Kohlenstoffatomen (C3) das kleinste getestete Dicarboxylat. In aktivierter Form spielt es eine Rolle bei der Fettsäuresynthese. 


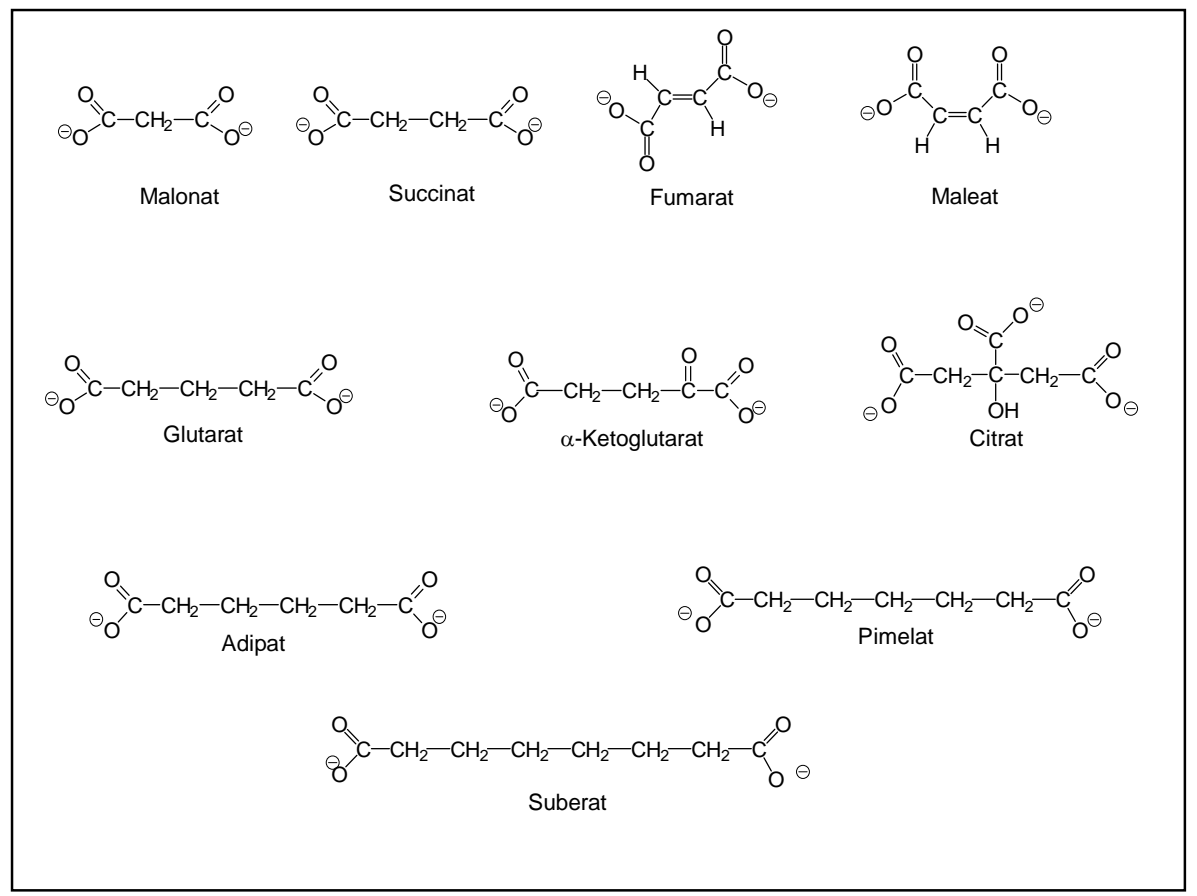

\section{Abb. 5: Strukturformeln der Dicarboxylate}

Die nächst größere gesättigte Dicarbonsäure ist die Bernsteinsäure oder Butandisäure. Ihre ionisierte Form ist das Succinat. Succinat ist ein Zwischenprodukt des Citratzyklus. Zwei ungesättigte C4-Dicarbonsäuren sind Fumarsäure (trans-2-Butensäuren) und Maleinsäure (cis2-Butensäure) mit ihren Anionen Fumarat und Maleat. In Fumarat ist die Doppelbindung trans-konfiguriert, im Maleat dagegen cis-konfiguriert. Fumarat ist Intermediat sowohl des Citrat- als auch des Harnstoffzyklus. Die gesättigte C5-Dicarbonsäure heißt Glutarsäure oder Pentandisäure. Ebenfalls eine C5-Dicarbonsäure ist die $\alpha$-Ketoglutarsäure oder 2-Oxoglutarsäure, die also eine zusätzliche Carbonylgruppe enthält. $\alpha$-Ketoglutarat entsteht als Zwischenprodukt im Citratzyklus und beim Aminosäurestoffwechsel. Auch die Citronensäure kann man formal als C5-Carbonsäure ansehen, die zusätzlich eine Carboxylgruppe und eine Hydroxylgruppe hat. Citrat ist natürlich ein Intermediat des Citratzyklus und spielt ebenfalls auch eine Rolle bei der Fettsäuresynthese (BERG et al. 2007). Weiter wurden in dieser Arbeit noch die Anionen der Adipinsäure oder Hexandisäure, der Pimelinsäure oder Heptandisäure und der Suberinsäure oder Octandisäure getestet. 
Wie weit die Carboxygruppen der Dicarbonsäuren in wässriger Lösung dissoziiert sind, und die Substanzen damit als Anionen oder Dianionen vorliegen, hängt vom pH-Wert der Lösung und von den Säurenkonstanten, den pKa-Werten, der Dicarbonsäuren ab. Je höher der pHWert der Lösung und je niedriger die $\mathrm{pK}_{\mathrm{a}}$-Werte der Säuren, desto höher der Dissoziationsgrad nach der Henderson-Hasselbalch-Gleichung: $\mathrm{pH}=\mathrm{pK}_{\mathrm{a}}+\frac{\left[\mathrm{A}^{-}\right]}{\mathrm{HA}} \quad$ (KLINKE und SILBERNAGL 2005).

Die in dieser Arbeit getesteten Dicarboxylate haben zwei ionisierbare Carboxylgruppen. Die $\mathrm{pK}_{\mathrm{a}}$-Werte der beiden Carboxylgruppen, also den negativen dekadischen Logarithmus der Dissoziationskonstanten, zeigt Tabelle 1.

In der Tabelle 1 entspricht der $\mathrm{pK}_{\mathrm{a} 1}$-Wert der Dissoziationskonstante der ersten Carboxylgruppe, der $\mathrm{pK}_{\mathrm{a} 2}$-Wert der Dissoziationskonstante der zweiten Carboxylgruppe. Für die dritte Carboxylgruppe des Citrats liegt der $\mathrm{pK}_{\mathrm{a} 3}$-Wert zwischen 5,4 und 6,4. Je nach Quelle werden die $\mathrm{pK}_{\mathrm{a}}$-Werte etwas unterschiedlich angegeben (VOLLHARDT und SCHORE 1995, WEAST und ASTLE 1979, ChemIDplus 2011).

\begin{tabular}{|l|l|l|}
\hline & \multicolumn{1}{|c|}{$\mathrm{pK}_{\mathrm{a} 1}$} & \multicolumn{1}{c|}{$\mathrm{pK}_{\mathrm{a} 2}$} \\
\hline Malonat & $2,8-3,2$ & $5,7-6,3$ \\
\hline Maleat & $1,8-3,1$ & $5,9-6,1$ \\
\hline Fumarat & $3,3-3,6$ & 4,4 \\
\hline Succinat & $4,3-5,8$ & $5,6-6,3$ \\
\hline Glutarat & 4,3 & $5,1-5,6$ \\
\hline a-Ketoglutarat & $2,5-2,6$ & $3,9-4,7$ \\
\hline Citrat & 3,1 & $4,7-4,8$ \\
\hline Adipat & $3,9-5,6$ & $4,4-6,4$ \\
\hline Pimelat & $4,1-4,7$ & $4,7-4,8$ \\
\hline Suberat & 4,2 & $4,2-4,9$ \\
\hline
\end{tabular}

Tab. 1: $\mathbf{p K}_{\mathrm{a}}$-Werte der getesteten Dicarboxylate

Nach der Henderson-Hasselbalch-Gleichung ist die Carboxylgruppe z.B. zu 50\% ionisiert, wenn der $\mathrm{pH}-$ Wert dem $\mathrm{pK}_{\mathrm{a}}$-Wert entspricht, und $\mathrm{zu} 90 \%$ ionisiert, wenn der $\mathrm{pH}-$ Wert um 1 über dem $\mathrm{pK}_{\mathrm{a}}$-Wert liegt. Die getesteten Dicarbonsäuren haben $\mathrm{pK}_{\mathrm{a}}$-Werte zwischen 1,8 und 6,4. Die Dicarbonsäuren liegen daher physiologisch bei einem $\mathrm{pH}-$ Wert von etwa 7,4 zu mindestens $90 \%$ zweifach ionisiert, also als Dianionen oder Dicarboxylate vor. 
Ein Ziel dieser Arbeit war, mehr Informationen über die Bindungsstelle der Dicarboxylate in den Transportern hOAT1 und hOAT3 zu erhalten. Dazu muss natürlich der Abstand der negativen Ladungen der dissoziierten Carboxylgruppen in den Dicarboxylaten bekannt sein, da diese negativ geladenen Strukturen sehr wahrscheinlich an der Bindung beteiligt sind.

Tabelle 2 zeigt die Abstände der Ladungen in den Dicarboxylaten: Zum einen die von FRITZSCH et al. (1989) publizierten Werte und zum anderen die von uns nach den Regeln des H2G2-Projektes (Projekt 2002) berechneten Ladungsabstände. Dabei wurde die Berechnung in der Hinsicht geändert, dass wir wie FRITZSCH et al. (1989) für den CCOWinkel der ionisierten Carboxylgruppe bei gesättigten Verbindungen $114^{\circ}$ und für den Abstand des Zentrums der negativen Ladung vom letzten C-Atom eine Distanz von etwa 65 pm angenommen haben.

\begin{tabular}{|l|c|c|}
\hline & \multicolumn{2}{|c|}{ Abstände der negativen Ladungen } \\
& nach FRITZSCH & eigene Berechnung \\
\hline Malonat & $390 \mathrm{pm}$ & $383 \mathrm{pm}$ \\
\hline Maleat & $400 \mathrm{pm}$ & $406 \mathrm{pm}$ \\
\hline Fumarat & & $523 \mathrm{pm}$ \\
\hline Succinat & $520 \mathrm{pm}$ & $514 \mathrm{pm}$ \\
\hline Glutarat & $640 \mathrm{pm}$ & $639 \mathrm{pm}$ \\
\hline$\alpha-$ Ketoglutarat & & $651 \mathrm{pm}$ \\
\hline Citrat & & $639 \mathrm{pm}$ \\
\hline Adipat & $770 \mathrm{pm}$ & $764 \mathrm{pm}$ \\
\hline Pimelat & $890 \mathrm{pm}$ & $890 \mathrm{pm}$ \\
\hline Suberat & $1020 \mathrm{pm}$ & $1015 \mathrm{pm}$ \\
\hline
\end{tabular}

Tab. 2: Abstände der negativen Ladungen in den Dicarboxylaten. Abstände nach FRITZSCH et al. (1989) (linke Spalte) und nach eigenen Berechnungen (rechte Spalte).

\subsection{Ziele der Dissertation}

In den proximalen Tubuli der Nieren werden verschiedene organische Anionen von den Organische-Anionen-Transportern OAT1 und OAT3 aus dem Blut in die Tubuluszellen aufgenommen. Im Gegenzug werden intrazelluläre organische Anionen, wahrscheinlich Dicarboxylate, von OAT1 und OAT3 aus den Zellen abgegeben. In dieser Arbeit sollte die Interaktion verschiedener Dicarboxylate mit unterschiedlichen Längen mit den Transportern OAT1 und OAT3 untersucht werden. Dazu sollte die Hemmung des Transports organischer Anionen über OAT1 und OAT3, die stabil in HEK293-Zellen transfiziert waren, durch die 
In einem $\mathrm{zu}$ dieser Arbeit parallel durchgeführten Projekt wurde die Affinität der Dicarboxylate gegenüber dem $\mathrm{Na}^{+}$-Dicarboxylat-Symporter $\mathrm{NaDC} 3$ untersucht, der physiologisch Dicarboxylate in die Tubuluszellen aufnimmt, die dann OAT1 und OAT3 zum Austausch zur Verfügung stehen. Alle diese Versuche wurden unter denselben Bedingungen und mit demselben Expressionssystem durchgeführt. So sollte bestimmt werden, welche Dicarboxylate von allen drei Transportern mit hoher Affinität gebunden werden, und damit wahrscheinlich die physiologischen Substrate der Transporter sind. 


\section{Material und Methoden}

\subsection{Zellkultur}

\subsubsection{Verwendete Zellen}

In allen Versuchen dieser Arbeit wurden Zellen der Zell-Linie HEK293 verwendet (human embryonic kidney). Diese Zell-Linie ist durch Transformation von humanen embryonalen Nierenzellen mit dem Adenovirus Typ 5 (GRAHAM et al. 1977) etabliert worden.

Die mit dem hOAT1 bzw. hOAT3 stabil-transfizierten Zellen wurden von Dr. B. Ugele (Frauenklinik-Innenstadt München) zur Verfügung gestellt. Die stabil-transfizierten TREx $^{\text {TM}}{ }^{\text {-HEK293-Zellen waren von Dr. Ugele mit Hilfe des Flp-In }}{ }^{\text {TM}}$-Expressionssystems (Invitrogen, Karlsruhe) etabliert worden (BAKHIYA et al. 2006). Die hOAT1- und hOAT3cDNA (GenBank Nr. AF097490 bzw. BI760120) waren vom Deutschen Ressourcenzentrum für Genomforschung (RZPD, Berlin) und wurden in den Expressionsvektor pcDNA5/FRT kloniert, der auch ein Hygromycin-Resistenz-Gen enthält. Als Kontrollzellen wurden Zellen nur mit dem Vektor stabil transfiziert. Die stabil transfizierten Zellen wurden durch Zusatz von Hygromycin zum Kulturmedium (200 $\mu \mathrm{g} / \mathrm{ml})$ selektiert.

\subsubsection{Kultivierung der Zellen}

Die Zellen wurden in $150 \mathrm{~mm}$ Zellkulturschalen (Sarstedt 831803150 x 20mm) mit Kulturmedium (siehe 2.4, Seite 19-20) bei $37^{\circ} \mathrm{C}$ und $5 \% \mathrm{CO}_{2}$ in einem Brutschrank (Function Line, Heraeus Instruments Hanau) kultiviert. Pro Zellkulturschale wurden ca. 5 x $10^{6}$ Zellen ausplattiert. Nach 4 oder 5 Tagen waren die Zellen konfluent und wurden 1:4 bis 1:5 passagiert. In steriler Umgebung unter der Werkbank (Microflow Biological Safety Cabinet, Nunc Wiesbaden) wurde das Kulturmedium abgesaugt und die Zellen einmal mit $37^{\circ} \mathrm{C}$ warmen PBS (phosphate buffered saline) gewaschen. Anschließend wurden die Zellen mit $10 \mathrm{ml} 37^{\circ} \mathrm{C}$ warmer Milieu-C-Lösung (siehe 2.4) von der Schale gelöst und die Suspension in ein steriles 15-ml-Röhrchen überführt (Sarstedt 62.554.502). Darauf folgte eine fünfminütige Zentrifugation (Laborfuge 400R, Heraeus Hanau) der Zellsuspension bei Raumtemperatur mit $1000 \mathrm{U} / \mathrm{min}$. 


\subsubsection{Zählen der Zellen}

Nach Entfernen der oberen Milieu-C-Phase wurden die Zellen in $2 \mathrm{ml}$ T-Rex-Kulturmedium resuspendiert. Nach einer Verdünnung von 1:20 (10 $\mu 1$ Zellsuspension mit $190 \mu 1$ Kulturmedium) wurden die Zellen unter einem Lichtmikroskop mit Hilfe einer Neubauer-Zählkammer gezählt. Dazu wurde ein Deckgläschen auf die Neubauer-Zählkammer gedrückt, bis NewtonRinge sichtbar wurden. Sie zeigen an, dass die Tiefe der Kammer richtig eingestellt ist $(0,1$ $\mathrm{mm}$ ). Die Zellsuspension wurde zwischen das Deckgläschen und die Zählkammer gegeben. Anschließend wurden die Zellen in vier Quadranten der Kammer gezählt und der Mittelwert gebildet. Um die Zellzahl pro Milliliter zu erhalten, wurde der Mittelwert pro Quadrant mit $10^{4}$, einem konstanten Faktor, der sich aus der Größe der Kammer ergibt, und mit der Vorverdünnung (1:20) multipliziert:

(Mittelwert Zellzahl/Quadrant) $\cdot 20 \cdot 10^{4}=$ Zellen $/ \mathrm{ml}$

\subsubsection{Aussäen der stabil-transfizierten Zellen in 24-Loch-Platten}

Vor der Aussaat der Zellen wurden die 24-Loch-Platten (Sarstedt 83.1836) mit Polylysin beschichtet, um eine bessere Anheftung der Zellen zu gewährleisten. Dazu wurden in jedes Loch $500 \mu$ 1 Polylysin-Lösung $(2 \mathrm{mg} / \mathrm{ml}$ steril in Wasser gelöst) gegeben. Nach fünf Minuten wurde die Lösung wieder abgesaugt und die Platten bei Raumtemperatur getrocknet. Die Zellen wurden in unterschiedlicher Dichte auf die 24-Loch-Platten ausplattiert: die Vektortransfizierten Zellen mit 1,5 $10^{5}$ Zellen/Loch, die hOAT1-transfizierten Zellen mit 1,75 $10^{5}$ Zellen/Loch und die hOAT3-transfizierten Zellen mit $2 \cdot 10^{5}$ Zellen/Loch. Die Zellen wurden vier Tage bis zur Konfluenz im Brutschrank kultiviert.

\subsection{Messung der Aufnahme radioaktiv markierter Substrate in die Zellen}

\subsubsection{Vorbereitung der Zellen und Herstellung der Transportlösungen}

Für jede Messreihe wurden als Transportlösungen zwei Ringerlösungen (siehe 2.4, Seite 19) angesetzt: eine Ringerlösung mit der höchsten Dicarboxylatkonzentration dieser Reihe, sowie eine Ringerlösung ohne Dicarboxylate. Der pH-Wert wurde jeweils mit $1 \mathrm{~N} \mathrm{NaOH}$ auf $\mathrm{pH} 7,4$ eingestellt. Den Lösungen wurden die radioaktiv markierten Substanzen in entsprechender Konzentration zugegeben: $1,1 \mu \mathrm{M}(4,8 \mu \mathrm{Ci} / \mathrm{ml}){ }^{3} \mathrm{H}-\mathrm{PAH}$ oder $10 \mathrm{nM}(0,6 \mu \mathrm{Ci} / \mathrm{ml}){ }^{3} \mathrm{H}$-Östronsulfat. Zur $\mathrm{K}_{\mathrm{i}}$-Bestimmung wurden zusätzlich Messungen mit $0,5 \mu \mathrm{M}(2,2 \mu \mathrm{Ci} / \mathrm{ml}){ }^{3} \mathrm{H}-\mathrm{PAH}$ 
bzw. $5 \mathrm{nM}(0,3 \mu \mathrm{Ci} / \mathrm{ml}){ }^{3} \mathrm{H}$-Östronsulfat durchgeführt. Bei den $\mathrm{K}_{\mathrm{m}}$-Bestimmungen wurden noch zusätzliche Konzentrationen, wie in den Legenden beschrieben, verwendet. Um die Transportlösungen mit den anderen Dicarboxylatkonzentrationen zu erhalten, wurden die Ringerlösungen mit der höchsten Dicarboxylatkonzentration mit der Ringerlösung ohne Dicarboxylate entsprechend gemischt.

Die Versuche zur Aufnahme der radioaktiv markierten Substrate in die Zellen wurden immer am vierten Tag nach der Aussaat mit konfluenten Zellen in den 24-Loch-Platten bei Raumtemperatur durchgeführt. Vor dem Transport wurde das T-Rex-Kulturmedium abgesaugt. Anschließend wurden die Zellen zweimal mit jeweils 0,5 ml PBS pro Loch gewaschen. Danach wurde in jedes Loch 0,5 ml Ringerlösung eingebracht. Um ein Ablösen der Zellen zu vermeiden, wurden die Puffer vorsichtig entlang der Wand in die Löcher der 24-Loch-Platten gegeben.

Getestet wurden zehn verschiedene Dicarboxylate: Malonat, Succinat, Fumarat, Maleat, $\alpha$ Ketoglutarat, Glutarat, Citrat, Adipat, Pimelat und Suberat. Bei hohen Dicarboxylatkonzentrationen wurden die Ringerlösungen so modifiziert, dass die Osmolarität konstant blieb. Dazu wurde der $\mathrm{NaCl}$-Anteil entsprechend verringert und durch das entsprechende Dicarboxylat bzw. Na-Glukonat ersetzt.

\subsubsection{Transportmessung mit radioaktiv markierten Substraten}

Nach dem Absaugen der Ringerlösung mit dem radioaktiv markierten Substrat von den Zellen wurden bei Raumtemperatur pro Loch $250 \mu$ Transportlösung vorsichtig auf die Zellen gegeben. Die Zellen wurden außer bei den Zeitreihen 1 min bei Raumtemperatur in der Transportlösung inkubiert. Anschließend wurde die Lösung mit dem radioaktiv markierten Substrat abgesaugt. Dann wurden die Zellen mit jeweils $750 \mu$ l eiskaltem PBS pro Loch dreimal gewaschen. Zum Auflösen der Zellen und Freisetzen der aufgenommenen radioaktiv markierten Substrate wurden anschließend $250 \mu 11 \mathrm{~N} \mathrm{NaOH}$ auf die Zellen gegeben und die Zellen 30 Minuten auf dem Schüttler (4020 Köttermann) in der NaOH-Lösung inkubiert. Nachdem sich die Zellen vollständig aufgelöst hatten, wurde mit $250 \mu 11 \mathrm{~N} \mathrm{HCl}$ neutralisiert. Je $400 \mu \mathrm{l}$ aus jedem Loch wurden dann in Szintillationsfläschchen (Sarstedt 73.680) gegeben. Im Anschluss wurden 2,5 ml Szintillationsflüssigkeit (Luma-safe Perkin-Elmer 3087) zugegeben und gemischt. Die Szintillationsfläschchen wurden nach 30 Minuten in den Szintillisationscounter (TRI CARB 2900 TR Liquid Scintillation Analyzer; Perkin-Elmer) gestellt und die radioaktiven Zerfälle jeweils 5 Minuten gemessen. 
In der Szintillationsflüssigkeit übertragen die Elektronen der radioaktiven Zerfälle ihre Energie auf Fluoreszenzfarbstoffe. Diese Fluoreszenzfarbstoffe emittieren diese Energie als Licht, das vom Szintillisationscounter gemessen wird.

Vor dem Transport wurden von der Transportlösung mit der höchsten Dicarboxylatkonzentration und der Transportlösung ohne Dicarboxylat jeweils viermal $5 \mu 1$ Standards entnommen und mit $250 \mu 11 \mathrm{~N} \mathrm{NaOH}$ und $250 \mu 11 \mathrm{~N} \mathrm{HCl}$ in Szintillationsfläschchen geben und ebenfalls im Counter gezählt. Durch diese Zählung der Zerfälle in den Lösungen bekannter Substratkonzentrationen können die gemessenen Zerfälle in den Zellproben in die aufgenommene Substratmenge umgerechnet werden.

\subsection{Proteinbestimmung}

Nachdem die Zellen nach dem Transportversuch solubilisiert worden waren, wurden $70 \mu 1$ dieser Lösung verwendet, um den Proteingehalt der aufgelösten Zellen in jedem Loch der 24Loch-Zellkulturplatte mit der Methode nach Bradford zu bestimmen (BRADFORD 1976). Die Methode beruht auf einer Verschiebung des Extinktionsmaximums des Farbstoffes Coomassie Blue G 250 durch eine Komplexbildung mit Proteinen von $465 \mathrm{~nm}$ nach $595 \mathrm{~nm}$. Diese Zunahme kann photometrisch gemessen werden und ist ein Maß für die Proteinkonzentration.

Die 70- $\mu 1$-Proteinlösung wurde in ein Eppendorf-Reagiergefäß (Sarstedt 72.690) pipettiert und mit $1 \mathrm{ml}$ Bradford-Reagenzlösung gemischt. Nach einer Inkubationszeit von 5 Minuten wurde die Extinktion bei $595 \mathrm{~nm}$ in Halbmikroküvetten (Sarstedt 67742) mit dem Novaspec II von Pharmacia Biotech (Freiburg) gemessen. Die Messung erfolgte gegen eine Leerprobe, in die statt der Proteinlösung $70 \mu 1$ Wasser gegeben worden ist.

Die Bradford-Reagenzlösung wurde hergestellt, indem 100 mg Coomassie-Brilliant-Blau G 250 (Merck 115 444) zu $50 \mathrm{ml}$ 96\%-Ethanol (AppliChem A1613) und $100 \mathrm{ml}$ 85\%ige Phosphorsäure (AppliChem A0637) gegeben wurden. Anschließend wurde mit Wasser auf $250 \mathrm{ml}$ aufgefüllt. Vor Gebrauch wurde diese Stammlösung noch mit Wasser 1:4 verdünnt. 


\subsection{Zusammensetzung der Kulturmedien und Lösungen}

Säugetier-Ringerlösung:

- $130 \mathrm{mM} \mathrm{NaCl}$

- $4 \mathrm{mM} \mathrm{KCl}$

- $1 \mathrm{mM} \mathrm{CaCl}_{2}$

- $1 \mathrm{mM} \mathrm{MgSO}_{4}$

- $1 \mathrm{mM} \mathrm{NaH}_{2} \mathrm{PO}_{4}$

- 18 mM Glukose

- $20 \mathrm{mM}$ Hepes

- mit $1 \mathrm{~N} \mathrm{NaOH-Lösung} \mathrm{auf} \mathrm{pH} \mathrm{7,4} \mathrm{eingestellt.}$

Phosphat Buffered Saline (PBS-Dulbecco):

- $0,2 \mathrm{~g} / 1 \mathrm{KCl}$

- $0,2 \mathrm{~g} / 1 \mathrm{KH}_{2} \mathrm{PO}_{4}$

- $8 \mathrm{~g} / \mathrm{l} \mathrm{NaCl}$

- $1,15 \mathrm{~g} / 1 \mathrm{Na}_{2} \mathrm{HPO}_{4}$.

Milieu-C-Lösung:

- $\quad$ PBS

- $2 \mathrm{~g} / 1$ Glukose

- $0,38 \mathrm{~g} / 1 \mathrm{EDTA}$

- $\mathrm{pH} 7,4$.

Kultur Medium:

- DMEM mit 4,5 g/l Glukose

- $44 \mathrm{mM} \mathrm{NaHCO}_{3}\left(3,7 \mathrm{~g} \mathrm{NaHCO}_{3} / \mathrm{l}\right)$

- $2 \mathrm{mM}$ L-Glutamin

- $5 \mu \mathrm{g} / \mathrm{ml}$ Blasticidin

- $100 \mu \mathrm{g} / \mathrm{ml}$ Penicillin/Streptomycin

- $10 \% \mathrm{FCS}$

- $\mathrm{pH} 7,4$

- das Medium für die hOAT3-Zellen enthält noch zusätzlich $200 \mu \mathrm{g} / \mathrm{ml}$ Hygromycin. 
Bestandteile der Kulturmedien:

- DMEM HG

Gibco 52100

(Dulbecco's Modified Eagle Medium with high-glucose (4,5 g/l Glukose))

- $\mathrm{NaHCO}_{3}$

- L-Glutamin

- Blasticidin

- Penicillin/Streptomycin

- Fetales Kälber-Serum (FCS)

- Hygromycin B

- Phosphat Buffered Saline (PBS-Dulbecco)AppliChem A0964 9100

- EDTA (Ethylendiamintetraacetat)

- Poly-D-Lysin

- $\mathrm{NaCl}$

- $\mathrm{KCl}$

- $\mathrm{CaCl}_{2}$

- $\mathrm{MgSO}_{4}$

- $\mathrm{NaH}_{2} \mathrm{PO}_{4}$

- Glukose

- Hepes

\subsection{Sonstige Chemikalien}

Getestete Dicarboxylate:

- Malonsäure (Propandisäure)

- Succinat (Butandisäure)

- Fumarat (trans-Butendisäure)

- Maleinsäure (cis-Butendisäure)

- $\alpha$-Ketoglutarat (Natriumsalz)

- Glutarsäure (Pentandisäure)

- Citrat (Natriumsalz)

- Adipinsäure (Hexandisäure)

- Pimelinsäure (Heptandisäure)

- Suberinsäure (Octandisäure)
AppliChem A0384

AppliChem A3704

PAA P05-017

PAA P11-010

Gibco C1070-106

PAA P21-014

Sigma E5513

Sigma-Aldrich P1149

AppliChem A2942

AppliChem A2939

Sigma C 3306

AppliChem A6287

Merck A420746

AppliChem A3666

AppliChem A1069.
Sigma M 1875

Sigma S 2378

Sigma F 4502

Merck-Schuchardt 800380

Sigma K1875

Sigma 49660

Sigma C 0909

Sigma A 5252

Sigma P 6753

Sigma S-7126. 
Radioaktiv markierte Substanzen:

- ${ }^{3} \mathrm{H}-p$-Aminohippursäure

$(4,35 \mathrm{Ci} / \mathrm{mmol}) 229,8 \mu \mathrm{M}$ in $10 \mathrm{mM} \mathrm{HCl}$

- ${ }^{3} \mathrm{H}$-Östronsulfat, $\mathrm{NH}_{4}{ }^{+}$-Salz

Perkin Elmer NET-203

$(57,3 \mathrm{Ci} / \mathrm{mmol}) 17,5 \mu \mathrm{M}$ in Ethanol.

\subsection{Statistische Auswertungen}

Die Substrataufnahme unter einer Versuchsbedingung wurde jeweils als Mittelwert aus vier separaten Aufnahmemessungen angegeben. Alle Versuche wurden mindestens dreimal mit unterschiedlichen Zellpräparationen durchgeführt. Die Ergebnisse wurden anschließend als Mittelwert mit Standardabweichung zusammengefasst. Die graphischen und statistischen Auswertungen erfolgten mit SigmaPlot11. Die Anpassungen der Gleichungen für die abgebildeten Kurven an die Messwerte erfolgte nach der Methode der kleinsten Fehlerquadrate mit dem Marquardt-Levenberg-Algorithmus (Systat Software, San Jose, CA, USA). 


\section{Ergebnisse}

\subsection{Zeitabhängigkeit des Organische-Anionen-Transports in hOAT1- und hOAT3-transfizierte Zellen}

Für die Untersuchungen zur Interaktion von Dicarboxylaten mit dem humanen OrganischeAnionen-Transporter 1 und 3 (hOAT1 und hOAT3) wurden T-REx-HEK293-Zellen verwendet, die entweder mit hOAT1 oder mit hOAT3 stabil transfiziert waren (BAKHIYA et al. 2006). Als Kontrollzellen dienten Vektor-transfizierte T-REx-HEK293-Zellen, die nur mit dem Transfektionsvektor pcDNA5/FRT transfiziert waren.

In den folgenden Versuchen sollte die Hemmung verschiedener Dicarboxylate auf den Transport von radioaktiv markierten p-Aminohippurat (PAH) durch den hOAT1 und auf den Transport von Östronsulfat durch den hOAT3 untersucht werden. hOAT1 und hOAT3 transportieren PAH bzw. Östronsulfat in die Zellen im Austausch gegen andere intrazelluläre organische Anionen, wahrscheinlich gegen Dicarboxylate.

Zunächst wurde die Zeitabhängigkeit der ${ }^{3} \mathrm{H}-\mathrm{PAH}-A u f n a h m e$ in die hOAT1-transfizierten Zellen untersucht. Für die folgenden kinetischen Hemmversuche wurde ein Zeitpunkt gesucht, indem die Zeitkurve noch linear ist, die Aufnahme also noch nicht gesättigt ist und es noch zu keinem Rückfluss aus der Zelle kommt. Auf der anderen Seite sollte der Zeitpunkt noch nicht zu kurz sein, so dass es zu einer gut messbaren ${ }^{3} \mathrm{H}-\mathrm{PAH}-\mathrm{Aufnahme} \mathrm{kommt.} \mathrm{Dazu}$ wurden die hOAT1-transfizierten Zellen in einer Ringerlösung mit $1,1 \mu \mathrm{M}{ }^{3} \mathrm{H}-\mathrm{PAH}$ bei Raumtemperatur inkubiert. Nach verschiedenen Zeiten (0,5min, $2 \mathrm{~min}, 5 \mathrm{~min}, 10 \mathrm{~min}, 20$ min, $40 \mathrm{~min}$ ) wurde die ${ }^{3} \mathrm{H}-\mathrm{PAH}-\mathrm{Aufnahme}$ gestoppt und das aufgenommene ${ }^{3} \mathrm{H}-\mathrm{PAH}$ gemessen.

Parallel wurde eine Zeitreihe mit Vektor-transfizierten HEK293-Zellen erstellt. Der hier gemessene ${ }^{3} \mathrm{H}-\mathrm{PAH}-\mathrm{Gehalt}$ entspricht einer unspezifischen Aufnahme in die Zellen bzw. einer Bindung an die Zellen.

Die Abb. 6 zeigt die Zusammenfassung von drei Versuchen. Die ${ }^{3} \mathrm{H}-\mathrm{PAH}-\mathrm{Aufnahme-Kurve}$ der hOAT1-transfizierten Zellen verläuft bis ca. 5 Minuten linear ansteigend. Anschließend flacht die Kurve ab. Als optimale Inkubationszeit wurde 1 Minute festgelegt, weil zu diesem Zeitpunkt ein Rücktransport ausgeschlossen werden kann und das Verhältnis der Aufnahme gegenüber den Vektor-transfizierten HEK293-Zellen ausreichend groß (3 pmol gegen 0,2 pmol) ist. 


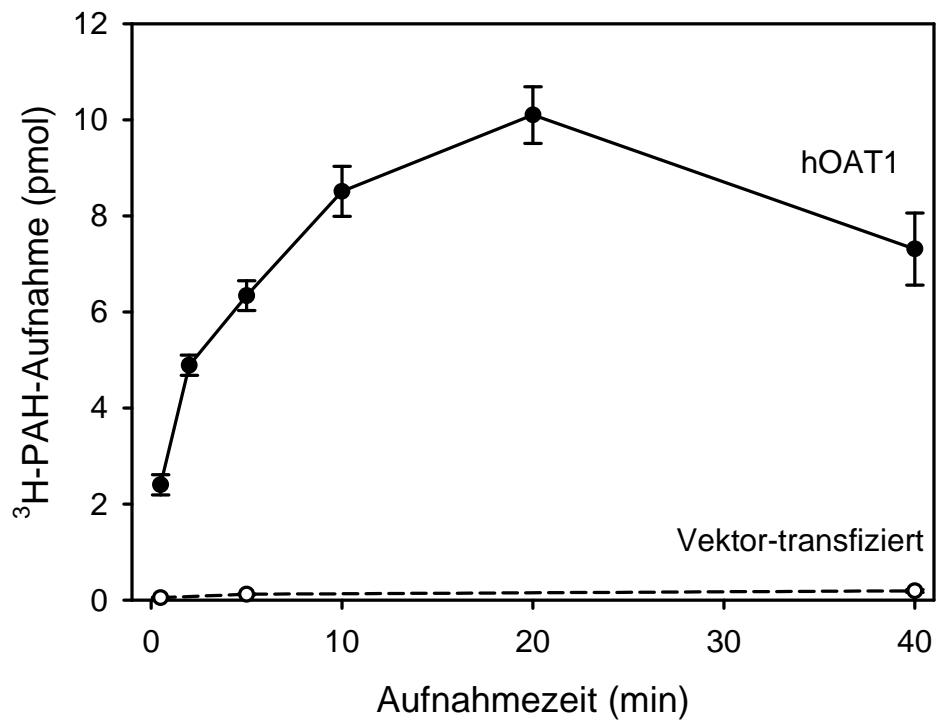

Abb. 6: Zeitabhängigkeit der Aufnahme von ${ }^{3} \mathrm{H}-\mathrm{PAH}$ in hOAT1-transfizierte HEK293-Zellen Die durchgehende Linie zeigt die ${ }^{3} \mathrm{H}-\mathrm{PAH}-A u f n a h m e$ in hOAT1-transfizierte HEK293-Zellen und die gestrichelte die ${ }^{3} \mathrm{H}-\mathrm{PAH}-\mathrm{Aufnahme}$ in Vektor-transfizierte HEK293-Zellen. Die Zellen wurden in Ringerlösung mit $1,1 \mu \mathrm{M}{ }^{3} \mathrm{H}-\mathrm{PAH}$ bei Raumtemperatur unterschiedlich lang inkubiert. $\mathrm{Zu}$ den angegebenen Zeitpunkten wurde die Aufnahme gestoppt und anschließend der ${ }^{3} \mathrm{H}-\mathrm{PAH}-$ Gehalt der Zellen gemessen. Dargestellt sind die Mittelwerte \pm Standardabweichung (SEM) aus 3 Versuchen an verschiedenen Zellpräparationen mit je 4 Einzelmessungen pro Zeitpunkt.

Ebenso wurde die Zeitabhängigkeit für den Östronsulfat-Transport in hOAT3-transfizierten Zellen gemessen. Östronsulfat ist das Standardsubstrat für hOAT3, das ebenfalls gegen intrazelluläre organische Anionen in die Zelle transportiert wird. An sechs Zeitpunkten zwischen 0,5 und 40 Minuten wurde die ${ }^{3} \mathrm{H}$-Östronsulfat-Aufnahme in die hOAT3-transfizierten Zellen gemessen und mit der Aufnahme der Vektor-transfizierten Zellen verglichen.

Die Abb. 7 zeigt die Ergebnisse. Auch hier verläuft die Kurve in den ersten 5 Minuten linear. Anschließend ist eine Abflachung der Kurve zu beobachten. Für den hOAT3 wurde deshalb ebenfalls eine Minute als optimale Aufnahmezeit für die folgenden Hemmversuche festgelegt, da zu diesem Zeitpunkt auch hier das Verhältnis der Aufnahme gegenüber den Vektortransfizierten HEK293-Zellen ausreichend (59 fmol gegen $5 \mathrm{fmol}$ ) groß ist und noch keine Sättigung zu beobachten ist. 


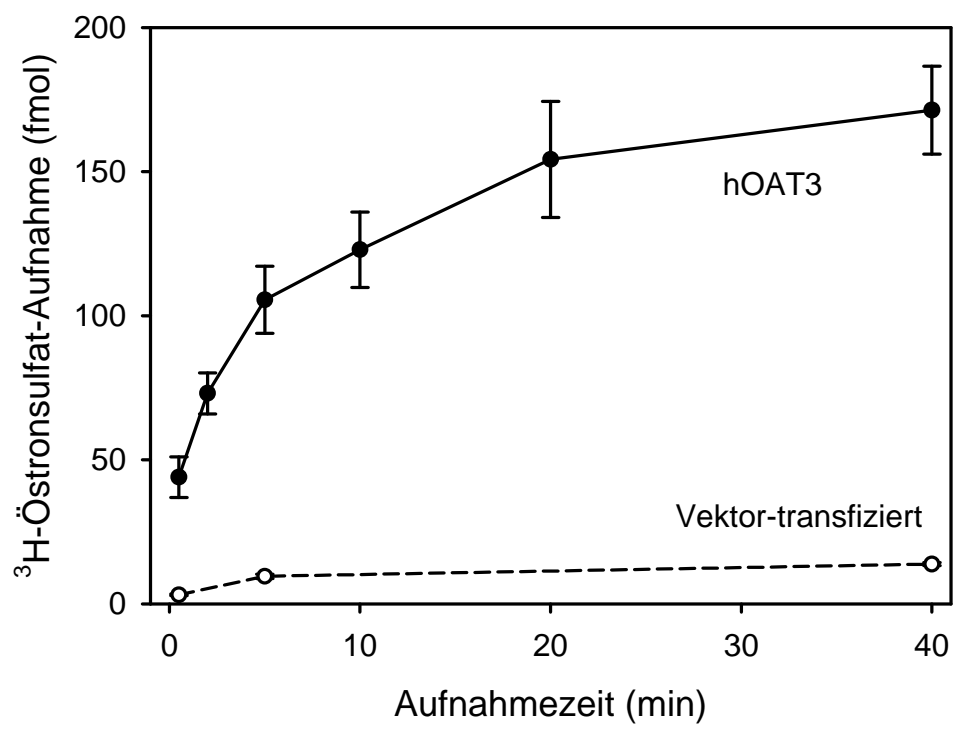

Abb. 7: Zeitabhängigkeit der Aufnahme von ${ }^{3} \mathrm{H}$-Östronsulfat in hOAT3-transfizierte HEK293-Zellen Die durchgehende Linie zeigt die ${ }^{3} \mathrm{H}$-Östronsulfat-Aufnahme in hOAT3-transfizierte HEK293-Zellen und die gestrichelte die ${ }^{3} \mathrm{H}$-Östronsulfat-Aufnahme in Vektor-transfizierte HEK293-Zellen. Die Zellen wurden in Ringerlösung mit $10 \mathrm{nM}{ }^{3} \mathrm{H}$ - Östronsulfat bei Raumtemperatur unterschiedlich lang inkubiert. Zu den angegebenen Zeitpunkten wurde die Aufnahme gestoppt und anschließend der ${ }^{3} \mathrm{H}-O ̈$ stronsulfat-Gehalt der Zellen gemessen. Dargestellt sind die Mittelwerte \pm Standardabweichung (SEM) aus 3 Versuchen an verschiedenen Zellpräparationen mit je 4 Einzelmessungen pro Zeitpunkt.

\subsection{Bestimmung des Zellproteingehalts}

Stichprobenartig wurde der Zellproteingehalt der einzelnen Löcher der 24-Loch-Platte bestimmt, in denen die Zellen zur Aufnahmemessung untersucht wurden. Der Zellproteingehalt ist ein Maß für die Anzahl der Zellen, die am Transport beteiligt sind. Damit sollte sichergestellt werden, dass Unterschiede in der Menge der aufgenommenen Substrate auf unterschiedlichen Transporteraktivitäten beruhen und nicht auf unterschiedlichen Zellzahlen. Es wurde der Zellproteingehalt bei drei Aufnahmeversuchen mit hOAT1-transfizierten und Vektor-transfizierten Zellen gemessen. Beim 1. Versuch war der Mittelwert von 72 Einzelmessungen 0,062 $\pm 0,002 \mathrm{mg}$ Zellprotein/ml für hOAT1-transfizierte Zellen. Die Löcher mit den Vektor-transfizierten Zellen hatten durchschnittlich einen etwas geringeren Proteingehalt von $0,037 \pm 0,001 \mathrm{mg} Z$ Zellprotein $/ \mathrm{ml}$. Beim 2. Versuch waren die Mittelwerte von 72 Einzelmessungen mit 0,075 $\pm 0,001 \mathrm{mg}$ Zellprotein/ml für die hOAT1-transfizierten und 0,069 \pm 0,001 mg Zellprotein/ml für die Vektor-transfizierten Zellen nahezu identisch. Der 3. Versuch ergab nach ebenfalls 72 Einzelmessungen für die hOAT1-transfizierten Zellen einen Mittelwert von 0,093 $\pm 0,002 \mathrm{mg}$ Zellprotein $/ \mathrm{ml}$. Die Vektor-transfizierten Zellen hatten pro Loch eine Proteinmenge von $0,082 \mathrm{mg} / \mathrm{ml} \pm 0,005 \mathrm{mg} / \mathrm{ml}$. 
Die geringen Standardabweichungen zeigen, dass die Unterschiede im Zellgehalt der einzelnen Löcher innerhalb eines Versuchs sehr klein waren. Auch der Proteingehalt pro Loch der hOAT1-transfizierten Zellen und Vektor-transfizierten Zellen sind ähnlich. Ebenso gibt es zwischen den verschiedenen Transportversuchen nur geringe Unterschiede im Hinblick auf den Proteingehalt.

Die Proteinbestimmung wurde in gleicher Weise für Versuche mit den hOAT3-transfizierten Zellen durchgeführt. Beim ersten Versuch war der Mittelwert von 20 Einzelmessungen 0,064 \pm 0,005 mg Zellprotein/ml für die hOAT3-transfizierten Zellen, gegenüber 0,059 $\pm 0,005 \mathrm{mg}$ Zellprotein/ml für die Vektor-transfizierten Zellen. Bei der 2. Zellproteinbestimmung von hOAT3-transfizierten Zellen war der Mittelwert von 16 Einzelmessungen 0,127 \pm 0,001 mg Zellprotein/ml. Der entsprechende Zellproteingehalt der Vektor-transfizierten Zellen war $0,128 \pm 0,001 \mathrm{mg} /$ Zellprotein $\mathrm{ml}$.

Das bedeutet, dass die Zellzahlen der Löcher innerhalb eines Versuchs und zwischen verschiedenen Versuchen miteinander vergleichbar sind. Auch zwischen den hOAT3transfizierten und den Vektor-transfizierten Zellen gab es nur geringe Unterschiede.

\subsection{Bestimmung der unspezifischen Substrataufnahme und Substrat- bindung}

Für die folgenden kinetischen Hemmversuche ist es wichtig, dass nur der Anteil der radioaktiv markierten Substrate berücksichtigt wird, der durch den spezifischen Transport über hOAT1 oder hOAT3 in die Zelle aufgenommen wird. Daneben wird bei den AufnahmeVersuchen auch ein unspezifischer Anteil mit gemessen. Dies ist radioaktiv markiertes Substrat, das unspezifisch oder über andere Transporter in die Zellen gelangt oder von außen an die Zellen bindet und nicht abgewaschen werden kann.

Zur Bestimmung dieses unspezifischen Anteils gibt es mehrere Möglichkeiten.

Eine Möglichkeit ist, die Vektor-transfizierten Zellen immer mitzumessen und den bei diesen Zellen gemessenen Wert, von der gemessenen Substrataufnahme der hOAT1- bzw. hOAT3transfizierten Zelle zu subtrahieren.

Eine zweite Möglichkeit ist, die Vektor-transfizierten Zellen mitzumessen, die gemessenen Werte über einen bestimmten Zeitraum zu mitteln, und diese Durchschnittswerte von der gemessenen Substrataufnahme der transfizierten Zellen abzuziehen.

Die dritte Variante ist eine rein rechnerische Ermittlung des unspezifischen Anteils über die Gleichung für die Hemmkinetik $\mathrm{v}=\frac{\mathrm{v}_{\max }}{1+\frac{[\mathrm{I}]}{\mathrm{IC}_{50}}}+\mathrm{v}_{\min }=\frac{\mathrm{v}_{\max } \cdot \mathrm{IC}_{50}}{\mathrm{IC}_{50}+[\mathrm{I}]}+\mathrm{v}_{\min }$ (DE LEAN et al. 1978). 
Der Term $v_{\min }$ in dieser Gleichung gibt den nicht hemmbaren Anteil und damit den unspezifischen Anteil an. $\mathrm{v}$ entspricht der Transportrate bei aktueller [I]-(InhibitorKonzentration). $\mathrm{V}_{\max }$ ist die maximale Transportrate des Transporters in Abwesenheit des Inhibitors. $\mathrm{IC}_{50}$ ist die Inhibitorkonzentration, bei der die Hemmung halbmaximal ist.

In dieser Arbeit wurde die zweite und dritte Variante kombiniert. Erstens wurde die durchschnittliche unspezifische Substrataufnahme bzw. Substratbindung der Vektortransfizierten Kontrollzellen von der Aufnahme der transfizierten HEK293-Zellen subtrahiert. Zweitens wurde zusätzlich der unspezifische nicht-hemmbare Anteil durch Anpassung der Gleichung nach der Methode der kleinsten Fehlerquadrate berechnet. Dieser Anteil war wie erwartet Null, außer in den Fällen, die im Folgenden noch diskutiert werden.

\section{4. $\quad K_{m}$-Bestimmung der Substrataufnahme}

Der $\mathrm{K}_{\mathrm{m}}$-Wert oder die Michaelis-Menten-Konstante ist die Substratkonzentration bei halbmaximaler Aufnahmegeschwindigkeit. Bei dieser Konzentration ist die Hälfte der Transportbindungsstellen mit dem Substrat besetzt: $v=\frac{v_{\max } \cdot[\mathrm{S}]}{\mathrm{K}_{\mathrm{m}}+[\mathrm{S}]}$ (BERG et al. 2007). In dieser Michaelis-Menten-Gleichung ist außerdem $v=$ Aufnahmegeschwindigkeit, $v_{\max }=$ maximale Aufnahmegeschwindigkeit und [S] die Substratkonzentration. Es wurde sowohl der $\mathrm{K}_{\mathrm{m}}$-Wert für den PAH-Transport durch hOAT1 als auch für den Östronsulfat-Transport durch hOAT3 bestimmt.

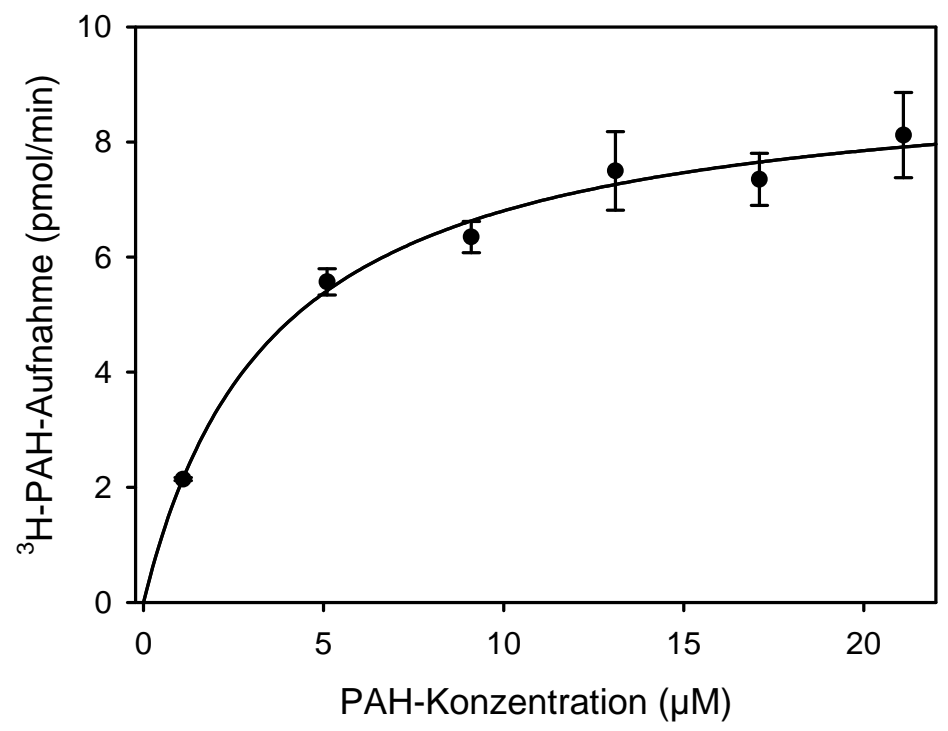

Abb. 8: $\mathrm{K}_{\mathrm{m}}$-Bestimmung des PAH-Transports in hOAT1-transfizierte HEK293-Zellen

Die Kurve zeigt die ${ }^{3}$ H-PAH-Aufnahme von hOAT1-transfizierten HEK293-Zellen abzüglich der bei Vektortransfizierten Zellen gemessenen ${ }^{3} \mathrm{H}-\mathrm{PAH}-$ Menge. Die Zellen wurden bei Raumtemperatur mit 1,1 bis $21,1 \mu \mathrm{M}$ ${ }^{3} \mathrm{H}-\mathrm{PAH}$ für 1 Minute inkubiert. Anschließend wurde das in die Zelle aufgenommene ${ }^{3} \mathrm{H}-\mathrm{PAH}$ gezählt. Dargestellt ist einer von drei Versuchen mit Mittelwerten \pm Standardabweichungen (SEM) aus 4 Einzelmessungen an einer Zellpräparation. 
Abb. 8 zeigt als Beispiel eine von drei Messungen zur Bestimmung des $\mathrm{K}_{\mathrm{m}}$-Wertes für den PAH-Transport. Die Anpassung der Michaelis-Menten-Gleichung an die Messpunkte ergab einen $\mathrm{K}_{\mathrm{m}}$-Wert von 4,8 $\pm 1,2 \mu \mathrm{M}$.

Bei diesen Messungen wird die PAH-Konzentration durch Zugabe von nicht markierten PAH erhöht. Bei der Berechnung der aufgenommenen Substratmenge geht man davon aus, dass das gesamte PAH zu einem bestimmten Prozentsatz radioaktiv markiert ist. Man kann dieses Experiment aber auch anders interpretieren und auswerten, nämlich dass die Aufnahme des radioaktiv markierten PAHs durch das nicht markierte PAH gehemmt wird. Das heißt, dass die Konzentration an radioaktiven Material immer gleich bleibt, die an nicht markierten PAH im Inkubationsmedium aber zunimmt. Nach dieser Berechnung sinkt natürlich die Aufnahme von radioaktiv markierten PAH bei höheren Konzentrationen an nicht markierten PAH. Das Ergebnis zeigt Abb. 9.

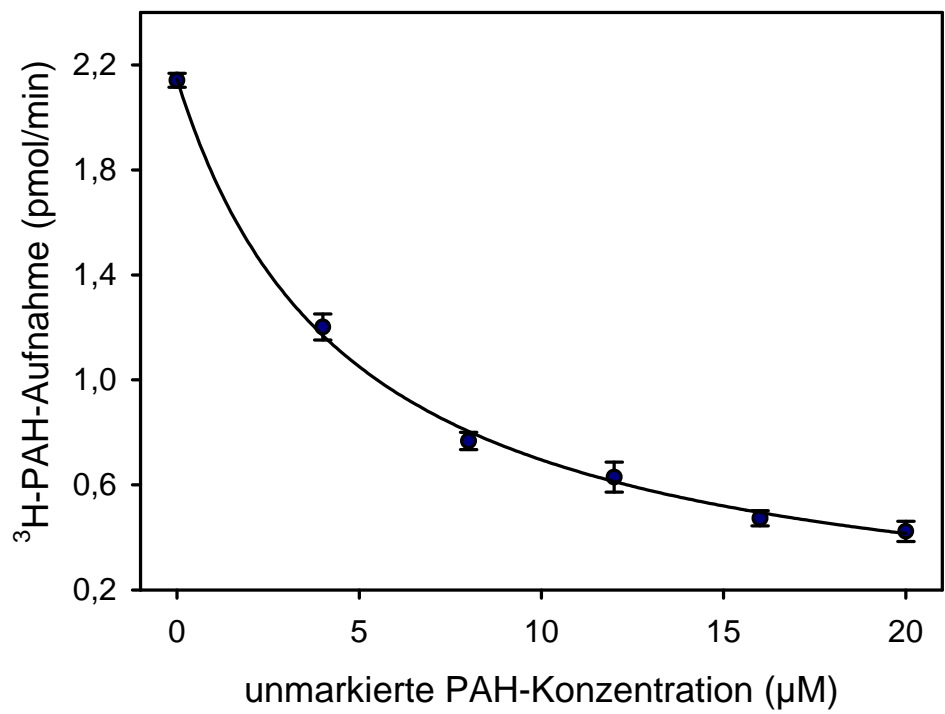

Abb. 9: $\mathrm{K}_{\mathrm{m}}-\mathrm{K}_{\mathrm{i}}$-Bestimmung des PAH-Transports in hOAT1-transfizierte HEK293-Zellen

Die Kurve zeigt die Hemmung der ${ }^{3} \mathrm{H}-\mathrm{PAH}-A u f n a h m e$ von hOAT1-transfizierten HEK293-Zellen durch nicht markiertes PAH. Die Zellen wurden bei Raumtemperatur mit $1,1 \mu \mathrm{M}^{3} \mathrm{H}-\mathrm{PAH}$ und 0 bis $20 \mu \mathrm{M}$ nicht markierten PAH für 1 Minute inkubiert. Anschließend wurde das in die Zelle aufgenommene ${ }^{3} \mathrm{H}-\mathrm{PAH}$ gezählt. Davon abgezogen wurde die bei Vektor-transfizierten Zellen gemessene ${ }^{3} \mathrm{H}-\mathrm{PAH}-\mathrm{Menge}$. Dargestellt ist einer von drei Versuchen mit Mittelwerten \pm Standardabweichungen (SEM) aus 4 Einzelmessungen an einer Zellpräparation.

Die allgemeine kinetische Gleichung für eine kompetitive Hemmung lautet $v=\frac{v_{\max } \cdot[\mathrm{S}]}{\mathrm{K}_{\mathrm{m}}\left(1+\frac{[\mathrm{I}]}{\mathrm{K}_{\mathrm{i}}}\right)+[\mathrm{S}]}$ (DIXON 1953). Dabei ist [S] die Substratkonzentration, [I] die Inhibitorkonzentration und $\mathrm{K}_{\mathrm{i}}$ die Inhibitorkonstante. Da in den hier beschriebenen Versuchen der Hemmstoff chemisch identisch ist mit dem Substrat, gilt $\mathrm{K}_{\mathrm{m}}=\mathrm{K}_{\mathrm{i}}$ und die Inhibitorkonzentration entspricht der Konzentration an nicht markiertem Substrat: $[\mathrm{I}]=[\mathrm{S}]$. Damit vereinfacht sich die Gleichung $\mathrm{zu}: \quad \mathrm{v}=\frac{\mathrm{v}_{\max } \cdot\left[\mathrm{S}^{*}\right]}{\mathrm{K}_{\mathrm{m}}+[\mathrm{S}]^{+}\left[\mathrm{S}^{*}\right]}$ (MALO und BERTELOOT 1991). [S*] ist die Konzentration des radioaktiv markierten Substrats. Die Anpassung der Gleichung an die Messwerte zeigt die Kurve in Abb. 9 für einen Versuch. Der Mittelwert der $\mathrm{K}_{\mathrm{m}}$-Werte aus drei Versuchen war 
7,3 $\pm 1,9 \mu \mathrm{M}$. Auch für den Östronsulfat-Transport durch hOAT3 wurde in gleicher Weise der $\mathrm{K}_{\mathrm{m}}$-Wert bestimmt. Der Mittelwert aus drei Versuchen war 2,7 $\pm 0,6 \mu \mathrm{M}$ bzw. 2,8 $\pm 0,3$ $\mu \mathrm{M}$. Eine Beispielmessung ist jeweils in Abbildung 10 und 11 dargestellt.

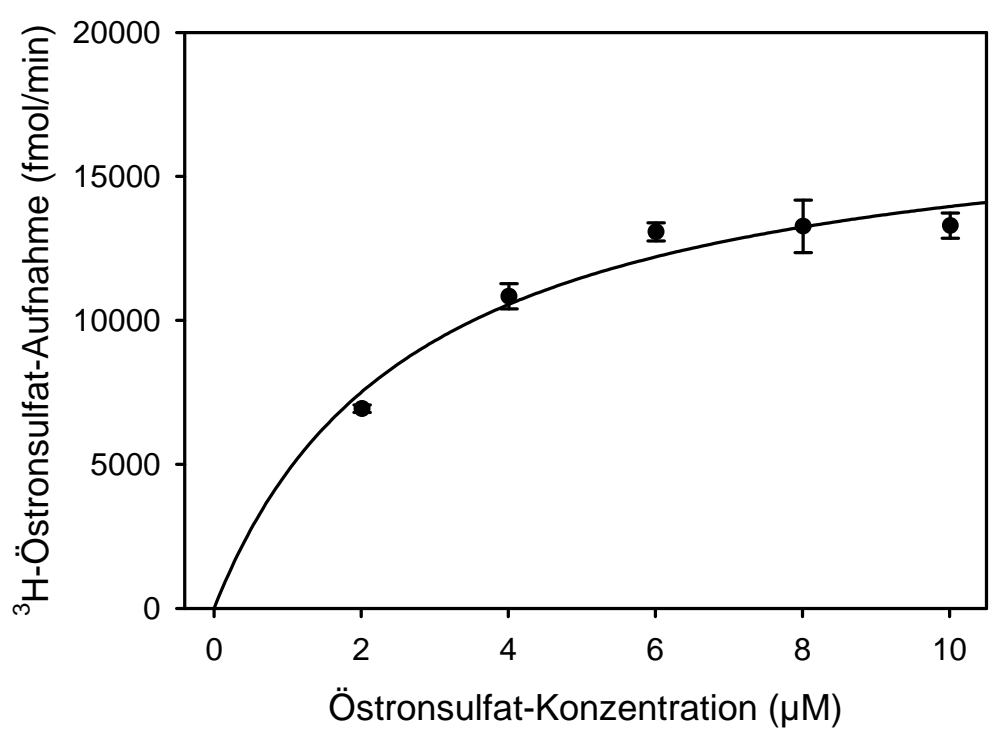

Abb. 10: $\mathrm{K}_{\mathrm{m}}$-Bestimmung des Östronsulfat-Transports in hOAT3-transfizierte HEK293-Zellen

Die Kurve zeigt die ${ }^{3} \mathrm{H}$-Östronsulfat-Aufnahme von hOAT3-transfizierten HEK293-Zellen abzüglich der bei Vektor-transfizierten Zellen gemessenen ${ }^{3} \mathrm{H}$-Östronsulfat-Menge. Die Zellen wurden bei Raumtemperatur mit $0,01-10,01 \mu \mathrm{M}{ }^{3} \mathrm{H}$-Östronsulfat für 1 Minute inkubiert. Anschließend wurde das in die Zelle aufgenommene ${ }^{3} \mathrm{H}$-Östronsulfat gezählt. Dargestellt ist einer von drei Versuchen mit Mittelwerten \pm Standardabweichungen (SEM) aus 4 Einzelmessungen an einer Zellpräparation.

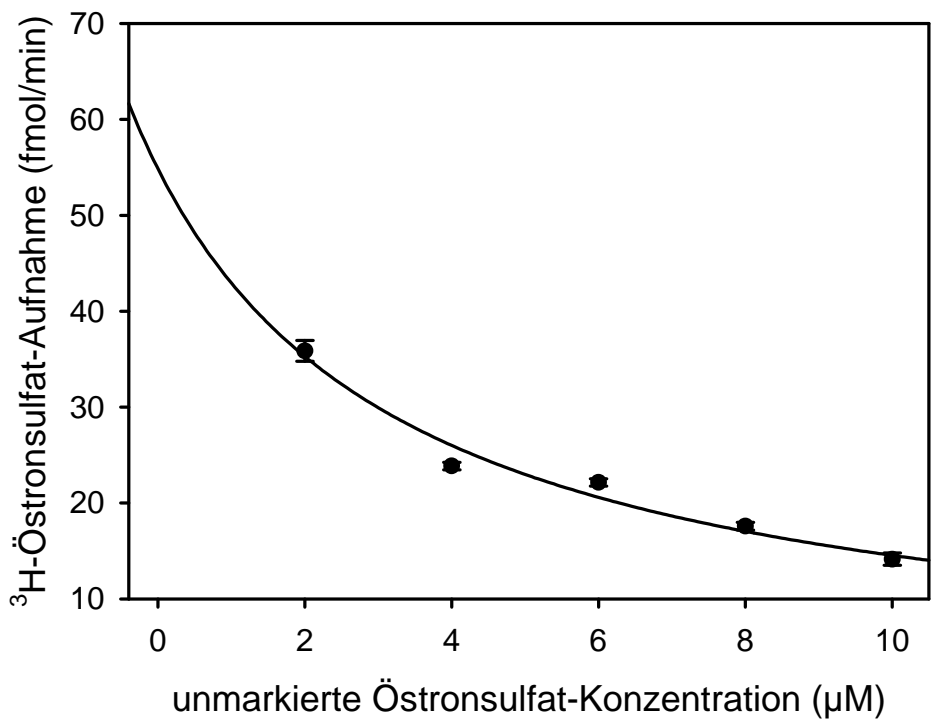

Abb. 11: $\mathrm{K}_{\mathrm{m}}-\mathrm{K}_{\mathrm{i}}$-Bestimmung des Östronsulfat-Transports in hOAT3-transfizierte HEK293-Zellen Die Kurve zeigt die Hemmung der ${ }^{3} \mathrm{H}$-Östronsulfat-Aufnahme von hOAT3-transfizierten HEK293-Zellen durch nicht markiertes Östronsulfat. Die Zellen wurden bei Raumtemperatur mit $0,01 \mu \mathrm{M}{ }^{3} \mathrm{H}$-Östronsulfat und 0 bis 10 uM nicht markiertem Östronsulfat für 1 Minute inkubiert. Anschließend wurde das in die Zelle aufgenommene ${ }^{3} \mathrm{H}$-Östronsulfat gezählt. Davon abgezogen wurde die bei Vektor-transfizierten Zellen gemessene ${ }^{3} \mathrm{H}-$ Östronsulfat-Menge. Dargestellt ist einer von drei Versuchen mit Mittelwerten \pm Standardabweichungen (SEM) aus 4 Einzelmessungen an einer Zellpräparation. 


\subsection{Bestimmung der $\mathrm{IC}_{50^{-}}$und $\mathrm{K}_{\mathrm{i}^{-}}$Werte für die Substrattransporte durch hOAT1 und hOAT3}

Im Folgenden wurden die $\mathrm{IC}_{50}$-Werte und zum Teil auch die $\mathrm{K}_{\mathrm{i}}$-Werte der Hemmung des ${ }^{3} \mathrm{H}$ PAH-Transports in hOAT1-transfizierte Zellen und des ${ }^{3} \mathrm{H}$-Östronsulfat-Transports in hOAT3-transfizierte Zellen durch verschiedene Dicarboxylate gemessen. Eingesetzt wurden Dicarboxylate unterschiedlicher Länge mit 3 bis 8 C-Atomen. Diese Dicarboxylate wurden gemeinsam mit den zu transportierenden Substraten ${ }^{3} \mathrm{H}-\mathrm{PAH}$ bzw. ${ }^{3} \mathrm{H}$-Östronsulfat den Transportern auf der extrazellulären Seite angeboten, so dass sie mit der Bindung der Substrate an die Transporter interagieren konnten. $\mathrm{IC}_{50}$ ist die Substratkonzentration, bei der eine 50\%ige Hemmung der Aufnahme vorliegt. Der $\mathrm{K}_{\mathrm{i}}$-Wert ist die Hemmkonstante des jeweiligen Dicarboxylats, die unabhängig von der jeweiligen Substratkonzentration ist. Der $\mathrm{IC}_{50}$-Wert wurde durch Anpassung der schon beschriebenen Gleichung für die Hemmkinetik an die Messwerte erhalten: $\mathrm{v}=\frac{\mathrm{v}_{\max } \cdot \mathrm{IC}_{50}}{\mathrm{IC}_{50}+[\mathrm{I}]}+\mathrm{v}_{\min }$.

Der $\mathrm{K}_{\mathrm{i}}$-Wert wurde für zwei besonders affine Dicarboxylate mittlerer Kettenlänge, durch Dixon-Plots bestimmt. Dabei wurde die Hemmung bei zwei verschiedenen Substratkonzentrationen gemessen. Der Schnittpunkt der beiden Geraden, der entsteht, wenn man den reziproken Transport gegen die Hemmstoffkonzentration aufträgt, ergibt die Hemmkonstante $\mathrm{K}_{\mathrm{i}}$.

Alle Versuche wurden immer nach dem gleichen Ablauf durchgeführt. Die Zellen wurden in einem Puffer mit ${ }^{3} \mathrm{H}-\mathrm{PAH}$ bzw. ${ }^{3} \mathrm{H}$-Östronsulfat und dem zu testenden Dicarboxylat inkubiert. Anschließend wurde die aufgenommene Substratmenge ermittelt.

Alle Werte wurden in mindestens drei unabhängigen Versuchen an drei verschiedenen Zellpräparaten bestimmt. Zum Teil wurde in einem Vorversuch erst der Bereich der DicarboxylatKonzentrationen bestimmt, der für die Messungen sinnvoll war. Bei hohen DicarboxylatKonzentrationen wurde die Gesamtosmolarität der Inkubationslösung durch Variation des $\mathrm{NaCl}$ - und NaGluc-Anteils der Ringerlösung konstant gehalten.

\subsection{Bestimmung der $\mathrm{IC}_{50}$-Werte der Dicarboxylate für den PAH- Transport durch hOAT1}

Zunächst wurden die $\mathrm{IC}_{50}$-Werte der Dicarboxylate für den PAH-Transport mit hOAT1transfizierten Zellen bestimmt. 


\subsubsection{Malonat}

Als erstes wurde der Einfluss von Malonat auf den ${ }^{3} \mathrm{H}-\mathrm{PAH}-\mathrm{Transport}$ in hOAT1transfizierten HEK293-Zellen geprüft. Getestet wurden Malonat-Konzentrationen von $0 \mathrm{mM}$ bis $50 \mathrm{mM}$. Abb. 12 zeigt als Beispiel einen von drei Versuchen nach Abzug der unspezifischen Aufnahme/Bindung, die mit Hilfe der Vektor-transfizierten Zellen bestimmt wurde. Offensichtlich interagiert Malonat nicht mit dem hOAT1.

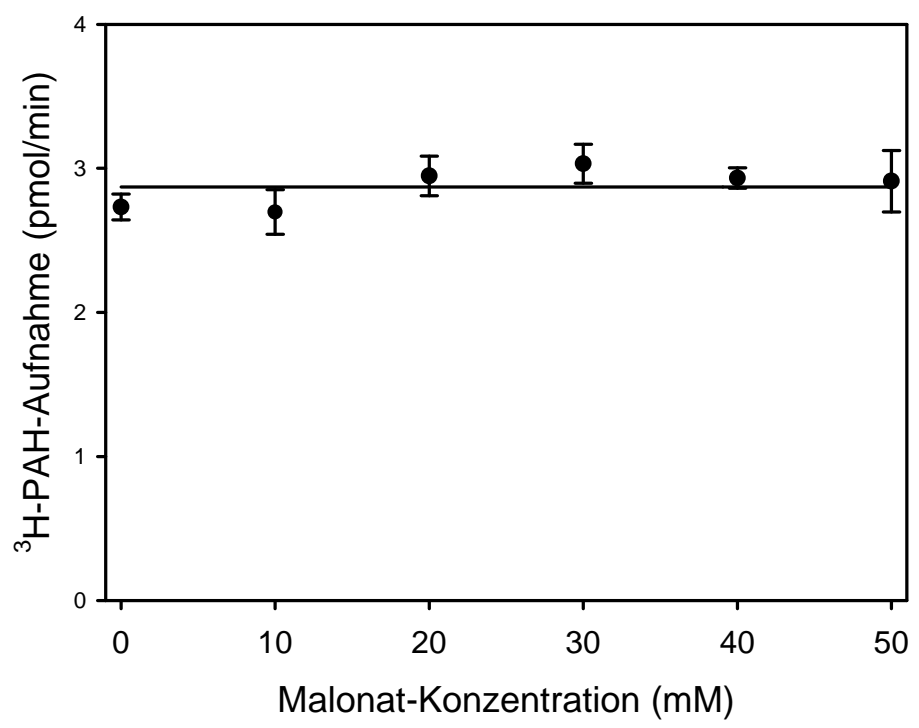

\section{Abb. 12: Aufnahme von ${ }^{3}$ H-PAH in Anwesenheit von Malonat in hOAT1-transfizierte Zellen}

hOAT1- und Vektor-transfizierte HEK293-Zellen wurden für eine Minute bei Raumtemperatur in Ringerlösung mit $1,1 \mu \mathrm{M}{ }^{3} \mathrm{H}-\mathrm{PAH}$ und verschiedenen Malonat-Konzentrationen inkubiert. Die Abbildung zeigt die in hOAT1transfizierte Zellen aufgenommene ${ }^{3} \mathrm{H}-\mathrm{PAH}-M e n g e$ abzüglich der bei den Vektor-transfizierten Zellen gemessenen ${ }^{3}$ H-PAH-Menge. Dargestellt ist eine von drei unabhängigen Messungen an drei verschiedenen Zellkulturen. Die gezeigten Werte sind Mittelwerte \pm Standardabweichungen (SEM) von jeweils vier Einzelmessungen an einer Zellkultur. Die Kurve wurde durch Anpassung der Gleichung für Hemmkinetiken an die Messdaten berechnet.

\subsubsection{Maleat}

Als Nächstes wurde die ${ }^{3} \mathrm{H}-\mathrm{PAH}-\mathrm{Aufnahme}$ durch den hOAT1 in Anwesenheit von Maleat bestimmt. Die getesteten Maleat-Konzentrationen lagen zwischen 0 bis $50 \mathrm{mM}$ (Abb. 13). Man sieht eine deutliche Hemmung mit steigender Maleat-Konzentration. Der $\mathrm{IC}_{50}$-Wert wurde durch Anpassung der Gleichung für Hemmkinetiken an die Messwerte erhalten. Die Auswertung von vier Versuchen ergibt für Maleat einen $\mathrm{IC}_{50}$-Wert mit einem Mittelwert von $12950 \pm 1258 \mu \mathrm{M}$. 


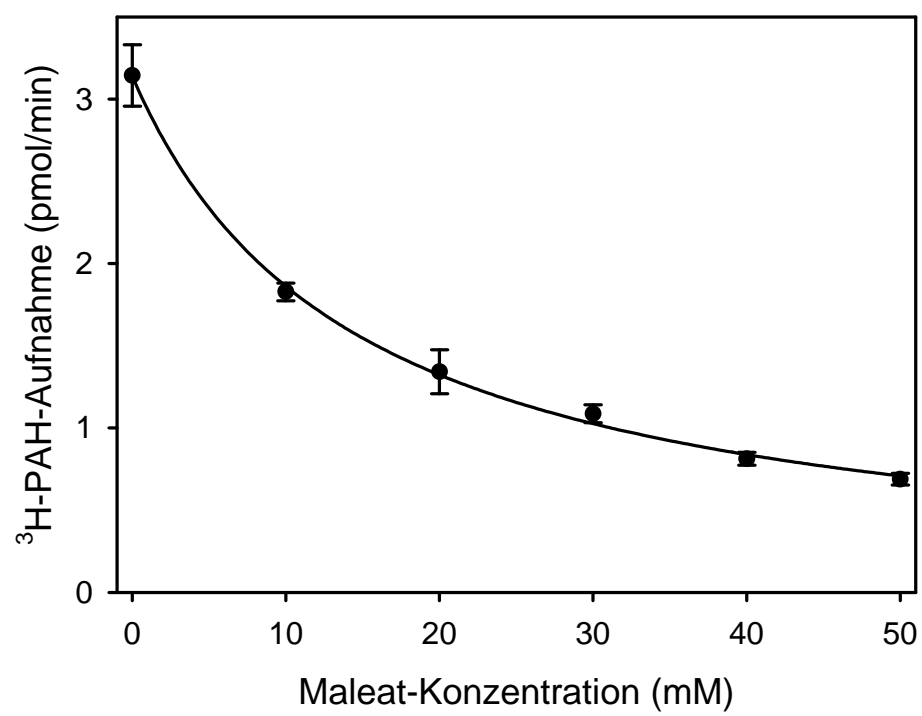

Abb. 13: Aufnahme von ${ }^{3}$ H-PAH in Anwesenheit von Maleat in hOAT1-transfizierte Zellen

hOAT1- und Vektor-transfizierte HEK293-Zellen wurden für eine Minute bei Raumtemperatur in Ringerlösung mit $1,1 \mu \mathrm{M}{ }^{3} \mathrm{H}-\mathrm{PAH}$ und verschiedenen Maleat-Konzentrationen inkubiert. Die Abbildung zeigt die in hOAT1transfizierte Zellen aufgenommene ${ }^{3} \mathrm{H}-\mathrm{PAH}-\mathrm{Menge}$ abzüglich der bei den Vektor-transfizierten Zellen gemessenen ${ }^{3} \mathrm{H}-\mathrm{PAH}-\mathrm{Menge}$. Dargestellt ist eine von vier unabhängigen Messungen an vier verschiedenen Zellkulturen. Die gezeigten Werte sind Mittelwerte \pm Standardabweichungen (SEM) von jeweils vier Einzelmessungen an einer Zellkultur. Die Kurve wurde durch Anpassung der Gleichung für Hemmkinetiken an die Messdaten berechnet.

\subsubsection{Fumarat}

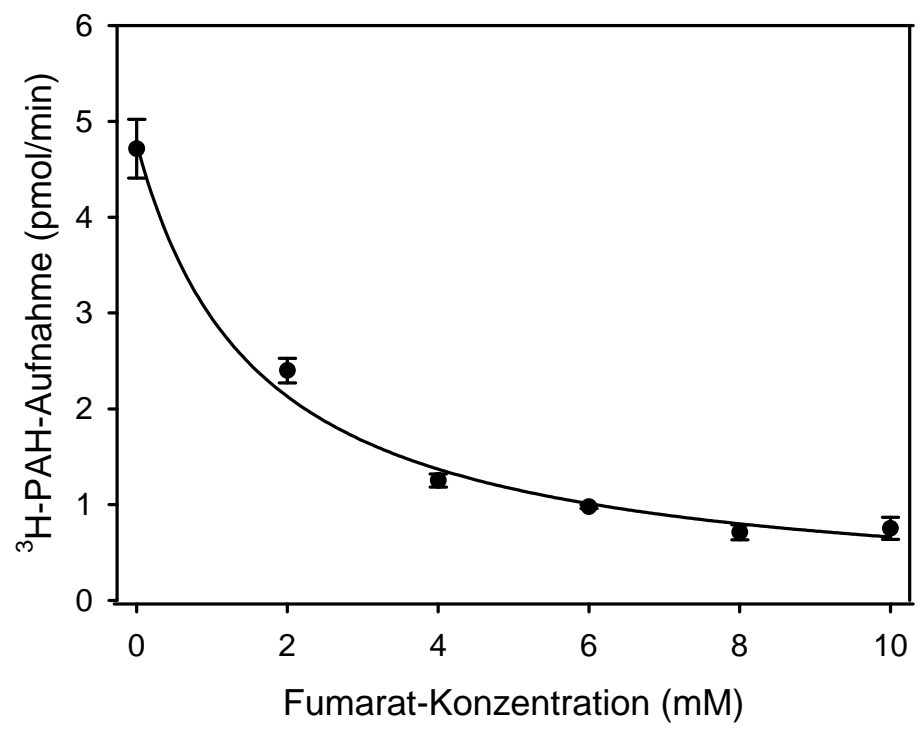

Abb. 14: Aufnahme von ${ }^{3}$ H-PAH in Anwesenheit von Fumarat in hOAT1-transfizierte Zellen

hOAT1- und Vektor-transfizierte HEK293-Zellen wurden für eine Minute bei Raumtemperatur in Ringerlösung mit 1,1 $\mu \mathrm{M}^{3} \mathrm{H}$-PAH und verschiedenen Fumarat-Konzentrationen inkubiert. Die Abbildung zeigt die in hOAT1transfizierte Zellen aufgenommene ${ }^{3} \mathrm{H}-\mathrm{PAH}-\mathrm{Menge}$ abzüglich der bei den Vektor-transfizierten Zellen gemessenen ${ }^{3} \mathrm{H}-\mathrm{PAH}-\mathrm{Menge}$. Dargestellt ist eine von drei unabhängigen Messungen an drei verschiedenen Zellkulturen. Die gezeigten Werte sind Mittelwerte \pm Standardabweichungen (SEM) von jeweils vier Einzelmessungen an einer Zellkultur. Die Kurve wurde durch Anpassung der Gleichung für Hemmkinetiken an die Messdaten berechnet. 
Den Einfluss des Dicarboxylats Fumarat auf den ${ }^{3} \mathrm{H}-\mathrm{PAH}-\mathrm{Transport}$ in hOAT1-transfizierte HEK293-Zellen wird in der Abb. 14 an einem Beispiel gezeigt. Zwei weitere Versuche zeigten ähnliche Ergebnisse. Zusammenfassend wurde eine $\mathrm{IC}_{50}$ von $1733 \pm 353 \mu \mathrm{M}$ ermittelt.

\subsubsection{Succinat}

Die Hemmversuche mit Succinat wurden mit Succinat-Konzentrationen zwischen 0 und 10 $\mu \mathrm{M}$ durchgeführt (Abb. 15). Aus vier Versuchen wurde eine $\mathrm{IC}_{50}$ von $4825 \pm 680 \mu \mathrm{M}$ errechnet.

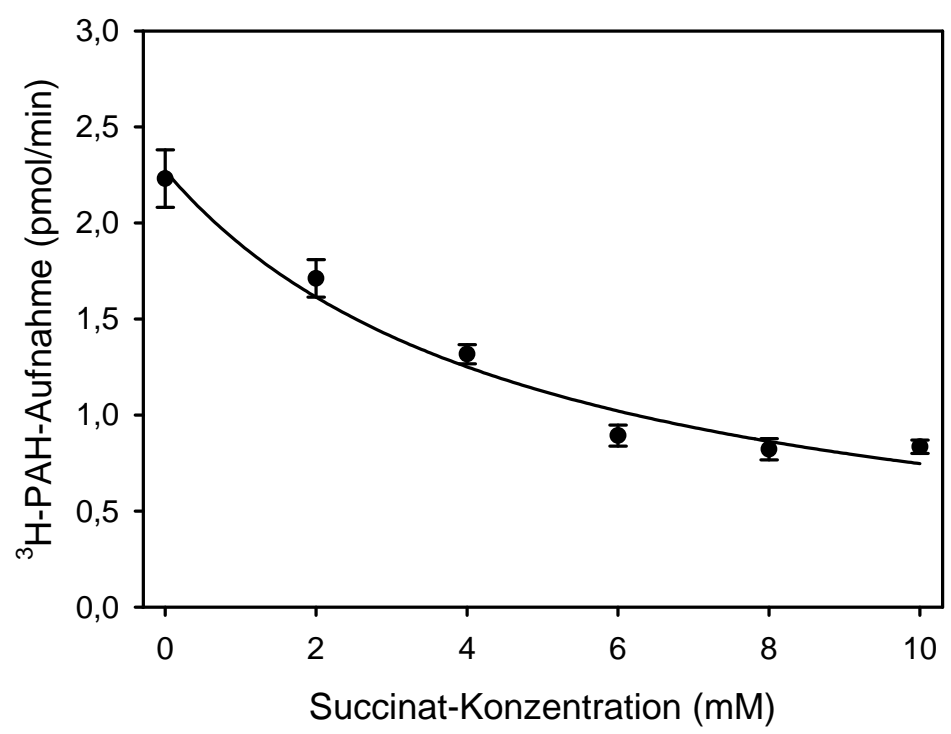

Abb. 15: Aufnahme von ${ }^{3}$ H-PAH in Anwesenheit von Succinat in hOAT1-transfizierte Zellen

hOAT1- und Vektor-transfizierte HEK293-Zellen wurden für eine Minute bei Raumtemperatur in Ringerlösung mit $1,1 \mu \mathrm{M}{ }^{3} \mathrm{H}-\mathrm{PAH}$ und verschiedenen Succinat-Konzentrationen inkubiert. Die Abbildung zeigt die in hOAT1transfizierte Zellen aufgenommene ${ }^{3} \mathrm{H}-\mathrm{PAH}-\mathrm{Menge}$ abzüglich der bei den Vektor-transfizierten Zellen gemessenen ${ }^{3} \mathrm{H}-\mathrm{PAH}-\mathrm{Menge}$. Dargestellt ist eine von vier unabhängigen Messungen an vier verschiedenen Zellkulturen. Die gezeigten Werte sind Mittelwerte \pm Standardabweichungen (SEM) von jeweils vier Einzelmessungen an einer Zellkultur. Die Kurve wurde durch Anpassung der Gleichung für Hemmkinetiken an die Messdaten berechnet.

\subsubsection{Glutarat}

Abb. 16 zeigt den Einfluss von Glutarat auf die ${ }^{3} \mathrm{H}-\mathrm{PAH}-\mathrm{Aufnahme}$ durch hOAT1. Die ${ }^{3} \mathrm{H}-$ PAH-Aufnahme wurde in Anwesenheit verschiedener Glutarat-Konzentrationen von 0 bis 10 $\mu \mathrm{M}$ gemessen. Der Graph, der beispielhaft eine Versuchsauswertung abbildet, zeigt eine deutliche Hemmung durch Glutarat.

Der Mittelwert der $\mathrm{IC}_{50}$ von Glutarat aus vier Versuchen beträgt 3,3 $\pm 1,2 \mu \mathrm{M}$. 


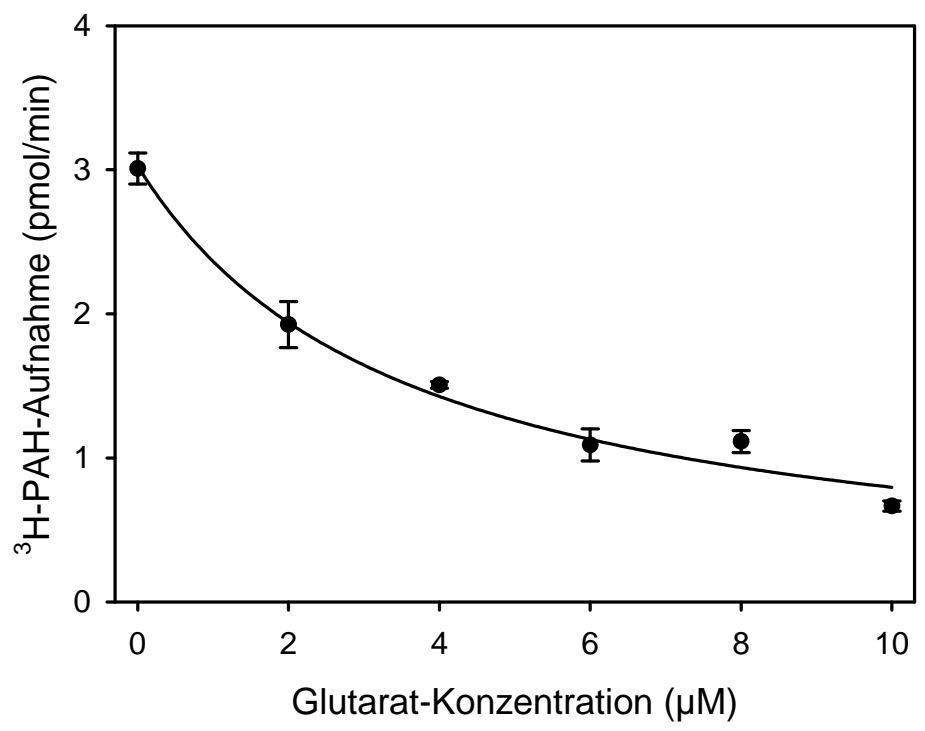

Abb. 16: Aufnahme von ${ }^{3}$ H-PAH in Anwesenheit von Glutarat in hOAT1-transfizierte Zellen

hOAT1- und Vektor-transfizierte HEK293-Zellen wurden für eine Minute bei Raumtemperatur in Ringerlösung mit 1,1 $\mu \mathrm{M}^{3} \mathrm{H}-\mathrm{PAH}$ und verschiedenen Glutarat-Konzentrationen inkubiert. Die Abbildung zeigt die in hOAT1transfizierte Zellen aufgenommene ${ }^{3} \mathrm{H}-\mathrm{PAH}-\mathrm{Menge}$ abzüglich der bei den Vektor-transfizierten Zellen gemessenen ${ }^{3} \mathrm{H}-\mathrm{PAH}-\mathrm{Menge}$. Dargestellt ist eine von vier unabhängigen Messungen an vier verschiedenen Zellkulturen. Die gezeigten Werte sind Mittelwerte \pm Standardabweichungen (SEM) von jeweils vier Einzelmessungen an einer Zellkultur. Die Kurve wurde durch Anpassung der Gleichung für Hemmkinetiken an die Messdaten berechnet.

\subsection{6. $\alpha$-Ketoglutarat}

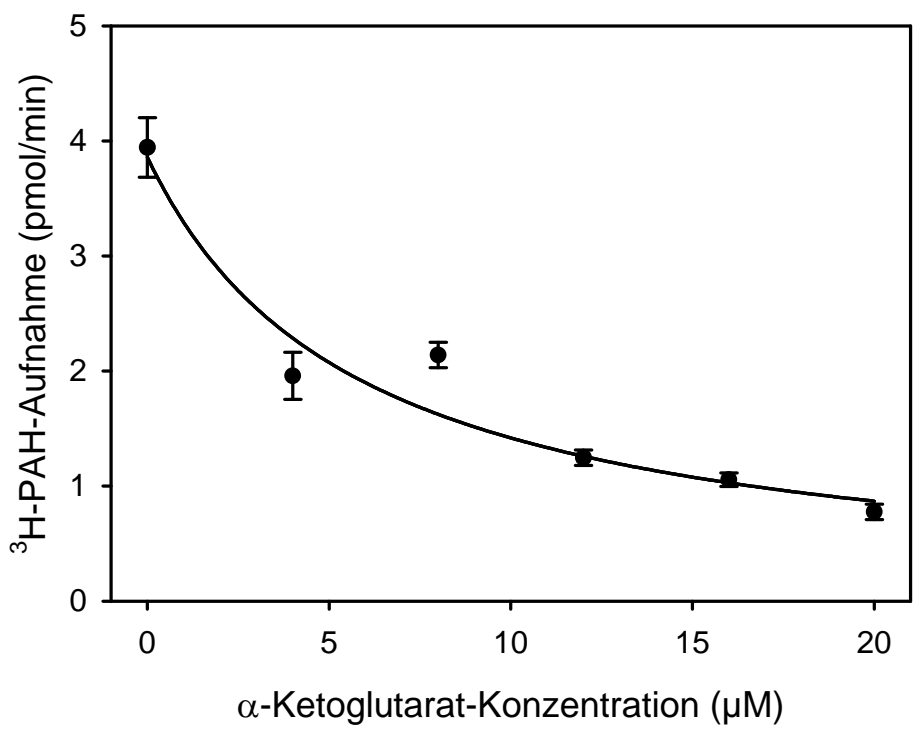

Abb. 17: Aufnahme von ${ }^{3}$ H-PAH in Anwesenheit von $\alpha$-Ketoglutarat in hOAT1-transfizierte Zellen hOAT1- und Vektor-transfizierte HEK293-Zellen wurden für eine Minute bei Raumtemperatur in Ringerlösung mit $1,1 \mu \mathrm{M}{ }^{3} \mathrm{H}-\mathrm{PAH}$ und verschiedenen $\alpha$-Ketoglutarat-Konzentrationen inkubiert. Die Abbildung zeigt die in hOAT1-transfizierte Zellen aufgenommene ${ }^{3} \mathrm{H}$-PAH-Menge abzüglich der bei den Vektor-transfizierten Zellen gemessenen ${ }^{3} \mathrm{H}-\mathrm{PAH}-\mathrm{Menge}$. Dargestellt ist eine von vier unabhängigen Messungen an vier verschiedenen Zellkulturen. Die gezeigten Werte sind Mittelwerte \pm Standardabweichungen (SEM) von jeweils vier Einzelmessungen an einer Zellkultur. Die Kurve wurde durch Anpassung der Gleichung für Hemmkinetiken an die Messdaten berechnet. 
Die Anwesenheit von $\alpha$-Ketoglutarat im Transportmedium bewirkte eine deutliche Hemmung der ${ }^{3} \mathrm{H}-\mathrm{PAH}-A u f n a h m e$ durch den hOAT1, wie in Abb. 17 an einer Beispielmessung zu sehen ist. Die getesteten $\alpha$-Ketoglutarat-Konzentrationen lagen zwischen 0 und $20 \mu \mathrm{M}$. Die Zusammenfassung von vier Versuchen ergab eine $\mathrm{IC}_{50}$ für $\alpha$-Ketoglutarat von $4,7 \pm 1,2 \mu \mathrm{M}$.

\subsubsection{Citrat}

Als Nächstes wurde der Einfluss von Citrat in Konzentrationen von 0 bis $10 \mathrm{mM}$ auf die Aufnahme von ${ }^{3} \mathrm{H}-\mathrm{PAH}$ durch den hOAT1 untersucht. Wie Abb. 18 zeigt, hemmt Citrat erst in relativ hohen Konzentrationen. Der $\mathrm{IC}_{50}$-Wert, gemittelt aus fünf Versuchen, beträgt 5460 $\pm 491 \mu \mathrm{M}$.

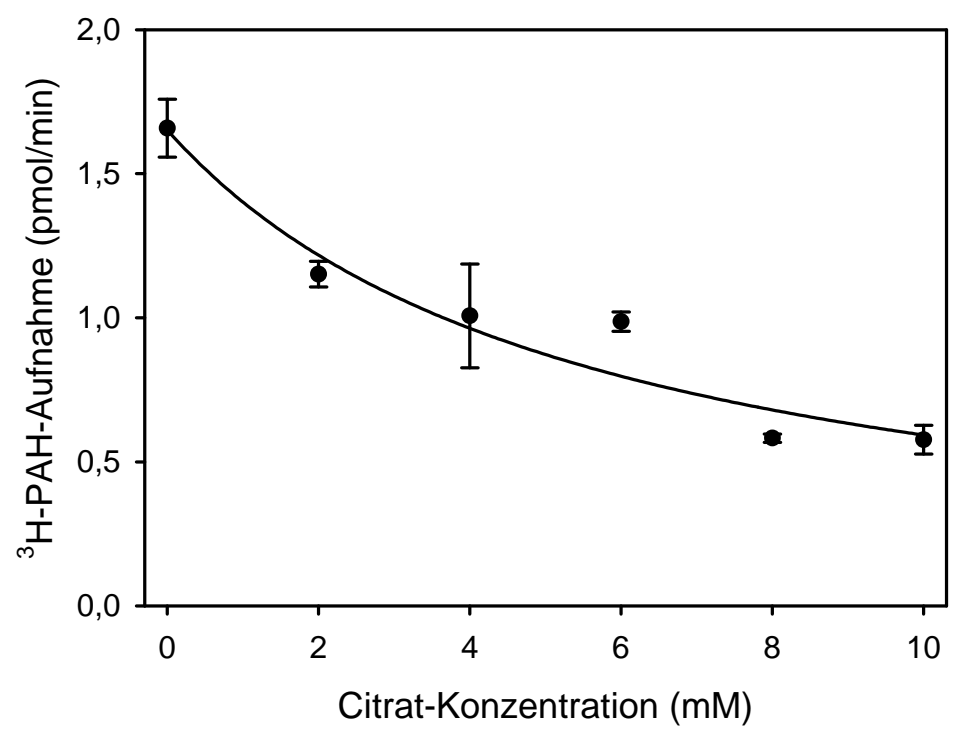

Abb. 18: Aufnahme von ${ }^{3} \mathrm{H}-\mathrm{PAH}$ in Anwesenheit von Citrat in hOAT1-transfizierte Zellen hOAT1- und Vektor-transfizierte HEK293-Zellen wurden für eine Minute bei Raumtemperatur in Ringerlösung mit $1,1 \mu \mathrm{M}{ }^{3} \mathrm{H}-\mathrm{PAH}$ und verschiedenen Citrat-Konzentrationen inkubiert. Die Abbildung zeigt die in hOAT1transfizierte Zellen aufgenommene ${ }^{3} \mathrm{H}-\mathrm{PAH}-M e n g e$ abzüglich der bei den Vektor-transfizierten Zellen gemessenen ${ }^{3}$ H-PAH-Menge. Dargestellt ist eine von fünf unabhängigen Messungen an fünf verschiedenen Zellkulturen. Die gezeigten Werte sind Mittelwerte \pm Standardabweichungen (SEM) von jeweils vier Einzelmessungen an einer Zellkultur. Die Kurve wurde durch Anpassung der Gleichung für Hemmkinetiken an die Messdaten berechnet.

\subsubsection{Adipat}

Die ${ }^{3} \mathrm{H}-\mathrm{PAH}-A u f n a h m e$ des hOAT1 in stabil-transfizierten HEK293-Zellen wurde in Anwesenheit von 0 bis $20 \mu \mathrm{M}$ Adipat getestet. Die aus fünf Versuchen gemittelte $\mathrm{IC}_{50}$ ist $6,2 \pm$ $1,0 \mu \mathrm{M}$. 


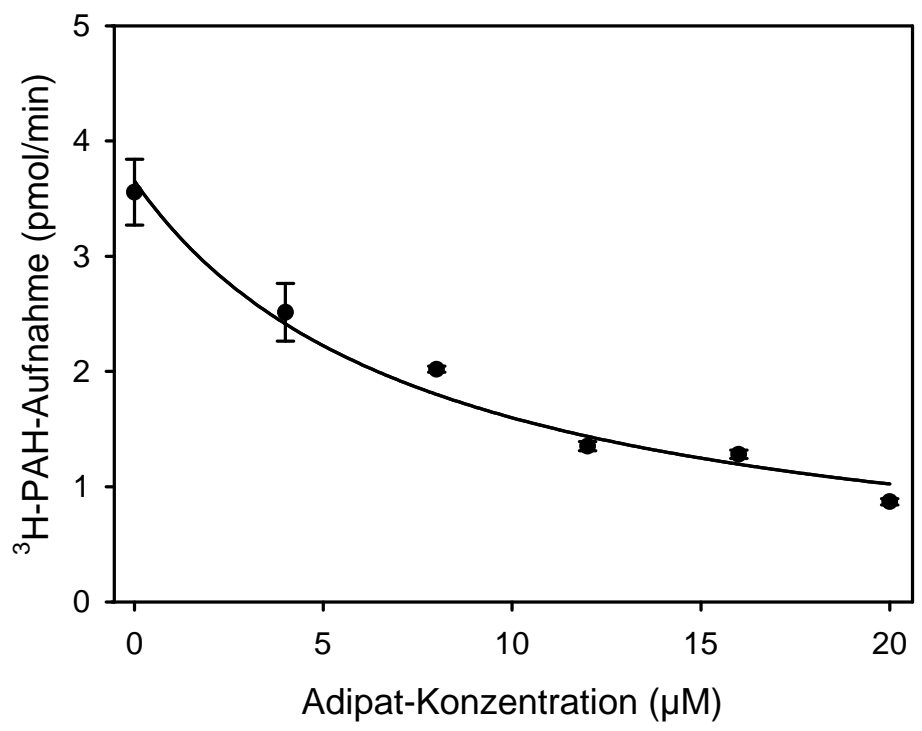

\section{Abb. 19: Aufnahme von ${ }^{3} \mathrm{H}-\mathrm{PAH}$ in Anwesenheit von Adipat in hOAT1-transfizierte Zellen}

hOAT1- und Vektor-transfizierte HEK293-Zellen wurden für eine Minute bei Raumtemperatur in Ringerlösung mit $1,1 \mu \mathrm{M}{ }^{3} \mathrm{H}-\mathrm{PAH}$ und verschiedenen Adipat-Konzentrationen inkubiert. Die Abbildung zeigt die in hOAT1transfizierte Zellen aufgenommene ${ }^{3} \mathrm{H}-\mathrm{PAH}-\mathrm{Menge}$ abzüglich der bei den Vektor-transfizierten Zellen gemessenen ${ }^{3} \mathrm{H}-\mathrm{PAH}-\mathrm{Menge}$. Dargestellt ist eine von fünf unabhängigen Messungen an fünf verschiedenen Zellkulturen. Die gezeigten Werte sind Mittelwerte \pm Standardabweichungen (SEM) von jeweils vier Einzelmessungen an einer Zellkultur. Die Kurve wurde durch Anpassung der Gleichung für Hemmkinetiken an die Messdaten berechnet.

\subsubsection{Pimelat}

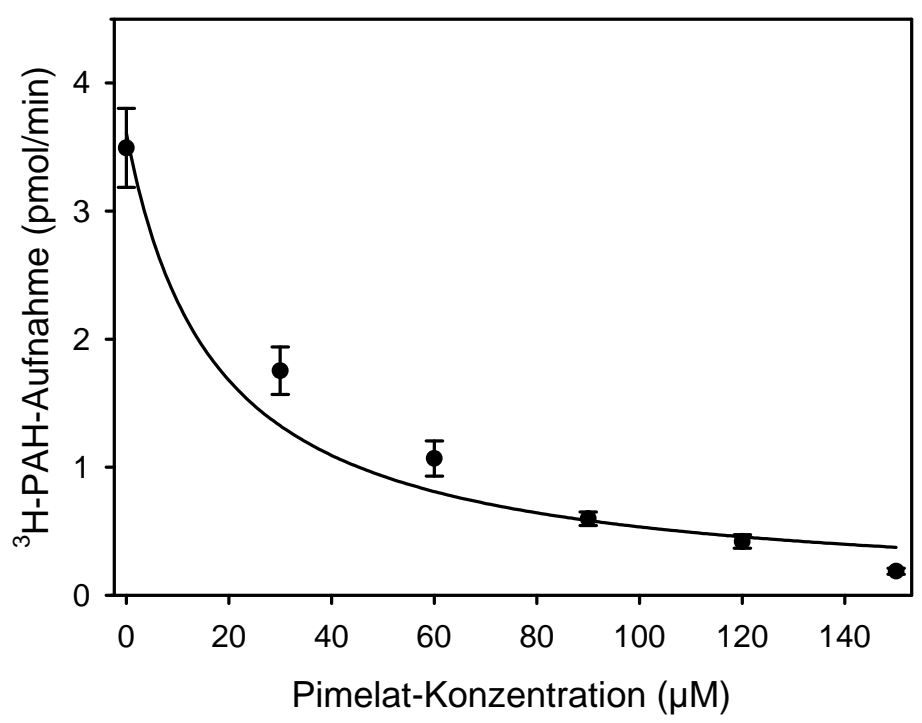

Abb. 20: Aufnahme von ${ }^{3}$ H-PAH in Anwesenheit von Pimelat in hOAT1-transfizierte Zellen

hOAT1 - und Vektor-transfizierte HEK293-Zellen wurden für eine Minute bei Raumtemperatur in Ringerlösung mit 1,1 $\mu \mathrm{M}{ }^{3} \mathrm{H}-\mathrm{PAH}$ und verschiedenen Pimelat-Konzentrationen inkubiert. Die Abbildung zeigt die in hOAT1transfizierte Zellen aufgenommene ${ }^{3} \mathrm{H}-\mathrm{PAH}-M e n g e$ abzüglich der bei den Vektor-transfizierten Zellen gemessenen ${ }^{3} \mathrm{H}-\mathrm{PAH}-\mathrm{Menge}$. Dargestellt ist eine von drei unabhängigen Messungen an drei verschiedenen Zellkulturen. Die gezeigten Werte sind Mittelwerte \pm Standardabweichungen (SEM) von jeweils vier Einzelmessungen an einer Zellkultur. Die Kurve wurde durch Anpassung der Gleichung für Hemmkinetiken an die Messdaten berechnet. 
Die Bestimmung des $\mathrm{IC}_{50}$ von Pimelat für die PAH-Aufnahme in hOAT1-transfizierte Zellen ergab einen Wert von 18,6 $\pm 2,6 \mu \mathrm{M}(\mathrm{n}=3)$.

\subsubsection{Suberat}

Zur Bestimmung des $\mathrm{IC}_{50}$-Wertes von Suberat wurde die ${ }^{3} \mathrm{H}-\mathrm{PAH}-\mathrm{Aufnahme}$ durch den hOAT1 in die HEK-293 Zellen in Anwesenheit von Suberat-Konzentrationen zwischen 0 und $100 \mu \mathrm{M}$ gemessen. Abb. 21 zeigt das Ergebnis eines Versuchs. Die $\mathrm{IC}_{50}$ gemittelt aus drei Versuchen beträgt 19,3 $\pm 2,2 \mu \mathrm{M}$.

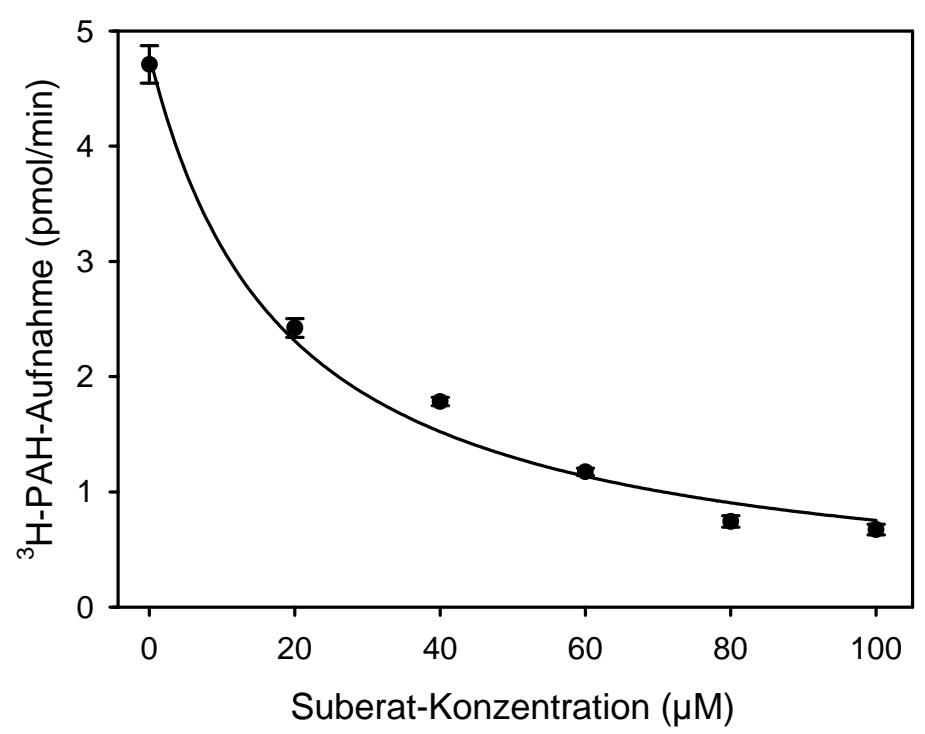

Abb. 21: Aufnahme von ${ }^{3}$ H-PAH in Anwesenheit von Suberat in hOAT1-transfizierte Zellen

hOAT1- und Vektor-transfizierte HEK293-Zellen wurden für eine Minute bei Raumtemperatur in Ringerlösung mit $1,1 \mu \mathrm{M}{ }^{3} \mathrm{H}-\mathrm{PAH}$ und verschiedenen Suberat-Konzentrationen inkubiert. Die Abbildung zeigt die in hOAT1transfizierte Zellen aufgenommene ${ }^{3} \mathrm{H}-\mathrm{PAH}-M e n g e$ abzüglich der bei den Vektor-transfizierten Zellen gemessenen ${ }^{3}$ H-PAH-Menge. Dargestellt ist eine von drei unabhängigen Messungen an drei verschiedenen Zellkulturen. Die gezeigten Werte sind Mittelwerte \pm Standardabweichungen (SEM) von jeweils vier Einzelmessungen an einer Zellkultur. Die Kurve wurde durch Anpassung der Gleichung für Hemmkinetiken an die Messdaten berechnet.

\subsection{Bestimmung der $K_{i}-$ Werte von zwei Dicarboxylaten für den PAH- Transport durch hOAT1}

Als Nächstes wurden mit Hilfe von Dixon-Plots die $\mathrm{K}_{\mathrm{i}}$-Werte von zwei Dicarboxylaten mittlerer Kettenlänge gemessen. Die Hemmkonstante $K_{i}$ ist ein Maß für die Affinität des Hemmstoffs zum Transporter. $\mathrm{Zu}$ der Bestimmung sind mindestens zwei verschiedene Substratkonzentrationen nötig. Die hier verwendeten PAH-Konzentrationen waren $1,1 \mu \mathrm{M}$ und $0,5 \mu \mathrm{M}{ }^{3} \mathrm{H}-\mathrm{PAH}$. Trägt man die mit den verschiedenen Substratkonzentrationen 
gemessenen Aufnahmeraten reziprok auf der y-Achse gegen die Hemmstoffkonzentrationen auf, so ergibt der Schnittpunkt der beiden Geraden den $\mathrm{K}_{\mathrm{i}}$-Wert (DIXON 1953).

\subsection{1. $\mathrm{K}_{\mathrm{i}}$-Wert von Glutarat für den PAH-Transport durch hOAT1}

Es wurden drei Versuche zur Bestimmung des $\mathrm{K}_{\mathrm{i}}$-Wertes von Glutarat durchgeführt. Eine Beispielbestimmung zeigt die Abb. 22. Im abgebildeten Dixon-Plot ist die reziproke ${ }^{3} \mathrm{H}-\mathrm{PAH}-$ Aufnahme gegen die getestete Glutarat-Konzentration von 0 bis $10 \mu \mathrm{M}$ aufgetragen. Der Schnittpunkt der Geraden liegt hier im zweiten Quadranten bei 2,4 $\mu \mathrm{M}$. Die gemittelte $\mathrm{K}_{\mathrm{i}}$ aus drei solcher Versuche beträgt $1,1 \pm 0,7 \mu \mathrm{M}$.

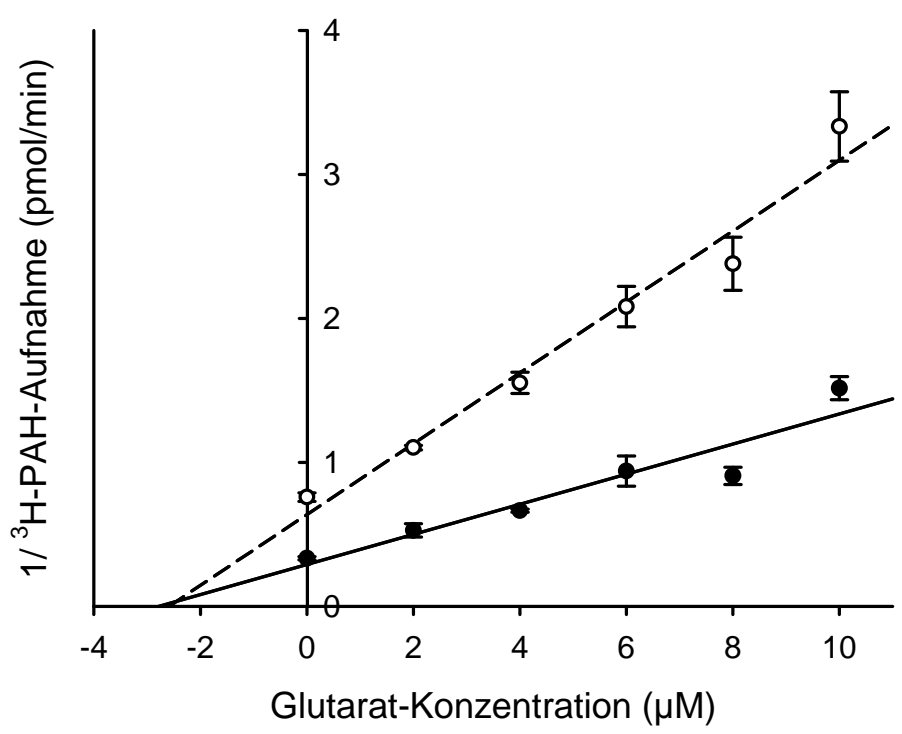

Abb. 22: Dixon-Plot zur Bestimmung der $\mathbf{K}_{\mathrm{i}}$ für Glutarat

Die ${ }^{3} \mathrm{H}-\mathrm{PAH}-\mathrm{Aufnahme}$ wurde bei zwei verschiedenen ${ }^{3} \mathrm{H}-\mathrm{PAH}-K o n z e n t r a t i o n e n, 0,5 \mu \mathrm{M}$ (gestrichelte Linie) und 1,1 $\mu \mathrm{M}$ (durchgezogene Linie), gemessen. Dazu wurden Zellen für 1 min bei Raumtemperatur in Ringerlösungen inkubiert, die zusätzlich Glutarat in Konzentrationen von 0 bis $10 \mu \mathrm{M}$ enthielten. Aufgetragen wurde der reziproke Wert der ${ }^{3} \mathrm{H}-\mathrm{PAH}$-Aufnahme gegen die Hemmstoffkonzentrationen. Dargestellt sind Mittelwerte \pm Standardabweichungen (SEM) von vier Einzelmessungen eines Beispielversuchs an einer Zellkultur abzüglich der Werte, die unter den gleichen Bedingungen an Vektor-transfizierten Zellen gemessen wurden.

\subsection{2. $\quad \mathrm{K}_{\mathrm{i}}$-Wert von $\alpha$-Ketoglutarat für den PAH-Transport durch hOAT1}

Abb. 23 zeigt eine Beispielmessung zur Bestimmung des $\mathrm{K}_{\mathrm{i}}$-Wertes von $\alpha$-Ketoglutarat. Die PAH-Aufnahme wurde in Anwesenheit von 0 bis $20 \mu \mathrm{M} \alpha$-Ketoglutarat gemessen. Der mittlere $\mathrm{K}_{\mathrm{i}}$ - Wert aus drei solcher Versuche beträgt 1,2 $\pm 0,4 \mu \mathrm{M}$. 


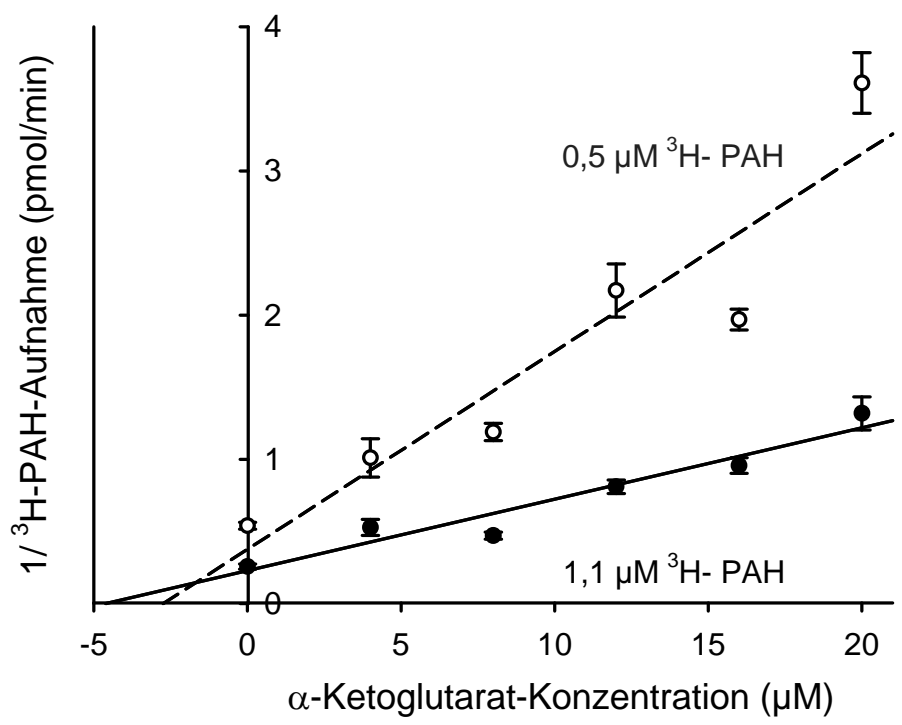

Abb. 23: Dixon-Plot zur Bestimmung der $K_{\mathrm{i}}$ für $\alpha$-Ketoglutarat

Die ${ }^{3} \mathrm{H}-\mathrm{PAH}-A u f n a h m e$ wurde bei zwei verschiedenen ${ }^{3} \mathrm{H}-\mathrm{PAH}-K o n z e n t r a t i o n e n, 0,5 \mu \mathrm{M}$ (gestrichelte Linie) und $1,1 \mu \mathrm{M}$ (durchgezogene Linie), gemessen. Dazu wurden Zellen für 1 min bei Raumtemperatur in Ringerlösungen inkubiert, die zusätzlich $\alpha$-Ketoglutarat in Konzentrationen von 0 bis $10 \mu \mathrm{M}$ enthielten. Aufgetragen wurde der reziproke Wert der ${ }^{3} \mathrm{H}-\mathrm{PAH}-\mathrm{Aufnahme}$ gegen die Hemmstoffkonzentrationen. Dargestellt sind Mittelwerte \pm Standardabweichungen (SEM) von vier Einzelmessungen eines Beispielversuchs an einer Zellkultur abzüglich der Werte, die unter den gleichen Bedingungen an Vektor-transfizierten Zellen gemessen wurden.

\subsection{Bestimmung der $\mathrm{IC}_{50^{-}}$-Werte der Dicarboxylate für den Östronsulfat-Transport durch hOAT3}

Als Nächstes wurden die $\mathrm{IC}_{50}$-Werte der Dicarboxylate für den Östronsulfat-Transport in hOAT3 stabil transfizierte HEK293-Zellen bestimmt.

\subsubsection{Malonat}

Der Einfluss von Malonat auf den hOAT3 wurde mit Konzentrationen zwischen $0 \mathrm{mM}$ und 50 $\mathrm{mM}$ getestet. Abb. 24 zeigt eine Beispielmessung, an der zu sehen ist, dass Malonat nicht mit hOAT3 interagiert. 


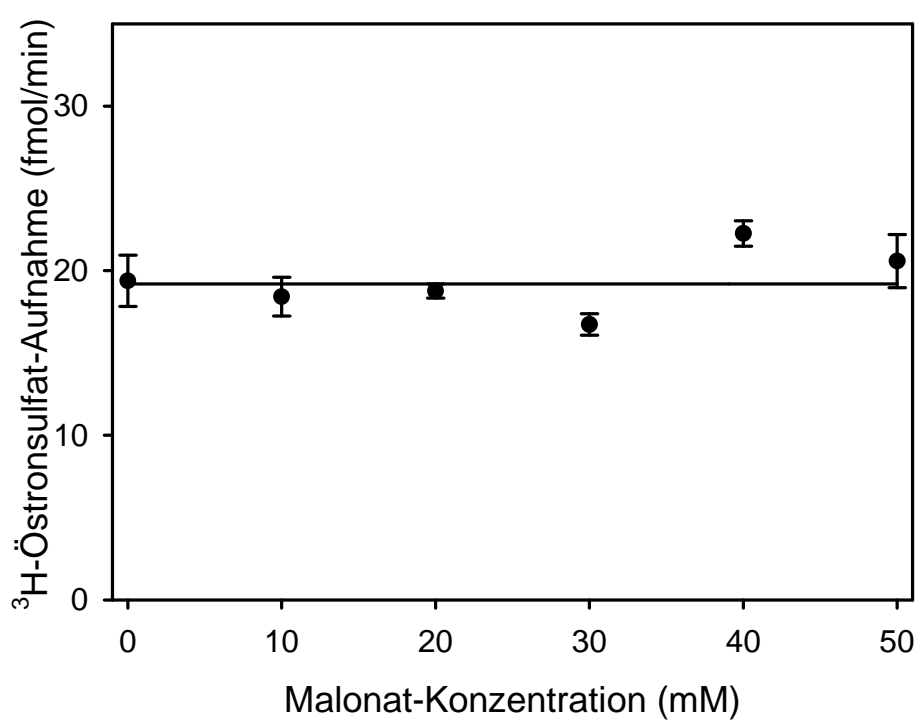

Abb. 24: Aufnahme von ${ }^{3} \mathrm{H}$-Östronsulfat in Anwesenheit von Malonat in hOAT3-transfizierte Zellen hOAT3- und Vektor-transfizierte HEK293-Zellen wurden für eine Minute bei Raumtemperatur in Ringerlösung mit $10 \mathrm{nM}{ }^{3} \mathrm{H}$-Östronsulfat und verschiedenen Malonat-Konzentrationen inkubiert. Die Abbildung zeigt die in hOAT3-transfizierte Zellen aufgenommene ${ }^{3} \mathrm{H}$-Östronsulfat-Menge abzüglich der bei den Vektor-transfizierten Zellen gemessenen ${ }^{3} \mathrm{H}$-Östronsulfat-Menge. Dargestellt ist eine von drei unabhängigen Messungen an drei verschiedenen Zellkulturen. Die gezeigten Werte sind Mittelwerte \pm Standardabweichungen (SEM) von jeweils vier Einzelmessungen an einer Zellkultur. Die Kurve wurde durch Anpassung der Gleichung für Hemmkinetiken an die Messdaten berechnet.

\subsubsection{Maleat}

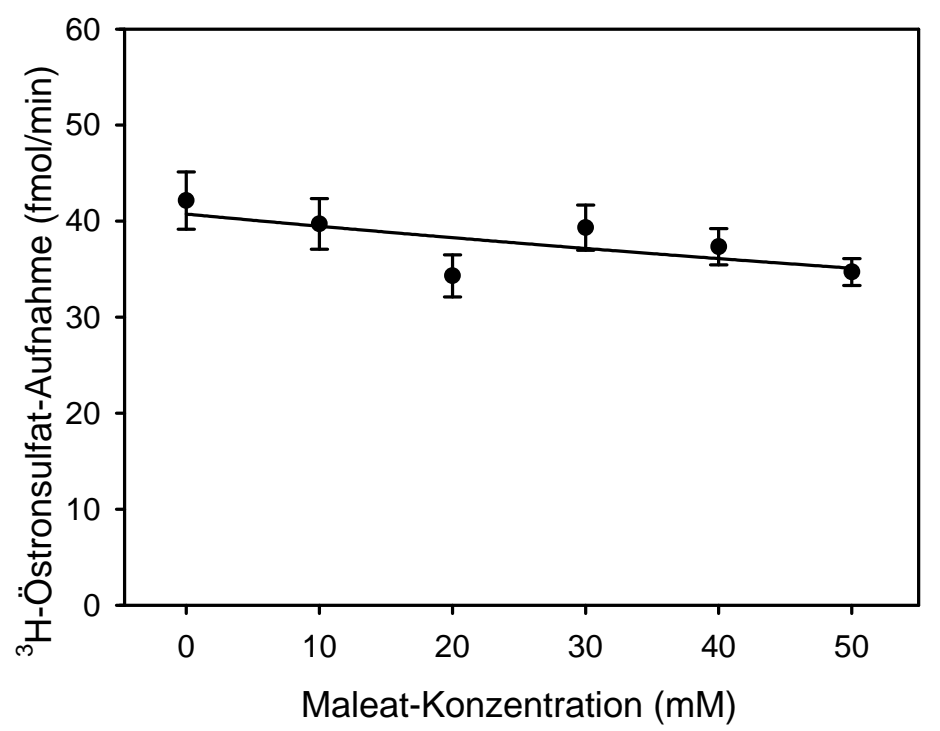

Abb. 25: Aufnahme von ${ }^{3} \mathrm{H}$-Östronsulfat in Anwesenheit von Maleat in hOAT3-transfizierte Zellen hOAT3- und Vektor-transfizierte HEK293-Zellen wurden für eine Minute bei Raumtemperatur in Ringerlösung mit $10 \mathrm{nM}{ }^{3} \mathrm{H}$-Östronsulfat und verschiedenen Maleat-Konzentrationen inkubiert. Die Abbildung zeigt die in hOAT3-transfizierte Zellen aufgenommene ${ }^{3} \mathrm{H}$-Östronsulfat-Menge abzüglich der bei den Vektor-transfizierten Zellen gemessenen ${ }^{3} \mathrm{H}$-Östronsulfat-Menge. Dargestellt ist eine von drei unabhängigen Messungen an drei verschiedenen Zellkulturen. Die gezeigten Werte sind Mittelwerte \pm Standardabweichungen (SEM) von jeweils vier Einzelmessungen an einer Zellkultur. Die Kurve wurde durch Anpassung der Gleichung für Hemmkinetiken ohne nicht hemmbaren Anteil an die Messdaten berechnet. 
Die Bestimmung des $\mathrm{IC}_{50}$ von Maleat für den Östronsulfat-Transport durch hOAT3 ergab in drei unabhängigen Messungen einen Wert von 141,1 $\pm 86,3 \mathrm{mM}$, wenn die Gleichung für Hemmkinetiken ohne nicht hemmbaren Anteil den Messdaten angepasst wird: $\mathrm{v}=\frac{\mathrm{v}_{\max } \cdot \mathrm{IC}_{50}}{\mathrm{IC}_{50}+[\mathrm{I}]}$. Abb. 25 zeigt eine Beispielmessung.

Geht man davon aus, dass Maleat nur eine partielle Hemmung hervorruft, und passt die Gleichung für Hemmkinetiken mit nicht hemmbaren Anteil $\mathrm{v}=\frac{\mathrm{v}_{\max } \cdot \mathrm{IC}_{50}}{\mathrm{IC}_{50}+[\mathrm{I}]}+\mathrm{v}_{\min }$ den gemessenen Werten an, erhält man die Kurve in Abb. 26 und bei drei Messungen eine $\mathrm{IC}_{50}$ von $10,0 \pm 3,2 \mathrm{mM}$ bei einem nicht hemmbaren Anteil der Aufnahme von $70 \pm 7 \%$.

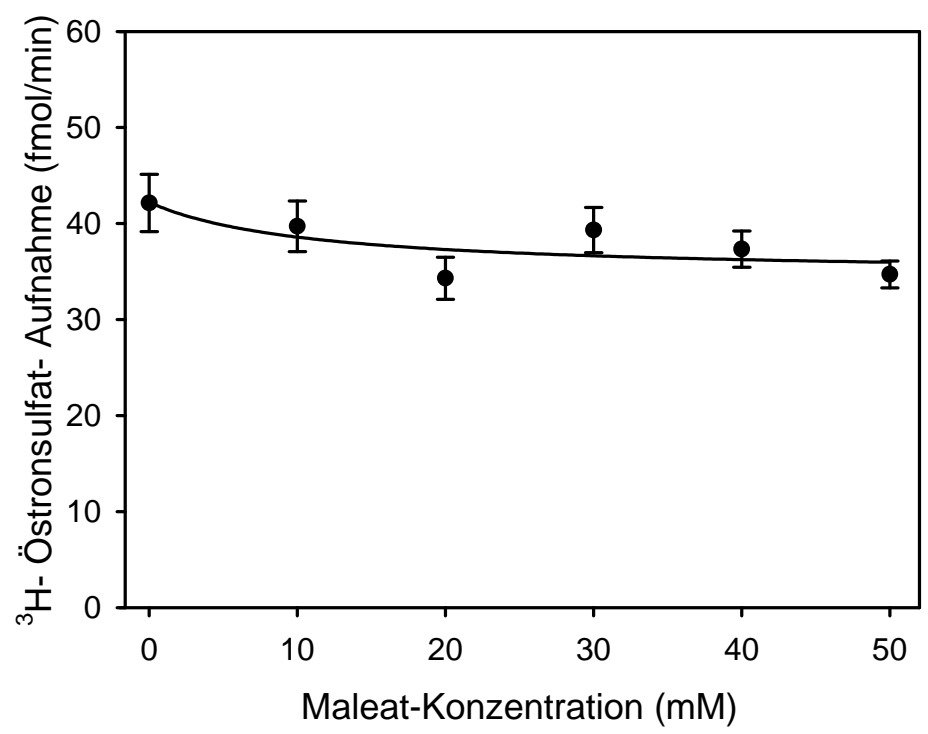

Abb. 26: Aufnahme von ${ }^{3}$ H-Östronsulfat in Anwesenheit von Maleat in hOAT3-transfizierte Zellen

Der Graph zeigt denselben Versuch wie Abb. 25. Die Kurve wurde hier durch Anpassung der Gleichung für Hemmkinetiken mit einem nicht hemmbaren Anteil an die Messdaten berechnet. hOAT3- und Vektortransfizierte HEK293-Zellen wurden für eine Minute bei Raumtemperatur in Ringerlösung mit $10 \mathrm{nM}{ }^{3} \mathrm{H}-$ Östronsulfat und verschiedenen Maleat-Konzentrationen inkubiert. Die Abbildung zeigt die in hOAT3transfizierte Zellen aufgenommene ${ }^{3} \mathrm{H}$-Östronsulfat-Menge abzüglich der bei den Vektor-transfizierten Zellen gemessenen ${ }^{3} \mathrm{H}$-Östronsulfat-Menge. Dargestellt ist eine von drei unabhängigen Messungen an drei verschiedenen Zellkulturen. Die gezeigten Werte sind Mittelwerte \pm Standardabweichungen (SEM) von jeweils vier Einzelmessungen an einer Zellkultur.

\subsubsection{Fumarat}

Fumarat bewirkte eine deutliche Hemmung der ${ }^{3} \mathrm{H}$-Östronsulfat-Aufnahme durch den hOAT3, wie in Abb. 27 zu sehen ist. Im Durchschnitt lag der $\mathrm{IC}_{50}$-Wert nach drei Versuchen bei $21,1 \pm 2,8 \mathrm{mM}$. 


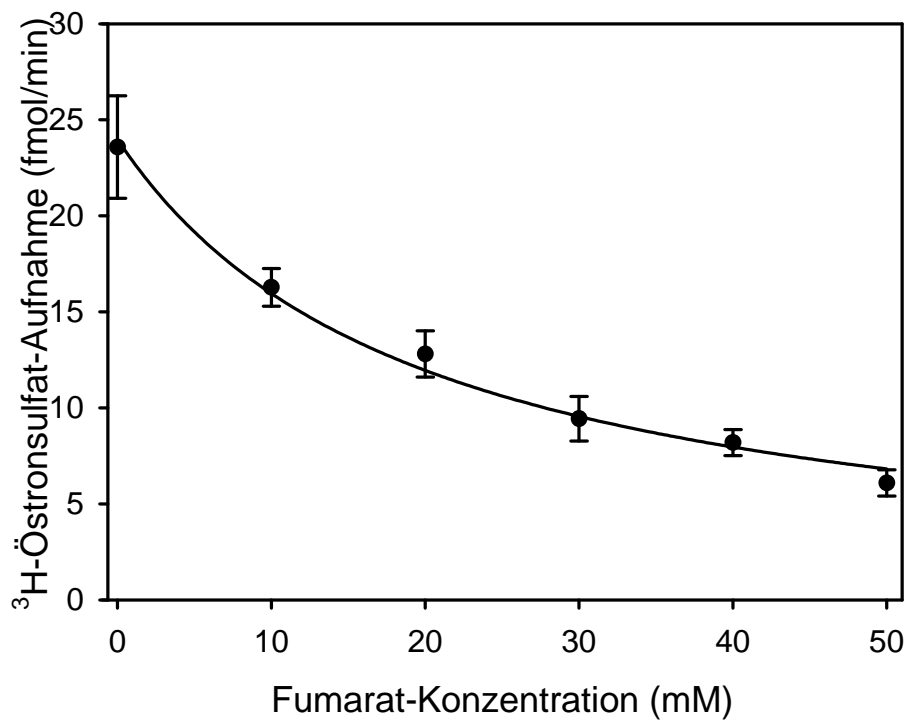

\section{Abb. 27: Aufnahme von ${ }^{3} \mathrm{H}$-Östronsulfat in Anwesenheit von Fumarat in hOAT3-transfizierte Zellen}

hOAT3- und Vektor-transfizierte HEK293-Zellen wurden für eine Minute bei Raumtemperatur in Ringerlösung mit $10 \mathrm{nM}{ }^{3} \mathrm{H}$-Östronsulfat und verschiedenen Fumarat-Konzentrationen inkubiert. Die Abbildung zeigt die in hOAT3-transfizierte Zellen aufgenommene ${ }^{3} \mathrm{H}$-Östronsulfat-Menge abzüglich der bei den Vektor-transfizierten Zellen gemessenen ${ }^{3} \mathrm{H}$-Östronsulfat-Menge. Dargestellt ist eine von drei unabhängigen Messungen an drei verschiedenen Zellkulturen. Die gezeigten Werte sind Mittelwerte \pm Standardabweichungen (SEM) von jeweils vier Einzelmessungen an einer Zellkultur. Die Kurve wurde durch Anpassung der Gleichung für Hemmkinetiken an die Messdaten berechnet.

\subsubsection{Succinat}

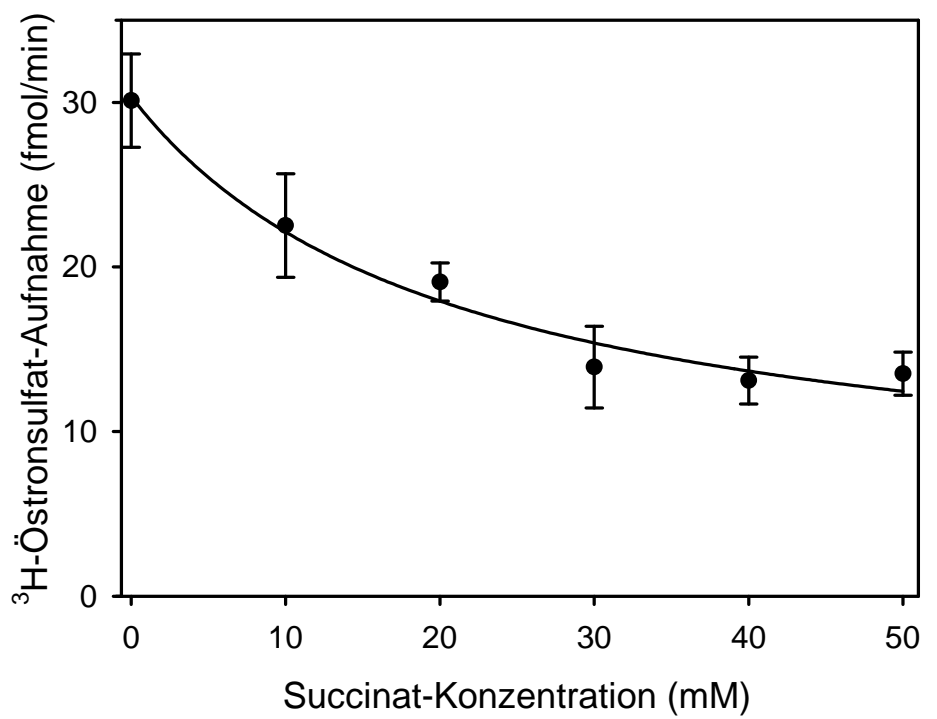

Abb. 28: Aufnahme von ${ }^{3}$ H-Östronsulfat in Anwesenheit von Succinat in hOAT3-transfizierte Zellen hOAT3- und Vektor-transfizierte HEK293-Zellen wurden für eine Minute bei Raumtemperatur in Ringerlösung mit $10 \mathrm{nM}{ }^{3} \mathrm{H}$-Östronsulfat und verschiedenen Succinat-Konzentrationen inkubiert. Die Abbildung zeigt die in hOAT3-transfizierte Zellen aufgenommene ${ }^{3} \mathrm{H}$-Östronsulfat-Menge abzüglich der bei den Vektor-transfizierten Zellen gemessenen ${ }^{3} \mathrm{H}$-Östronsulfat-Menge. Dargestellt ist eine von drei unabhängigen Messungen an drei verschiedenen Zellkulturen. Die gezeigten Werte sind Mittelwerte \pm Standardabweichungen (SEM) von jeweils vier Einzelmessungen an einer Zellkultur. Die Kurve wurde durch Anpassung der Gleichung für Hemmkinetiken an die Messdaten berechnet. 
Als Nächstes wurde der Einfluss von Succinat getestet. Gemessen wurde die Aufnahme von ${ }^{3} \mathrm{H}$-Östronsulfat durch den hOAT3 in Anwesenheit von 0 bis $50 \mathrm{mM}$ Succinat. Der aus drei Versuchen gemittelte $\mathrm{IC}_{50}$-Wert beträgt $55,7 \pm 16,5 \mathrm{mM}$.

\subsubsection{Glutarat}

Der Einfluss des Dicarboxylats Glutarat auf den ${ }^{3} \mathrm{H}$-Östronsulfat-Transport des hOAT3 wird in der Abb. 29 an einem Beispiel gezeigt. Drei weitere Versuche führten $\mathrm{zu}$ ähnlichen Ergebnissen. Zusammen wurde ein Mittelwert der $\mathrm{IC}_{50}$ von $79 \pm 5 \mu \mathrm{M}$ ermittelt.

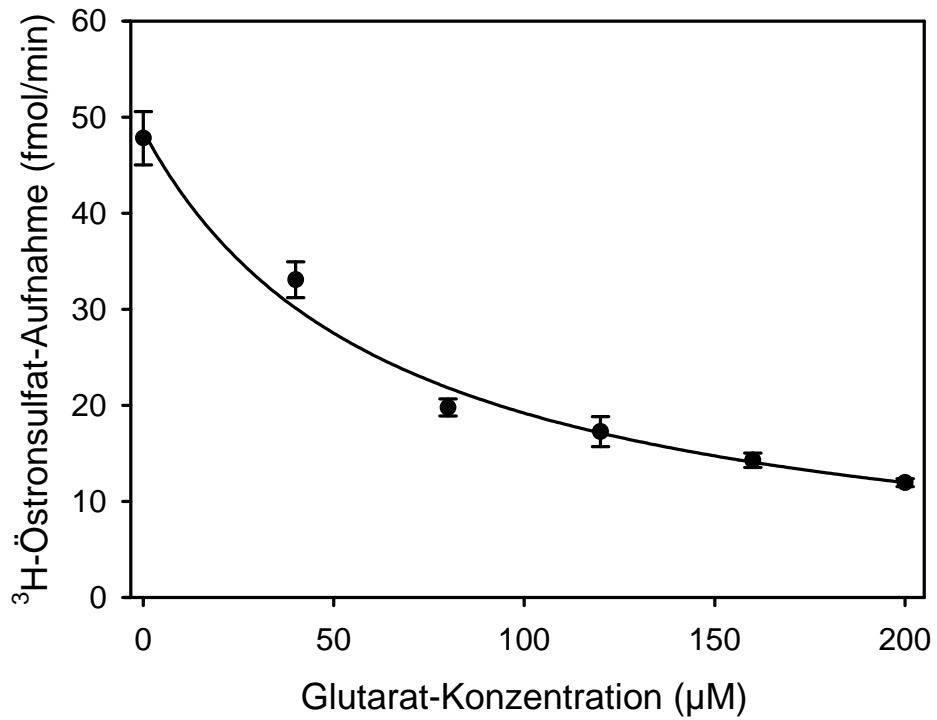

Abb. 29: Aufnahme von ${ }^{3} \mathrm{H}$-Östronsulfat in Anwesenheit von Glutarat in hOAT3-transfizierte Zellen hOAT3- und Vektor-transfizierte HEK293-Zellen wurden für eine Minute bei Raumtemperatur in Ringerlösung mit $10 \mathrm{nM}{ }^{3} \mathrm{H}$-Östronsulfat und verschiedenen Glutarat-Konzentrationen inkubiert. Die Abbildung zeigt die in hOAT3-transfizierte Zellen aufgenommene ${ }^{3} \mathrm{H}$-Östronsulfat-Menge abzüglich der bei den Vektor-transfizierten Zellen gemessenen ${ }^{3} \mathrm{H}$-Östronsulfat-Menge. Dargestellt ist eine von vier unabhängigen Messungen an vier verschiedenen Zellkulturen. Die gezeigten Werte sind Mittelwerte \pm Standardabweichungen (SEM) von jeweils vier Einzelmessungen an einer Zellkultur. Die Kurve wurde durch Anpassung der Gleichung für Hemmkinetiken an die Messdaten berechnet.

\subsection{6. $\alpha$-Ketoglutarat}

Der $\mathrm{IC}_{50}$ von $\alpha$-Ketoglutarat wurde in vier Messungen mit $92 \pm 34 \mu \mathrm{M}$ bestimmt. 


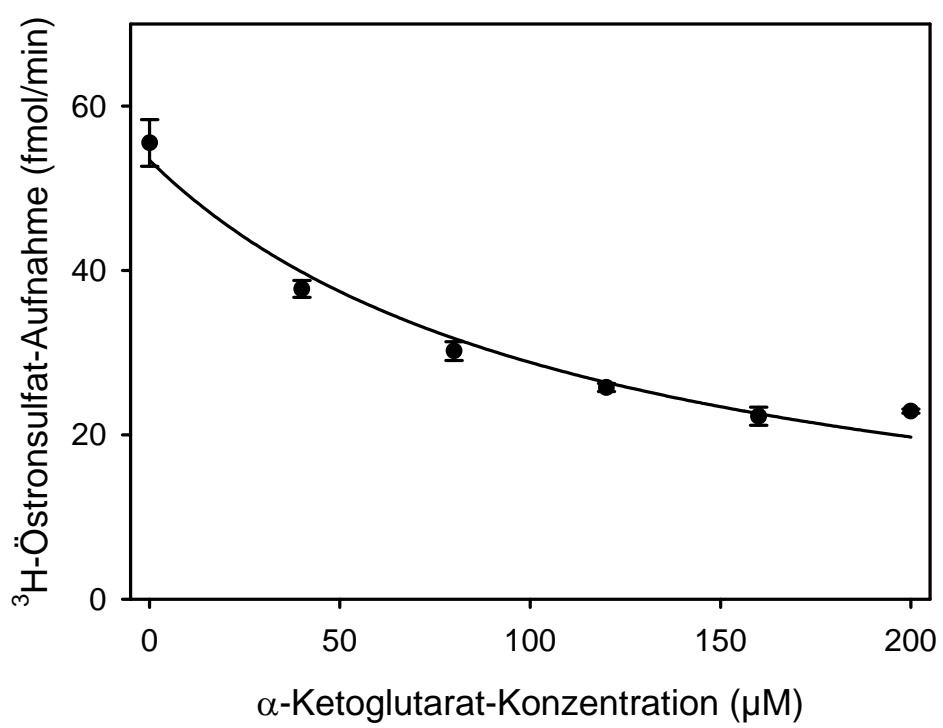

Abb. 30: Aufnahme von ${ }^{3} \mathrm{H}$-Östronsulfat in Anwesenheit von $\alpha$-Ketoglutarat in hOAT3-transfizierte Zellen

hOAT3- und Vektor-transfizierte HEK293-Zellen wurden für eine Minute bei Raumtemperatur in Ringerlösung mit $10 \mathrm{nM}{ }^{3} \mathrm{H}$-Östronsulfat und verschiedenen $\alpha$-Ketoglutarat-Konzentrationen inkubiert. Die Abbildung zeigt die in hOAT3-transfizierte Zellen aufgenommene ${ }^{3} \mathrm{H}$-Östronsulfat-Menge abzüglich der bei den Vektortransfizierten Zellen gemessenen ${ }^{3} \mathrm{H}$-Östronsulfat-Menge. Dargestellt ist eine von vier unabhängigen Messungen an vier verschiedenen Zellkulturen. Die gezeigten Werte sind Mittelwerte \pm Standardabweichungen (SEM) von jeweils vier Einzelmessungen an einer Zellkultur. Die Kurve wurde durch Anpassung der Gleichung für Hemmkinetiken an die Messdaten berechnet.

\subsubsection{Citrat}

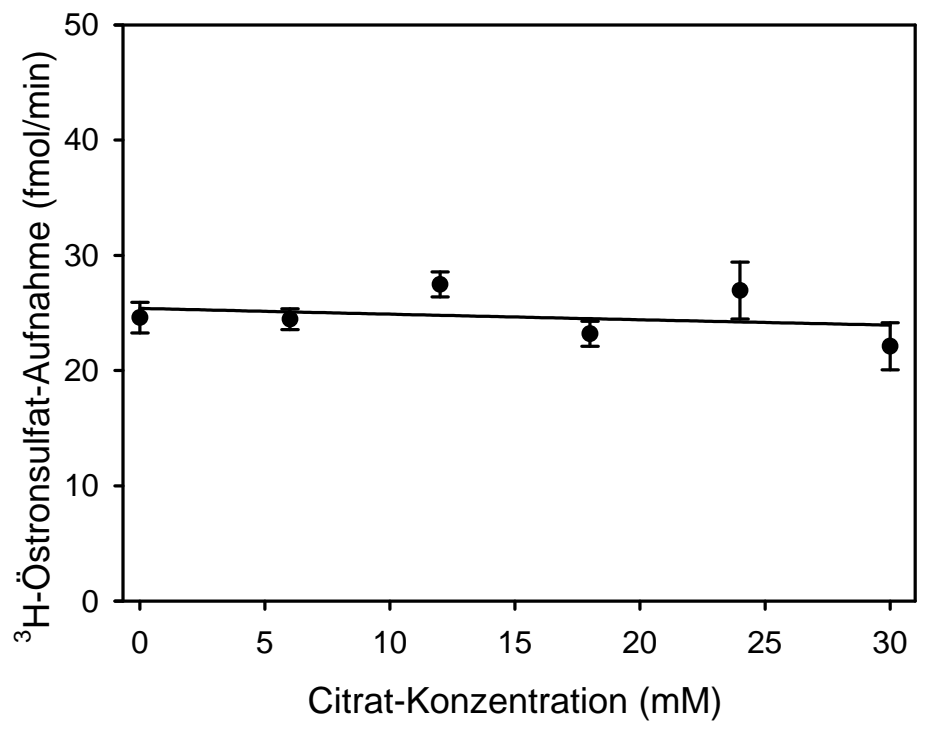

\section{Abb. 31: Aufnahme von ${ }^{3} \mathrm{H}$-Östronsulfat in Anwesenheit von Citrat in hOAT3-transfizierte Zellen}

hOAT3- und Vektor-transfizierte HEK293-Zellen wurden für eine Minute bei Raumtemperatur in Ringerlösung mit $10 \mathrm{nM}{ }^{3} \mathrm{H}$-Östronsulfat und verschiedenen Citrat-Konzentrationen inkubiert. Die Abbildung zeigt die in hOAT3-transfizierte Zellen aufgenommene ${ }^{3} \mathrm{H}$-Östronsulfat-Menge abzüglich der bei den Vektor-transfizierten Zellen gemessenen ${ }^{3} \mathrm{H}$-Östronsulfat-Menge. Dargestellt ist eine von drei unabhängigen Messungen an drei verschiedenen Zellkulturen. Die gezeigten Werte sind Mittelwerte \pm Standardabweichungen (SEM) von jeweils vier Einzelmessungen an einer Zellkultur. Die Kurve wurde durch Anpassung der Gleichung für Hemmkinetiken an die Messdaten berechnet. 
Citrat zeigte in Konzentrationen von $0 \mathrm{mM}$ bis $30 \mathrm{mM}$ keine Hemmung der ÖstronsulfatAufnahme in hOAT3-transfizierte Zellen (Abb. 31).

\subsubsection{Adipat}

Dagegen hemmt Adipat den Östronsulfat-Transport durch hOAT3 deutlich. In drei unabhängigen Messungen wurde eine $\mathrm{IC}_{50}$ von $136 \pm 57 \mu \mathrm{M}$ bestimmt.

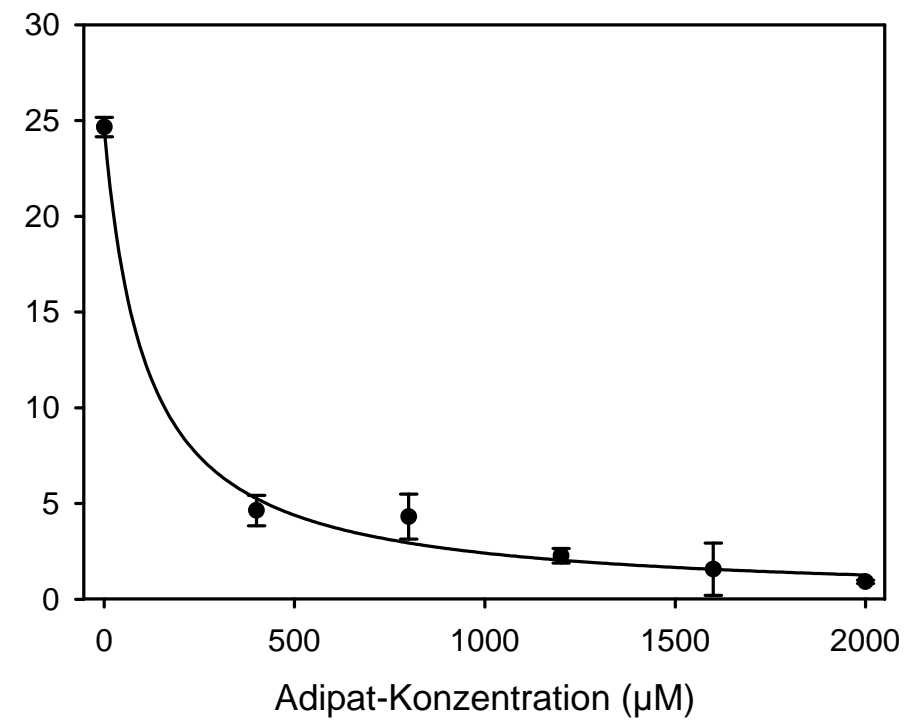

Abb. 32: Aufnahme von ${ }^{3} \mathrm{H}$-Östronsulfat in Anwesenheit von Adipat in hOAT3-transfizierte Zellen hOAT3- und Vektor-transfizierte HEK293-Zellen wurden für eine Minute bei Raumtemperatur in Ringerlösung mit $10 \mathrm{nM}{ }^{3} \mathrm{H}$-Östronsulfat und verschiedenen Adipat-Konzentrationen inkubiert. Die Abbildung zeigt die in hOAT3-transfizierte Zellen aufgenommene ${ }^{3} \mathrm{H}$-Östronsulfat-Menge abzüglich der bei den Vektor-transfizierten Zellen gemessenen ${ }^{3} \mathrm{H}$-Östronsulfat-Menge. Dargestellt ist eine von drei unabhängigen Messungen an drei verschiedenen Zellkulturen. Die gezeigten Werte sind Mittelwerte \pm Standardabweichungen (SEM) von jeweils vier Einzelmessungen an einer Zellkultur. Die Kurve wurde durch Anpassung der Gleichung für Hemmkinetiken an die Messdaten berechnet.

\subsubsection{Pimelat}

Den Einfluss des Dicarboxylats Pimelat auf den ${ }^{3} \mathrm{H}$-Östronsulfat-Transport durch hOAT3 zeigt die Abb. 33 an einem Beispiel. Aus vier Messungen mit $0 \mathrm{mM}$ bis $5 \mathrm{mM}$ Pimelat wurde ein $\mathrm{IC}_{50}$-Wert von $634 \pm 225 \mu \mathrm{M}$ berechnet. 


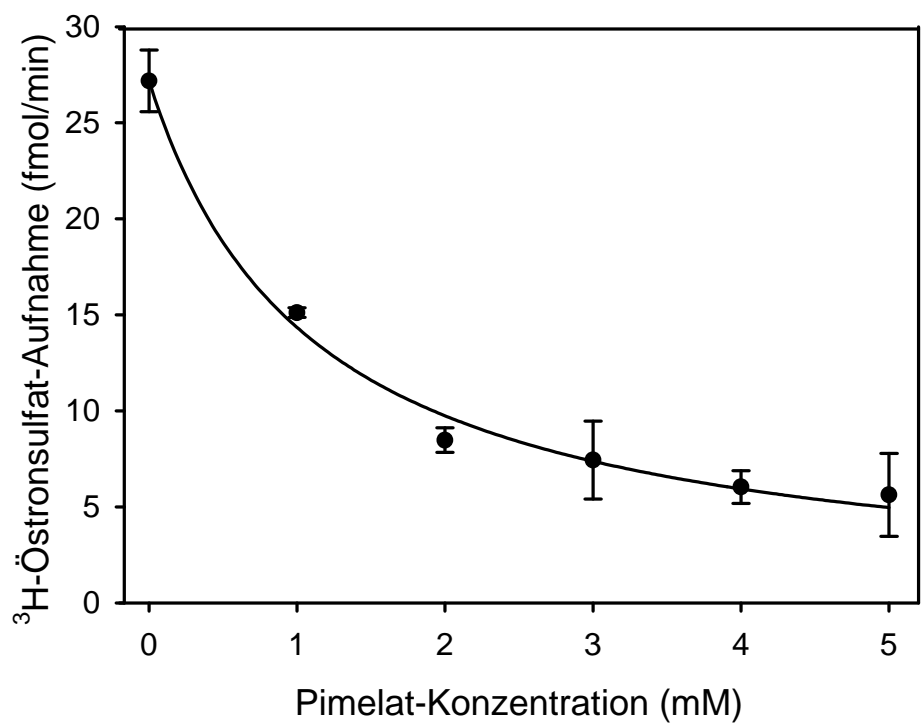

Abb. 33: Aufnahme von ${ }^{3} \mathrm{H}$-Östronsulfat in Anwesenheit von Pimelat in hOAT3-transfizierte Zellen hOAT3- und Vektor-transfizierte HEK293-Zellen wurden für eine Minute bei Raumtemperatur in Ringerlösung mit $10 \mathrm{nM}{ }^{3} \mathrm{H}$-Östronsulfat und verschiedenen Pimelat-Konzentrationen inkubiert. Die Abbildung zeigt die in hOAT3-transfizierte Zellen aufgenommene ${ }^{3} \mathrm{H}$-Östronsulfat-Menge abzüglich der bei den Vektor-transfizierten Zellen gemessenen ${ }^{3} \mathrm{H}$-Östronsulfat-Menge. Dargestellt ist eine von vier unabhängigen Messungen an vier verschiedenen Zellkulturen. Die gezeigten Werte sind Mittelwerte \pm Standardabweichungen (SEM) von jeweils vier Einzelmessungen an einer Zellkultur. Die Kurve wurde durch Anpassung der Gleichung für Hemmkinetiken an die Messdaten berechnet.

\subsubsection{Suberat}

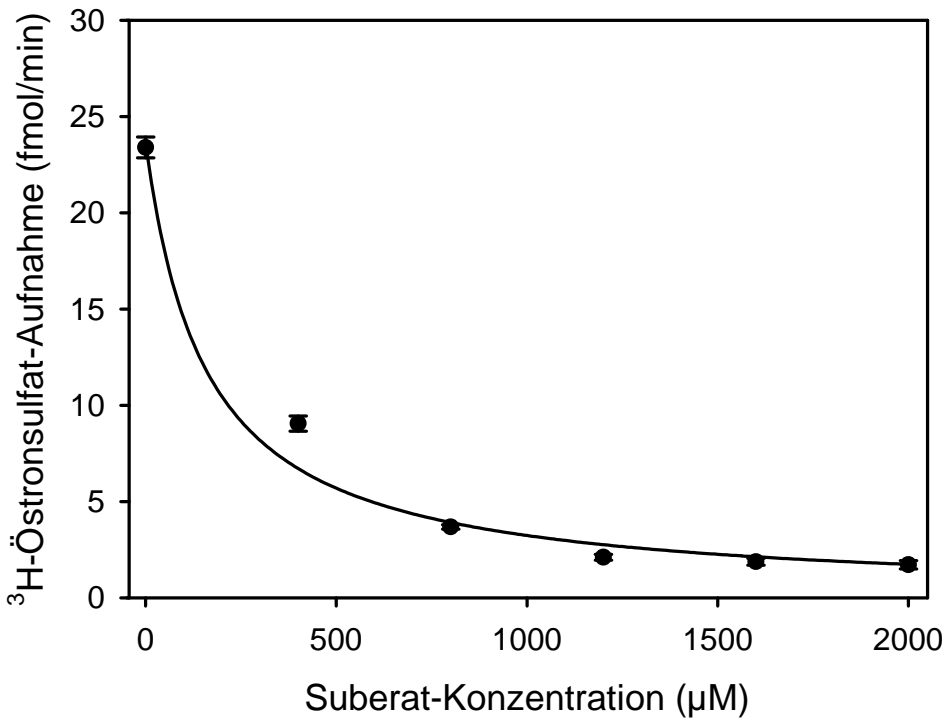

Abb. 34: Aufnahme von ${ }^{3}$ H-Östronsulfat in Anwesenheit von Suberat in hOAT3-transfizierte Zellen hOAT3- und Vektor-transfizierte HEK293-Zellen wurden für eine Minute bei Raumtemperatur in Ringerlösung mit $10 \mathrm{nM}{ }^{3} \mathrm{H}$-Östronsulfat und verschiedenen Suberat-Konzentrationen inkubiert. Die Abbildung zeigt die in hOAT3-transfizierte Zellen aufgenommene ${ }^{3} \mathrm{H}$-Östronsulfat-Menge abzüglich der bei den Vektor-transfizierten Zellen gemessenen ${ }^{3} \mathrm{H}$-Östronsulfat-Menge. Dargestellt ist eine von drei unabhängigen Messungen an drei verschiedenen Zellkulturen. Die gezeigten Werte sind Mittelwerte \pm Standardabweichungen (SEM) von jeweils vier Einzelmessungen an einer Zellkultur. Die Kurve wurde durch Anpassung der Gleichung für Hemmkinetiken an die Messdaten berechnet. 
In der Abb. 34 wird der Einfluss von Suberat auf die ${ }^{3} \mathrm{H}$-Östronsulfat-Aufnahme durch den hOAT3 dargestellt. Suberat wurde in Konzentrationen von $0 \mu \mathrm{M}$ bis $2000 \mu \mathrm{M}$ getestet. In drei Messungen wurde eine $\mathrm{IC}_{50}$ von $232 \pm 42 \mu \mathrm{M}$ bestimmt.

\subsection{Bestimmung der $K_{\mathrm{i}}$-Werte von zwei Dicarboxylaten für den Östronsulfat-Transport durch hOAT3}

Zusätzlich wurden noch die $\mathrm{K}_{\mathrm{i}}$-Werte von zwei Dicarboxylaten mit Hilfe von Dixon-Plots bestimmt. Gemessen wurde jeweils die Hemmung der Östronsulfat-Aufnahme durch die Dicarboxylate bei zwei Östronsulfat-Konzentrationen: $5 \mathrm{nM}$ und $10 \mathrm{nM}$.

\subsection{1. $\mathrm{K}_{\mathrm{i}}$-Wert von Glutarat für den Östronsulfat-Transport durch hOAT3}

Abb. 35 zeigt den Dixon-Plot einer Beispielmessung der Bestimmung des $\mathrm{K}_{\mathrm{i}}$-Wertes von Glutarat für den Östronsulfat-Transport durch hOAT3. Aufgetragen wurden die reziproken Aufnahme-Werte mit $5 \mathrm{nM}$ bzw. $10 \mathrm{nM}{ }^{3} \mathrm{H}$-Östronsulfat gegen die Glutarat-Konzentration (0 bis $200 \mu \mathrm{M}$ ). Die den Messdaten angepassten Geraden schneiden sich im zweiten Quadranten. Der Schnittpunkt bei 58,7 $\mu \mathrm{M}$ entspricht dem $\mathrm{K}_{\mathrm{i}}$-Wert. Gemittelt aus drei Versuchen ergab sich ein $\mathrm{K}_{\mathrm{i}}$-Wert von $60 \mu \mathrm{M} \pm 8 \mu \mathrm{M}$.

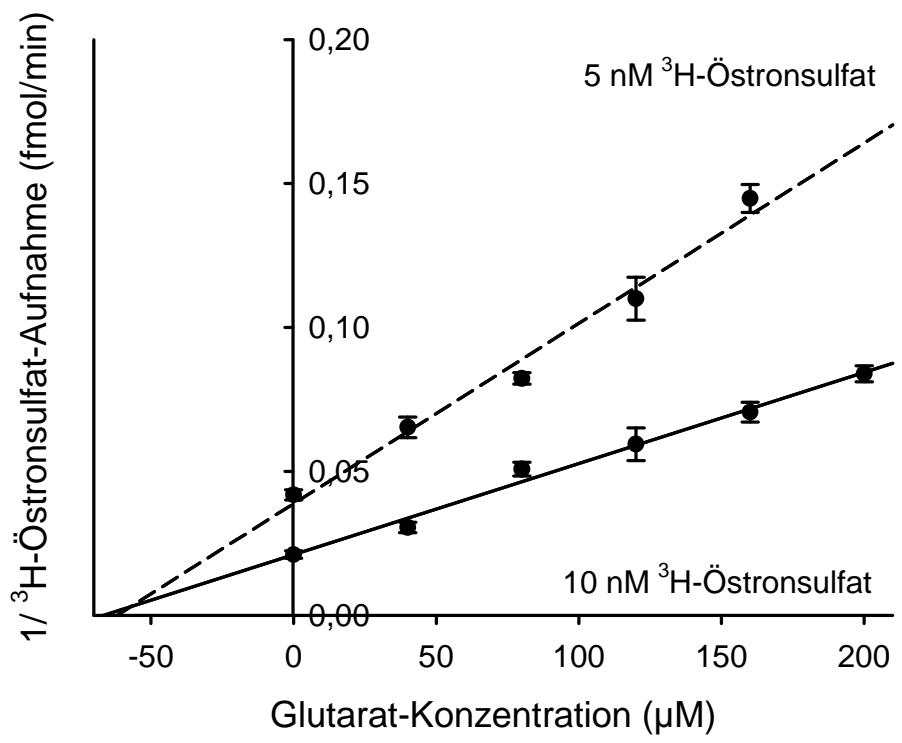

Abb. 35: Dixon-Plot zur Bestimmung der $K_{i}$ für Glutarat

Die ${ }^{3} \mathrm{H}$-Östronsulfat-Aufnahme wurde bei zwei verschiedenen ${ }^{3} \mathrm{H}$-Östronsulfat-Konzentrationen, $5 \mathrm{nM}$ (gestrichelte Linie) und $10 \mathrm{nM}$ (durchgezogene Linie), gemessen. Dazu wurden Zellen für 1 min bei Raumtemperatur in Ringerlösungen inkubiert, die zusätzlich Glutarat in Konzentrationen von 0 bis $200 \mu \mathrm{M}$ enthielten. Aufgetragen wurde der reziproke Wert der ${ }^{3} \mathrm{H}$-Östronsulfat-Aufnahme gegen die Hemmstoffkonzentrationen. Dargestellt sind Mittelwerte \pm Standardabweichungen (SEM) von vier Einzelmessungen eines Beispielversuchs an einer Zellkultur abzüglich der Werte, die unter den gleichen Bedingungen an Vektor-transfizierten Zellen gemessen wurden. 
3.9.2. $\mathrm{K}_{\mathrm{i}}$-Wert von $\alpha$-Ketoglutarat für den Östronsulfat-Transport durch hOAT3

Auch von $\alpha$-Ketoglutarat wurde der $\mathrm{K}_{\mathrm{i}}$-Wert für den Östronsulfat-Transport durch hOAT3 bestimmt. Abb. 36 zeigt wieder eine Beispielmessung. Aus drei unabhängigen Messungen wurde eine $\mathrm{K}_{\mathrm{i}}$ von $72 \pm 35 \mu \mathrm{M}$ ermittelt.

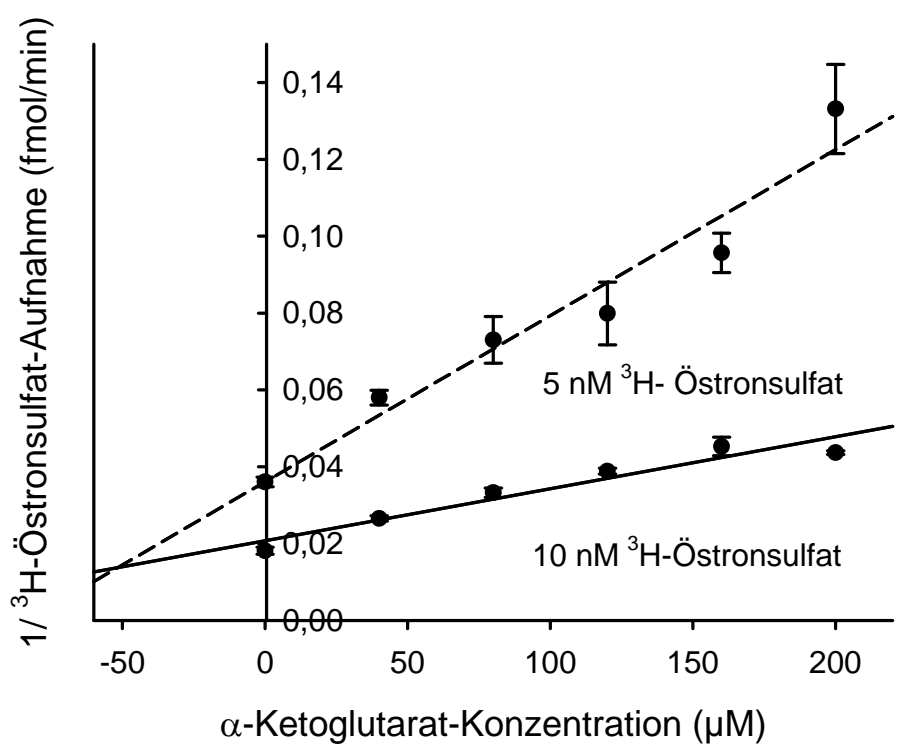

Abb. 36: Dixon-Plot zur Bestimmung der $K_{i}$ für $\alpha$-Ketoglutarat

Die ${ }^{3} \mathrm{H}$-Östronsulfat-Aufnahme wurde bei zwei verschiedenen ${ }^{3} \mathrm{H}$-Östronsulfat-Konzentrationen, $5 \mathrm{nM}$ (gestrichelte Linie) und $10 \mathrm{nM}$ (durchgezogene Linie), gemessen. Dazu wurden Zellen für 1 min bei Raumtemperatur in Ringerlösungen inkubiert, die zusätzlich $\alpha$-Ketoglutarat in Konzentrationen von 0 bis $200 \mu \mathrm{M}$ enthielten. Aufgetragen wurde der reziproke Wert der ${ }^{3} \mathrm{H}$-Östronsulfat-Aufnahme gegen die Hemmstoffkonzentrationen. Dargestellt sind Mittelwerte \pm Standardabweichungen (SEM) von vier Einzelmessungen eines Beispielversuchs an einer Zellkultur abzüglich der Werte, die unter den gleichen Bedingungen an Vektortransfizierten Zellen gemessen wurden.

\subsection{Versuche zum Mechanismus der Hemmung}

Um Informationen über den Mechanismus der Hemmung durch die Dicarboxylate zu erhalten, wurde die Substrataufnahme in hOAT1 bzw. hOAT3-transfizierten HEK293-Zellen in An- bzw. Abwesenheit eines Beispiel-Dicarboxylats, $\alpha$-Ketoglutarat, gemessen.

\subsubsection{Messung der ${ }^{3} \mathrm{H}-\mathrm{PAH}-\mathrm{Aufnahme}$ durch hOAT1 in An- und Abwesenheit von $\alpha$-Ketoglutarat}

Abb. 37 zeigt eine Aufnahme von PAH in hOAT1-transfizierte Zellen in Abhängigkeit von der Substratkonzentration ohne $\alpha$-Ketoglutarat und in Anwesenheit von $10 \mu \mathrm{M} \alpha-$ Ketoglutarat. Die Anpassung der Michaelis-Menten-Gleichung $\mathrm{v}=\frac{\mathrm{v}_{\max } \cdot \mathrm{IC}_{50}}{\mathrm{IC}_{50}+[\mathrm{I}]}+\mathrm{v}_{\min }$ an die Messwerte ergab eine $K_{m}=3,6 \pm 0,6 \mu \mathrm{M}$ für die Aufnahme in Abwesenheit von $\alpha$ - 
Ketoglutarat und eine $\mathrm{K}_{\mathrm{m}}=17,4 \pm 3,0 \mu \mathrm{M}$ in Anwesenheit von $\alpha$-Ketoglutarat. $\mathrm{v}_{\max }$ war in An- und Abwesenheit von $\alpha$-Ketoglutarat nicht signifikant verschieden: $v_{\max }=9,3 \pm 0,4$ $\mathrm{pmol} / \mathrm{min}$ in Abwesenheit von $\alpha$-Ketoglutarat und $\mathrm{v}_{\max }=9,2 \pm 0,9 \mathrm{pmol} / \mathrm{min}$ in Anwesenheit von $10 \mu \mathrm{M} \alpha$-Ketoglutarat.

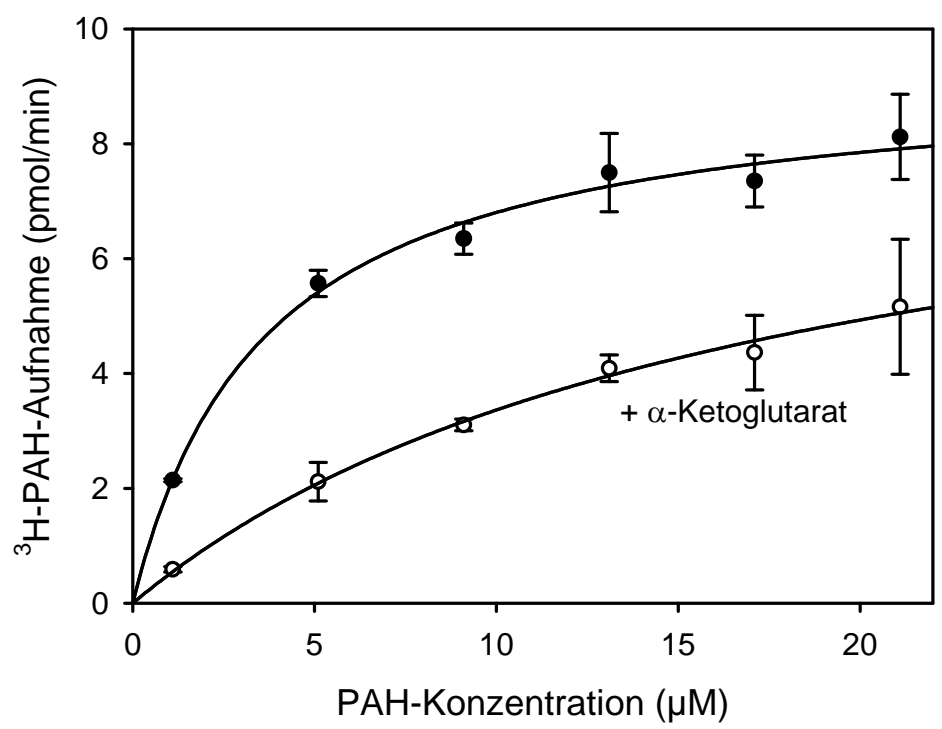

Abb. 37: PAH-Aufnahme durch hOAT1 in An- und Abwesenheit von $\alpha$-Ketoglutarat

Die ${ }^{3} \mathrm{H}-\mathrm{PAH}-A$ ufnahme in hOAT1-transfizierte HEK293-Zellen wurde in Anwesenheit von $10 \mu \mathrm{M} \alpha-$ Ketoglutarat (weiße Kreise) und ohne $\alpha$-Ketoglutarat (schwarze Kreise) bei verschiedenen PAHKonzentrationen gemessen. Die Zellen wurden bei Raumtemperatur eine Minute inkubiert. Anschließend wurde das in die Zelle aufgenommene ${ }^{3} \mathrm{H}-\mathrm{PAH}$ gezählt. Die gezeigten Werte sind Mittelwerte \pm Standardabweichungen (SEM) von jeweils vier Einzelmessungen an einer Zellkultur abzüglich der bei Vektor-transfizierten Zellen gemessenen ${ }^{3}$ H-PAH-Menge. Die Kurve wurde durch Anpassung der Michaelis-Menten-Gleichung an die Messwerte erhalten.

Die Abb. 38 zeigt ein Eadie-Hofstee-Diagramm (BISSWANGER 2000) der Messung. Aufgetragen wurde die PAH-Aufnahme in Abwesenheit von $\alpha$-Ketoglutarat (schwarze Kreise) und in Anwesenheit von $\alpha$-Ketoglutarat (weiße Kreise) gegen den Quotienten aus ${ }^{3} \mathrm{H}$ PAH-Aufnahme durch PAH-Konzentration. Die gestrichelten Linien geben den 95\%Vertrauensbereich an. Wie man sieht, überlappen sich die 95\%-Vertrauensbereiche auf der yAchse. 


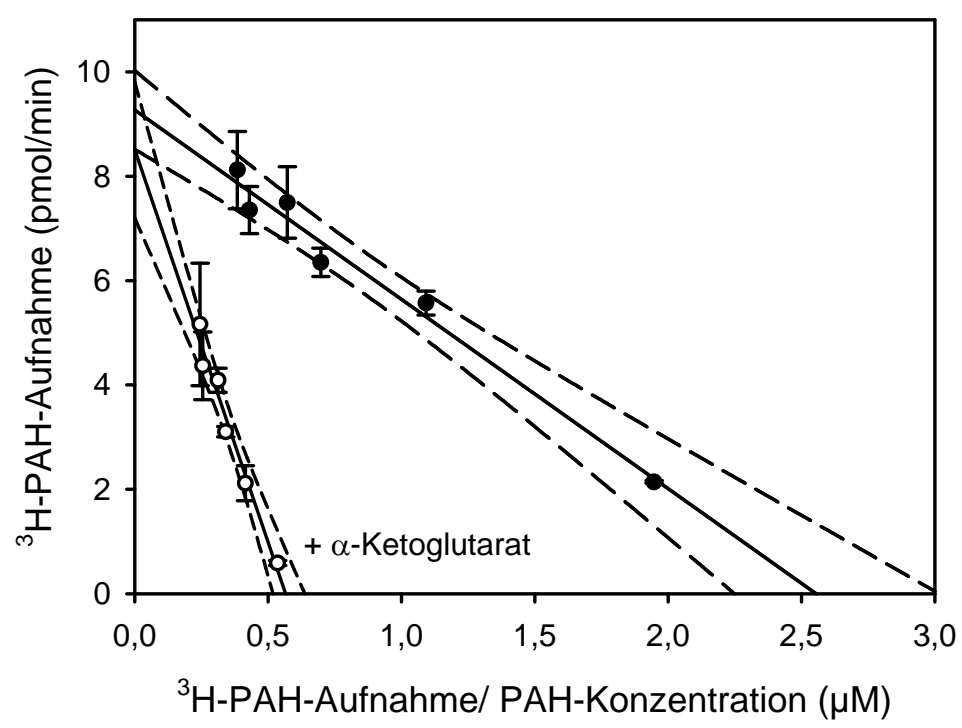

Abb. 38: Eadie-Hofstee-Auftragung der ${ }^{3} \mathrm{H}-\mathrm{PAH}-A u f n a h m e$ durch hOAT1 in An- und Abwesenheit von $\alpha$ Ketoglutarat

Die Messwerte, die, wie in Abb. 37 beschrieben, erhalten wurden, sind hier gegen die ${ }^{3} \mathrm{H}-\mathrm{PAH}-\mathrm{Aufnahme}{ }^{\beta} \mathrm{H}-$ PAH-Konzentration aufgetragen (schwarze Kreise ohne $\alpha$-Ketoglutarat, weiße Kreise mit $\alpha$-Ketoglutarat). Es wurde jeweils eine Regressionsgerade mit ihrem 95\%-Vertrauensintervall den Daten angepasst.

Abb. 39 zeigt eine Lineweaver-Burk-Auftragung (BISSWANGER 2000) derselben Messung. Hier wurde also die reziproke PAH-Aufnahme (schwarze Kreise ohne $\alpha$-Ketoglutarat, weiße Keise mit $\alpha$-Ketoglutarat) gegen die reziproke PAH-Konzentration aufgetragen. Auch hier überlappen sich die 95\% Vertrauensbereiche auf der y-Achse.

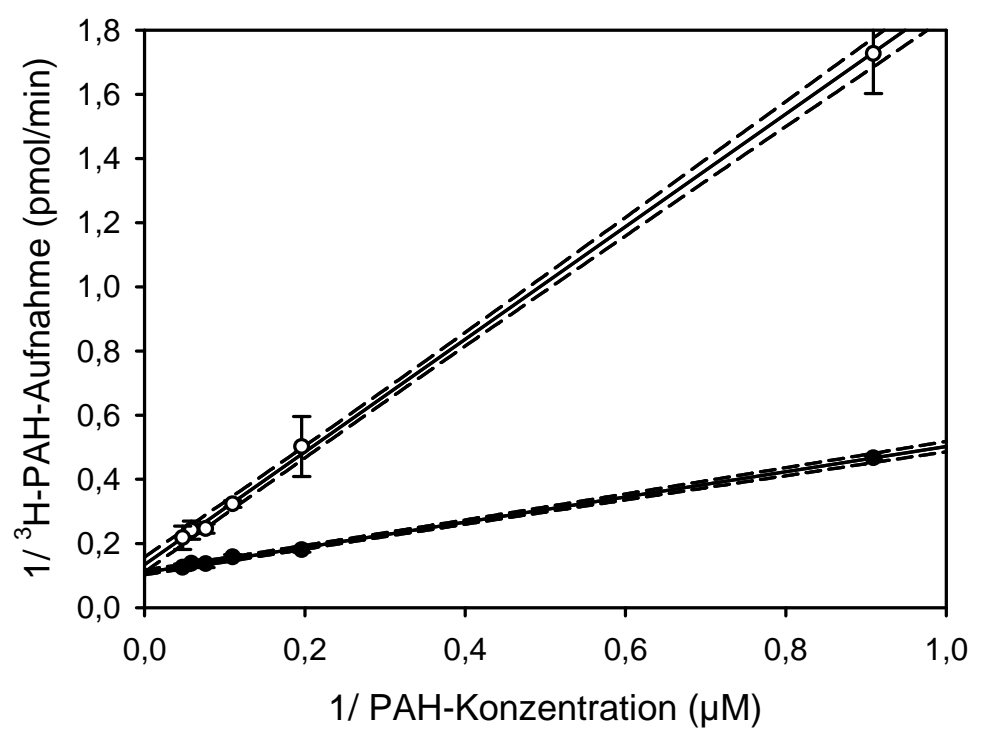

Abb. 39: Lineweaver-Burk-Auftragung der ${ }^{3} \mathrm{H}-\mathrm{PAH}-A u f n a h m e$ durch hOAT1 in An- und Abwesenheit von $\alpha$-Ketoglutarat

Die Messwerte, die, wie in Abb. 37 beschrieben, erhalten wurden, sind hier in reziproker Form gegen die reziproke ${ }^{3} \mathrm{H}$-PAH-Konzentration aufgetragen (schwarze Kreise ohne $\alpha$-Ketoglutarat, weiße Kreise mit $\alpha$ Ketoglutarat). Es wurde jeweils eine Regressionsgerade mit ihren 95\%-Vertrauensintervall den Daten angepasst. 


\subsubsection{Messung der ${ }^{3} \mathrm{H}$-Östronsulfat-Aufnahme durch hOAT3 in An- und Abwesenheit von $\alpha$-Ketoglutarat}

Ebenso wurde die ${ }^{3} \mathrm{H}$-Östronsulfat-Aufnahme in hOAT3-transfizierten Zellen bei verschiedenen Östronsulfat-Konzentrationen in An- und Abwesenheit von $\alpha$-Ketoglutarat gemessen, um so Informationen über den Typ der Hemmung des hOAT3 durch Dicarboxylate zu erhalten.

Abb. 40 zeigt die ${ }^{3} \mathrm{H}$-Östronsulfat-Aufnahme ohne Anwesenheit (schwarze Kreise) und in Anwesenheit (weiße Kreise) von $100 \mu \mathrm{M} \alpha$-Ketoglutarat in Abhängigkeit von der Östronsulfat-Konzentration $(0 \mu \mathrm{M}$ bis $10 \mu \mathrm{M})$. In Abwesenheit von $\alpha$-Ketoglutarat wurde ein $\mathrm{K}_{\mathrm{m}}$-Wert des Östronsulfat-Transports durch hOAT3 von 3,8 $\pm 1,1 \mu \mathrm{M}$ gemessen, in Anwesenheit von $\alpha$-Ketoglutarat war der $\mathrm{K}_{\mathrm{m}}$-Wert $11,9 \pm 3,1 \mu \mathrm{M}$. Die $\mathrm{v}_{\max }$-Werte waren wieder nicht signifikant unterschiedlich (in Abwesenheit von $\alpha$-Ketoglutarat $v_{\max }=20220 \pm$ $2216 \mathrm{fmol} / \mathrm{min}$; in Anwesenheit $24910 \pm 3986 \mathrm{fmol} / \mathrm{min})$.

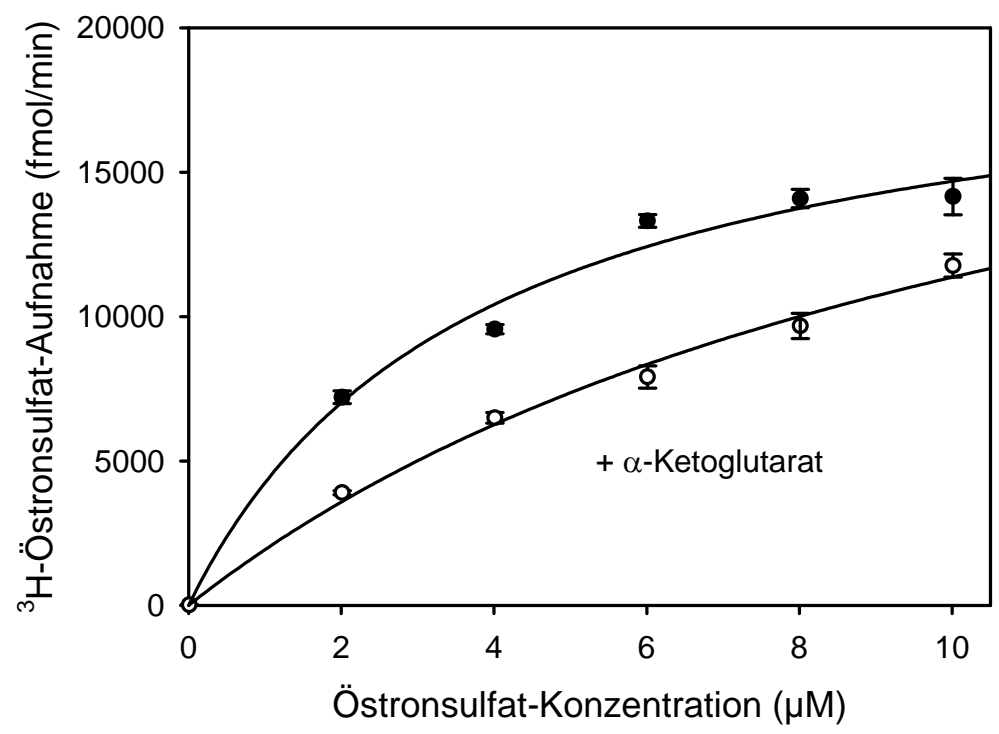

\section{Abb. 40: Östronsulfat-Aufnahme durch hOAT3 in An- und Abwesenheit von $\alpha$-Ketoglutarat}

Die ${ }^{3} \mathrm{H}$-Östronsulfat-Aufnahme in hOAT3-transfizierten HEK293-Zellen wurde in Anwesenheit von $100 \mu \mathrm{M} \alpha$ Ketoglutarat (weiße Kreise) und ohne $\alpha$-Ketoglutarat (schwarze Kreise) bei verschiedenen ÖstronsulfatKonzentrationen gemessen. Die Zellen wurden bei Raumtemperatur eine Minute inkubiert. Anschließend wurde das in die Zelle aufgenommene ${ }^{3} \mathrm{H}$-Östronsulfat gezählt. Die gezeigten Werte sind Mittelwerte \pm Standardabweichungen (SEM) von jeweils vier Einzelmessungen an einer Zellkultur abzüglich der bei Vektortransfizierten Zellen gemessenen ${ }^{3} \mathrm{H}$-Östronsulfat-Menge. Die Kurve wurde durch Anpassung der MichaelisMenten-Gleichung an die Messwerte erhalten.

Abb. 41 zeigt eine Eadie-Hofstee-Auftragung der Messwerte (weiße Kreise: in Anwesenheit von $100 \mu \mathrm{M} \alpha$-Ketoglutarat; schwarze Kreise: ohne $\alpha$-Ketoglutarat). Auch hier schneiden sich zumindest die 95\%-Vertrauensbereiche auf der y-Achse. 


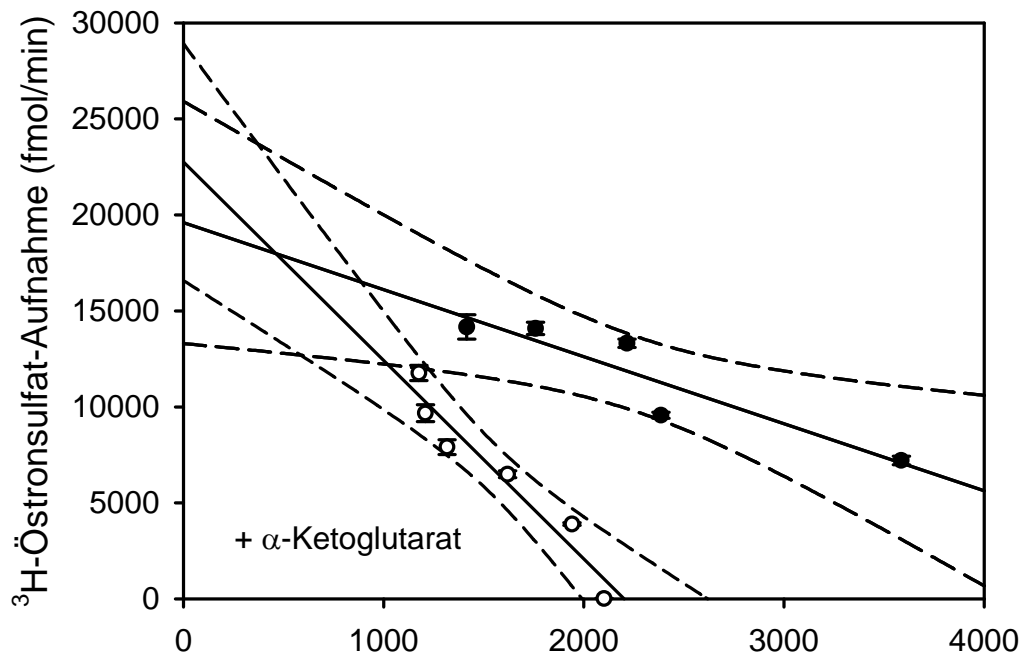

${ }^{3} \mathrm{H}$-Östronsulfat-Aufnahme (fmol)/ Östronsulfat-Konzentration $(\mu \mathrm{M})$

Abb. 41: Eadie-Hofstee-Auftragung der ${ }^{3} \mathrm{H}$-Östronsulfat-Aufnahme durch hOAT3 in An- und Abwesenheit von $\alpha$-Ketoglutarat

Die Messwerte, die, wie in Abb. 40 beschrieben, erhalten wurden, sind hier gegen die ${ }^{3} \mathrm{H}$-ÖstronsulfatAufnahme ${ }^{\beta} \mathrm{H}$-Östronsulfat-Konzentration aufgetragen (schwarze Kreise ohne $\alpha$-Ketoglutarat, weiße Kreise mit $\alpha$-Ketoglutarat). Es wurde jeweils eine Regressionsgerade mit ihrem $95 \%$-Vertrauensintervall den Daten angepasst.

In der Lineweaver-Burk-Auftragung (Abb. 42) schneiden sich die Geraden auf der y-Achse.

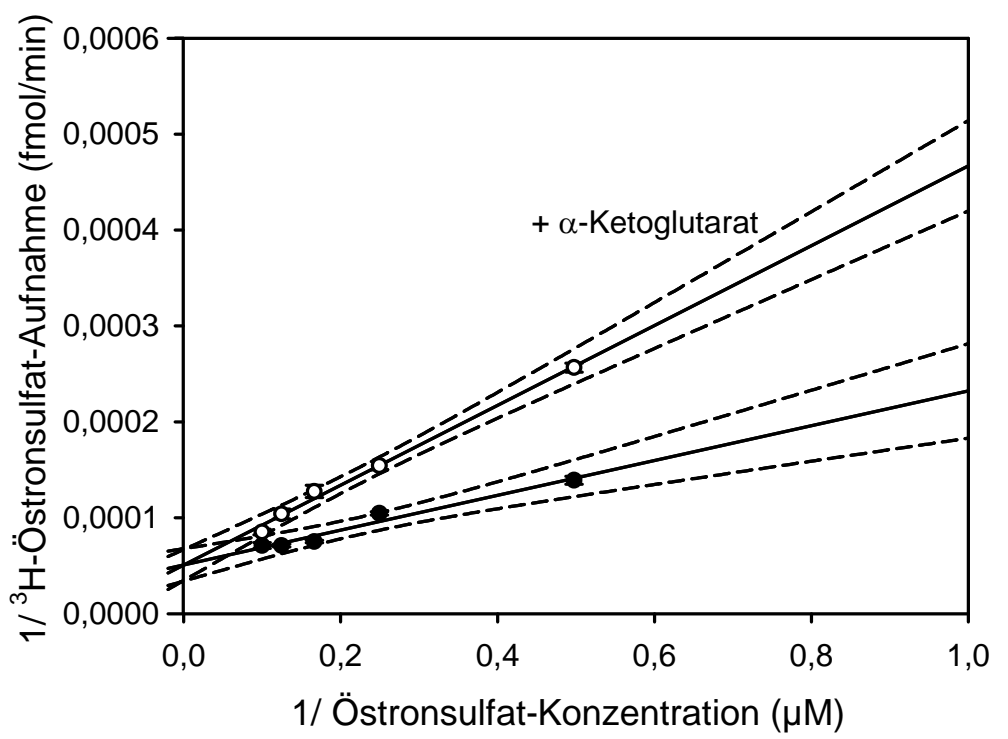

Abb. 42: Lineweaver-Burk-Auftragung der ${ }^{3} \mathrm{H}$-Östronsulfat-Aufnahme durch hOAT3 in An- und Abwesenheit von $\alpha$-Ketoglutarat

Die Messwerte, die, wie in Abb. 40 beschrieben, erhalten wurden, sind hier in reziproker Form gegen die reziproke ${ }^{3} \mathrm{H}$-Östronlfat-Konzentration aufgetragen (schwarze Kreise ohne $\alpha$-Ketoglutarat, weiße Kreise mit $\alpha$ Ketoglutarat). Es wurde jeweils eine Regressionsgerade mit ihren 95\%-Vertrauensintervall den Daten angepasst. 


\subsection{Zusammenfassung der gemessenen $\mathrm{IC}_{50^{-}}$und $\mathrm{K}_{\mathrm{i}^{-}}$-Werte}

Es wurden die $\mathrm{IC}_{50}$-Werte von zehn Dicarboxylaten für den PAH-Transport durch hOAT1 und für den Östronsulfat-Transport durch hOAT3 bestimmt. Außerdem wurden noch für zwei Dicarboxylate die entsprechenden $\mathrm{K}_{\mathrm{i}}$-Werte ermittelt.

\begin{tabular}{|c|c|c|c|c|}
\hline & $\begin{array}{l}\mathrm{IC}_{50} \mathrm{hOAT} 1 \\
(\mu \mathrm{M})\end{array}$ & $\begin{array}{l}\mathrm{K}_{\mathrm{i}} \text { hOAT1 } \\
\quad(\mu \mathrm{M})\end{array}$ & $\begin{array}{l}\mathrm{IC}_{50} \mathrm{hOAT} 3 \\
(\mu \mathrm{M})\end{array}$ & $\begin{array}{c}\mathrm{K}_{\mathrm{i}} \text { hOAT3 } \\
(\mu \mathrm{M})\end{array}$ \\
\hline 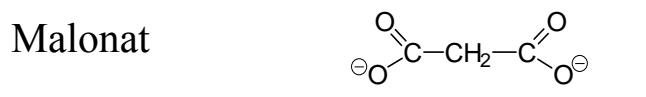 & $\begin{array}{l}\text { k. H. } \\
(\mathrm{n}=3)\end{array}$ & & $\begin{array}{l}\text { k. H. } \\
(\mathrm{n}=3)\end{array}$ & \\
\hline Maleat & $\begin{array}{l}12950 \pm 1258 \\
(\mathrm{n}=4)\end{array}$ & & $\begin{array}{l}141100 \pm 86300 \\
(\mathrm{n}=3)\end{array}$ & \\
\hline Fumarat & $\begin{array}{l}1733 \pm 353 \\
(\mathrm{n}=3)\end{array}$ & & $\begin{array}{l}21100 \pm 2800 \\
\quad(\mathrm{n}=3)\end{array}$ & \\
\hline Succinat $\quad \stackrel{0}{\theta_{0}-0}$ & $\begin{array}{l}4825 \pm 680 \\
\quad(n=4)\end{array}$ & & $\begin{aligned} 55700 & \pm 16500 \\
(\mathrm{n} & =3)\end{aligned}$ & \\
\hline Glutarat $\quad \stackrel{\mathrm{O}}{\theta_{0} \mathrm{C}-}$ & $\begin{aligned} 3,3 & \pm 1,2 \\
(\mathrm{n} & =4)\end{aligned}$ & $\begin{aligned} 1,1 & \pm 0,7 \\
(\mathrm{n} & =3)\end{aligned}$ & $\begin{array}{l}79 \pm 5 \\
(\mathrm{n}=4)\end{array}$ & $\begin{array}{l}60 \pm 8 \\
(\mathrm{n}=3)\end{array}$ \\
\hline$\alpha$-Ketoglutarat $\stackrel{0}{\theta_{0}^{\prime \prime}}$ & $\begin{array}{l}4,7 \pm 1,2 \\
(\mathrm{n}=4)\end{array}$ & $\begin{array}{l}1,2 \pm 0,4 \\
(\mathrm{n}=3)\end{array}$ & $\begin{array}{r}92 \pm 34 \\
(\mathrm{n}=4)\end{array}$ & $\begin{array}{l}72 \pm 35 \\
(\mathrm{n}=3)\end{array}$ \\
\hline Citrat & $\begin{array}{l}5460 \pm 491 \\
\quad(\mathrm{n}=5)\end{array}$ & & $\begin{array}{l}\mathrm{k} . \mathrm{H} . \\
(\mathrm{n}=3)\end{array}$ & \\
\hline Adipat $\quad{ }_{\mathrm{O}^{\prime}}^{\mathrm{O}} \mathrm{C}-\mathrm{CH}_{2}-\mathrm{CH}_{2}-\mathrm{CH}_{2}-\mathrm{CH}_{2}-\mathrm{C}_{\mathrm{O}}^{\prime \prime}$ & $\begin{array}{l}6,2 \pm 1,0 \\
(\mathrm{n}=5)\end{array}$ & & $\begin{array}{l}136 \pm 57 \\
(\mathrm{n}=3)\end{array}$ & \\
\hline Pimelat ${ }_{\theta_{0}^{\prime}}^{\mathrm{d}} \mathrm{c}-\mathrm{c}$ & $\begin{array}{l}18,6 \pm 2,6 \\
(\mathrm{n}=3)\end{array}$ & & $\begin{aligned} 634 & \pm 225 \\
(\mathrm{n} & =4)\end{aligned}$ & \\
\hline Suberat ${ }_{\mathrm{O}} \mathrm{C}^{\mathrm{C}}-\mathrm{CH}_{2}-\mathrm{CH}_{2}-\mathrm{CH}_{2}-\mathrm{CH}_{2}-\mathrm{CH}_{2}-\mathrm{CH}_{2}-$ & $\begin{array}{l}19,3 \pm 2,2 \\
(\mathrm{n}=3)\end{array}$ & & $\begin{array}{c}232 \pm 42 \\
(\mathrm{n}=3)\end{array}$ & \\
\hline
\end{tabular}

Tab. 3: $\mathbf{I C}_{50}$-Werte und $\mathbf{K}_{\mathrm{i}}$-Werte der getesteten Dicarboxylate. $\mathrm{k} . \mathrm{H}$. = keine Hemmung

Tabelle 3 und die Abb. 43 und 44 fassen die Ergebnisse zusammen. Während Malonat noch keine Hemmung bewirkte, werden die $\mathrm{IC}_{50}$-Werte mit steigender Länge der Dicarboxylate kleiner. Die niedrigsten $\mathrm{IC}_{50}$-Werte wurden für die $\mathrm{C} 5$-Dicarboxylate Glutarat und 
$\alpha$-Ketoglutarat gemessen. Mit weiter anwachsender Kettenlänge wurde die Hemmung wieder schwächer. Aus dieser Tendenz fällt Citrat heraus, das eine zusätzliche Carboxylgruppe hat, also ein Tricarboxylat ist, und das eine relativ schwache Hemmung zeigt.

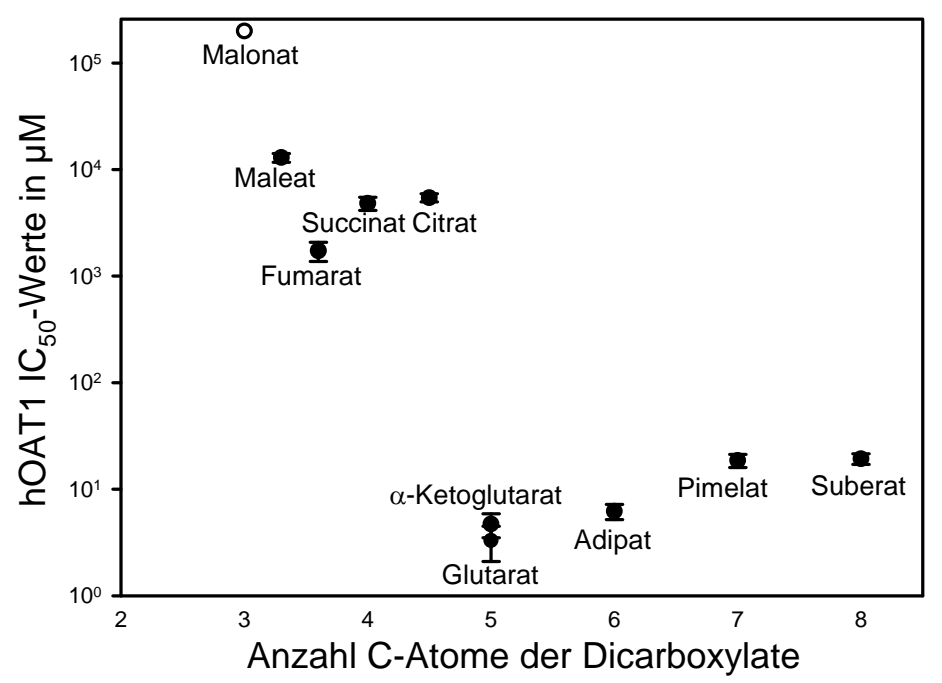

Abb. 43: Auftragung der $\mathrm{IC}_{50}$-Werte der Dicarboxylate für den PAH-Transport durch hOAT1 gegen die Anzahl der C-Atome der Dicarboxylate

Die schwarzen Kreise entsprechen den $\mathrm{IC}_{50}$-Werten aus Tab. 3. Malonat (weißer Kreis) zeigte keine Hemmung.

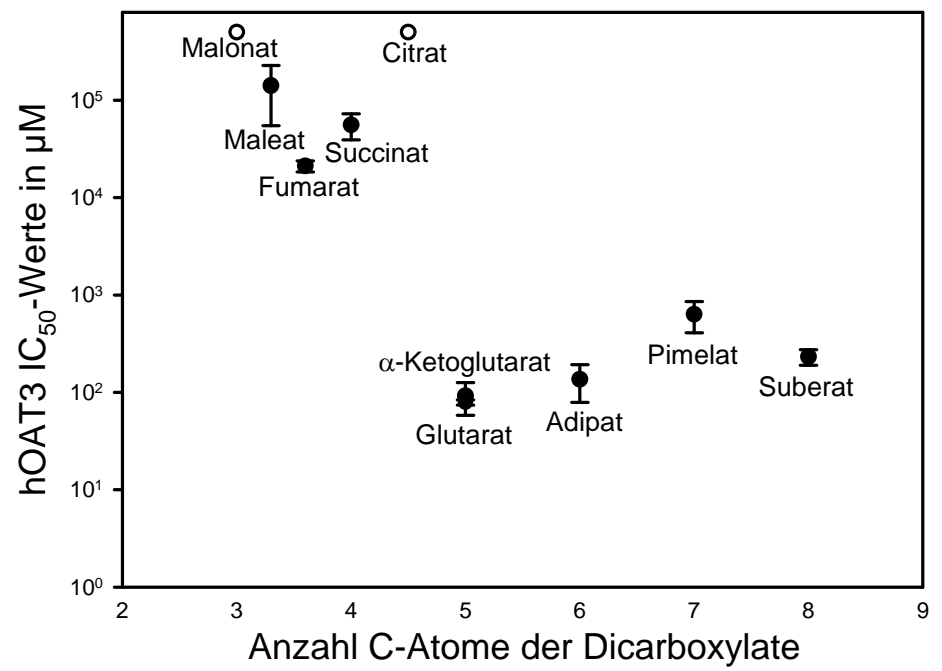

Abb. 44: Auftragung der $\mathrm{IC}_{50}$-Werte der Dicarboxylate für den Östronsulfat-Transport durch hOAT3 gegen die Anzahl der C-Atome der Dicarboxylate

Die schwarzen Kreise entsprechen den $\mathrm{IC}_{50}$-Werten aus Tab. 3. Malonat und Citrat (weiße Kreise) zeigten keine Hemmung.

Die Hemmtendenz ist für hOAT1 und hOAT3 ähnlich, die $\mathrm{IC}_{50}$-Werte sind für den Östronsulfat-Transport durch hOAT3 aber allgemein deutlich größer als für den PAHTransport durch hOAT1. Dies wird deutlich in der Abb. 45, in der die hOAT1-IC ${ }_{50}$-Werte gegen die hOAT3-IC ${ }_{50}$-Werte aufgetragen wurden. Die $\mathrm{IC}_{50}$-Werte liegen auf einer Geraden mit der Geradengleichung $\mathrm{y}=0,91 \mathrm{x}+1,13$ (bei logarithmischer Auftragung) und einem 
Korrelationskoeffizient von $\mathrm{r}^{2}=0.99$. Das heißt, dass die Affinitäten der Dicarboxylate $10^{1,13}$ mal, also etwa 13-mal größer für den hOAT1 als für den hOAT3 sind.

Dies wird auch durch die $\mathrm{K}_{\mathrm{i}}$-Werte bestätigt, die ebenfalls zeigen, dass die Dicarboxylate Glutarat und $\alpha$-Ketoglutarat eine größere Affinität zum hOAT1 als zum hOAT3 besitzen.

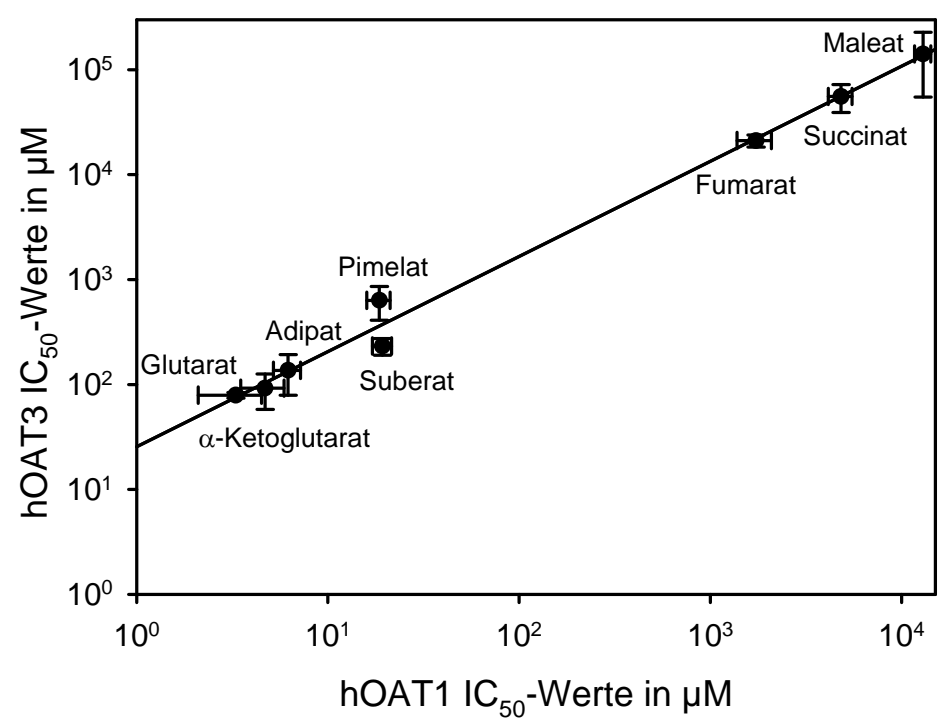

Abb. 45: Auftragung der $\mathrm{IC}_{50}$-Werte der Dicarboxylate für den hOAT1 gegen die $\mathrm{IC}_{50}$-Werte für den hOAT3

Die $\mathrm{IC}_{50}$-Werte für den Transport durch hOAT1 und hOAT3 aus Tab.3 wurden hier gegeneinander aufgetragen. Dargestellt sind Mittelwerte \pm Standardabweichungen (SEM). Citrat und Malonat wurden nicht berücksichtigt. 


\section{Diskussion}

\subsection{Bestimmung der spezifischen Substrataufnahme durch hOAT1 und hOAT3}

Die spezifische Substrataufnahme ist in der vorliegenden Studie die Substratmenge, die durch die Transporter hOAT1 bzw. hOAT3 in die Zellen aufgenommen wird. Daneben wurde bei allen Versuchen auch immer eine sogenannte unspezifische Substrataufnahme mitgemessen. Diese unspezifische Aufnahme beinhaltet die Substratmenge, die nicht durch die Transporter hOAT1 oder hOAT3, sondern durch andere endogene Transporter oder durch unspezifische Diffusion in die Zellen aufgenommen wird. Sie beinhaltet ebenfalls die Substratmenge, die außen an die Zellen bindet und sich nicht abwaschen lässt. Diese Substratmenge ist gleich der gemessenen Substrataufnahme der Kontrollzellen, die nicht mit dem hOAT1 oder hOAT3, sondern nur mit dem Vektor transfiziert waren. Die unspezifische Substrataufnahme der Vektor-transfizierten Zellen wurde jeweils über einen bestimmten Zeitraum von einigen Wochen gemittelt. Dieser Durchschnittswert, der relativ konstant war, wurde von der gemessenen Substrataufnahme der mit hOAT1 oder hOAT3 transfizierten Zellen subtrahiert. Die Differenz ist die spezifische Substrataufnahme der Transporter.

Zusätzlich wurde bei den $\mathrm{IC}_{50}$-Bestimmungen über die Formel $\mathrm{v}=\frac{\mathrm{v}_{\max } \cdot \mathrm{IC}_{50}}{\mathrm{IC}_{50}+[\mathrm{I}]}+\mathrm{v}_{\min }$ der nichthemmbare Substratanteil $\mathbf{v}_{\min }$ bestimmt. Wenn der nicht-hemmbare Substratanteil $\mathbf{v}_{\min }$ der unspezifischen Substrataufnahme entspricht, müsste er in den Hemmversuchen Null sein, da die Aufnahme der Vektor-transfizierten Zellen vor Berechnung der $\mathrm{IC}_{50}$-Werte abgezogen wurde. Dies war auch tatsächlich der Fall, mit Ausnahme der Hemmung der ÖstronsulfatAufnahme durch hOAT3 durch die Dicarboxylate Maleat und Succinat. Für Maleat und Succinat konnte die Gleichung so angepasst werden, dass ein nicht-hemmbarer Anteil erhalten wurde. Maleat und Succinat bewirken möglicherweise keine vollständige Hemmung des hOAT3, wie im folgenden Text unter 4.2 noch diskutiert wird.

\subsection{Bestimmung der $\mathrm{IC}_{50}$-Werte}

Zur Bestimmung der $\mathrm{IC}_{50}$-Werte der Dicarboxylate wurde der Transport von Modellsubstanzen über hOAT1 und hOAT3 in Anwesenheit steigender Konzentrationen der Dicarboxylate gemessen. Da die Dicarboxylate den Transportern auf der gleichen Seite wie die zu transportierenden Modellsubstrate angeboten wurden, konnten sie mit den Transportern interagieren und die Bindung und den Transport der Modellsubstanzen hemmen. Die $\mathrm{IC}_{50^{-}}$ 
Werte wurden durch Anpassung der Gleichung v $=\frac{\mathrm{v}_{\max } \cdot \mathrm{IC}_{50}}{\mathrm{IC}_{50}+[\mathrm{I}]}+\mathrm{v}_{\min }$ an die Messwerte erhalten. Zuvor wurde die Substrataufnahme der Vektor-transfizierten Zellen, also der unspezifische Anteil der Substrataufnahme, von der Gesamtsubstrataufnahme der OAT-transfizierten Zellen abgezogen. Der Anteil $\mathrm{V}_{\min }$ war unter diesen Bedingungen Null, die Hemmung der Transporter also vollständig, außer, wie schon erwähnt, bei den Hemmversuchen mit dem hOAT3 durch Maleat und Succinat.

Bei Maleat wurde eine $\mathrm{IC}_{50}$ von $10,0 \pm 3,2 \mathrm{mM}$ und ein nicht-hemmbarer Anteil an der Aufnahme von $70 \pm 7 \%$ erhalten. Abb. 26 zeigt einen Beispielversuch. Passt man dagegen die Hemmkinetik-Gleichung ohne nicht hemmbaren Anteil, $\mathrm{v}=\frac{\mathrm{v}_{\max } \cdot \mathrm{IC}_{50}}{\mathrm{IC}_{50}+[\mathrm{I}]}$, den Messwerten an, erhielt man in diesem Versuch eine $\mathrm{IC}_{50}$ von $141,1 \pm 86,3 \mathrm{mM}$ bei vollständiger Hemmung (Abb. 26). Auch bei zwei von drei Versuchen mit Succinat wurde durch Anpassung der Hemmgleichung mit nicht hemmbaren Anteil an die Messwerte ebenfalls ein nichthemmbarer Anteil errechnet, der allerdings mit durchschnittlich $21 \pm 14 \%$ deutlich kleiner war.

Unvollständige Hemmungen von Transporten sind nicht ungewöhnlich. So beobachteten WANG X et al. (1993) eine unvollständige Hemmung der Lactat- und Pyruvat-Aufnahme in Herzmyozyten durch Stilbendisulfonate. Sie vermuteten die Beteiligung von zwei verschiedenen Transportern mit unterschiedlichen Affinitäten. Aber auch wenn nur ein Transporter beteiligt ist, lässt sich eine unvollständige Hemmung verstehen, vor allem wenn es sich um eine nicht-kompetitive Hemmung handelt, Substrat und Inhibitor also an verschiedenen Stellen des Transporters binden.

Welches unserer beiden Hemmmodelle - hohe $\mathrm{IC}_{50}$ mit vollständiger Hemmung oder niedrige $\mathrm{IC}_{50}$ mit unvollständiger Hemmung - ist nun richtig? Dazu haben wir beispielhaft die Kurvenanpassungen nach beiden Modellen an einem Hemmversuch mit Maleat verglichen. Der Korrelationskoeffizient $r^{2}$ der Kurve, die unter der Annahme einer vollständigen Hemmung angepasst wurde, betrug 0,455, bei Annahme einer unvollständigen Hemmung 0,551. Die Summe der Fehlerquadrate war bei Annahme einer vollständigen Hemmung 0,674 und bei Annahme einer unvollständigen Hemmung 0,551 (SYSTAT SOFTWARE 2008). Die Anpassung an die Gleichung mit unvollständiger Hemmung war also geringfügig besser und damit das Hemmmodell mit unvollständiger Hemmung etwas wahrscheinlicher. Als Beweis für eine unvollständige Hemmung kann dies aber nicht angesehen werden.

Auch bei zwei Hemmversuchen des hOAT3, in denen niedrige $\alpha$-KetoglutaratKonzentrationen eingesetzt worden waren, ergab das Rechenmodell eine unvollständige Hemmung. Wurden aber hohe $\alpha$-Ketoglutarat-Konzentrationen eingesetzt, konnten 
experimentell vollständige Hemmungen beobachtet werden. Dies deutet darauf hin, dass die scheinbar unvollständigen Hemmungen eher Auswerte-Artefakte sind.

Außerdem ist zu fragen, ob man bei den hohen $\mathrm{IC}_{50}$-Werten für die Hemmung des hOAT3 durch Maleat und Succinat von 141 bzw. $56 \mathrm{mM}$ überhaupt von einer realen Hemmung sprechen kann, oder ob das nicht nur rein rechnerische Hemmungen sind.

Bei den Dicarboxylaten mit geringer Affinität zu hOAT1 und hOAT3 wurden in den Hemmversuchen relativ hohe Dicarboxylat-Konzentrationen bis $50 \mathrm{mM}$ eingesetzt. Um die Osmolarität des Transportpuffers konstant zu halten, wurde entsprechend die $\mathrm{NaCl}$ Konzentration im Puffer verringert. Der Transport von organischen Anionen durch OAT1 (HOSOYAMADA et al. 1999, RACE et al. 1999, WOLFF et al. 2003) und OAT3 (UEO et al. 2007) wird durch die Anwesenheit von $\mathrm{Cl}^{-}$-Ionen im Transportpuffer stimuliert. RIZWAN (2006) hat in seiner Dissertation (Göttingen 2006: The importance of charged amino acids in the human organic anion transporter 1) gezeigt, dass die PAH-Aufnahme durch hOAT1 bei einer Verringerung der $\mathrm{Cl}^{-}$-Konzentration im Transportmedium von $140 \mathrm{mM}$, etwa der normalen Konzentration im Ringer-Medium, auf $90 \mathrm{mM}$ die PAH-Aufnahme um etwa 30\% erniedrigt. Die erniedrigte $\mathrm{Cl}^{-}$-Konzentration kann in unseren Versuchen aber nicht die Ursache der beobachteten Hemmung sein, da die Hemmung immer berechnet wurde gegenüber der Aufnahme in einem Transportpuffer, der anstelle der Dicarboxylate bei hohen Konzentration Na-Glukonat enthielt, und damit genau so viel $\mathrm{Cl}^{-}$.

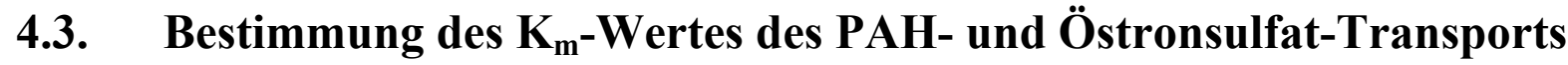

Der $\mathrm{K}_{\mathrm{m}}$-Wert entspricht der Substratkonzentration, bei der die Transportgeschwindigkeit halbmaximal ist, da die Hälfte der Bindungsstellen der Transporter mit Substrat besetzt sind. Er ist das Verhältnis der Geschwindigkeitskonstanten $K_{m}=\frac{k_{-1}+k_{2}}{k_{1}}$, wobei $k_{1}$ die Geschwindigkeitskonstante der Bildung des Transporter-Substrat-Komplexes, $\mathrm{k}_{-1}$ die Geschwindigkeitskonstante des Zerfalls des Komplexes zurück zum freien Transporter und Substrat und $\mathrm{k}_{2}$ die Geschwindigkeitskonstante des Transports des Substrats über die Zellmembran darstellt. Wenn $\mathrm{k}_{-1}$ viel größer ist als $\mathrm{k}_{2}$, dann ist der $\mathrm{K}_{\mathrm{m}}$-Wert das Verhältnis $\frac{\mathrm{k}_{-1}}{\mathrm{k}_{1}}$ und damit die Dissoziationskonstante des Transporter-Substrat-Komplexes. Ein niedriger $\mathrm{K}_{\mathrm{m}}$-Wert bedeutet dann also eine hohe Affinität des Substrats zum Transporter (COX und NELSON 2001).

Der $\mathrm{K}_{\mathrm{m}}$-Wert des PAH- und des Östronsulfat-Transports wurde in dieser Arbeit mit Hilfe der Michaelis-Menten-Gleichung $\quad \mathrm{v}=\frac{\mathrm{v}_{\max } \cdot[\mathrm{S}]}{\mathrm{K}_{\mathrm{m}}+[\mathrm{S}]} \quad$ bestimmt, indem die Substrataufnahme bei steigenden Substratkonzentrationen gemessen wurde. Praktisch gibt man dabei dem 
radioaktiv markierten Substrat steigende Mengen an nicht radioaktiv markiertem Substrat hinzu und rechnet den Transport von markiertem Substrat in den Transport von markiertem und nicht markiertem Substrat um. So wurde in dieser Arbeit der $\mathrm{K}_{\mathrm{m}}$-Wert des PAHTransports durch den hOAT1 zu 4,8 $\pm 1,2 \mu \mathrm{M}$ und der $\mathrm{K}_{\mathrm{m}}$-Wert des Östronsulfat-Transports durch den hOAT3 zu 2,7 $\pm 0,6 \mu \mathrm{M}$ bestimmt.

Diese Auswerte-Methode hat den Nachteil, dass bei hohen Substrat-Konzentrationen nur noch relativ wenig radioaktiv markiertes Substrat in die Zellen aufgenommen wird, weil sein Transport durch das nicht markierte Substrat gehemmt wird. Den gemessenen kleinen Mengen an aufgenommenem markiertem Substrat entsprechen aber hohe Mengen an aufgenommenem Gesamt-Substrat. Da die gemessenen Werte also sehr gering sind, werden die berechneten Mengen an Gesamt-Substrat bei hohen Substratkonzentrationen daher relativ ungenau.

Bei einer anderen Auswertemethode wird das zugefügte nicht markierte Substrat als Inhibitor angesehen, der die Aufnahme des markierten Substrats hemmt. Man berechnet also nur die Aufnahme des markierten Substrats, nicht des gesamten Substrats. Die Berechnung des $\mathrm{K}_{\mathrm{m}}{ }^{-}$ Wertes erfolgt hier über die Gleichung für kompetitive Hemmung: $v=\frac{v_{\max }[\mathrm{S}]}{\mathrm{K}_{\mathrm{m}}\left(1+\frac{[\mathrm{I}]}{\mathrm{K}_{i}}+[\mathrm{S}]\right.}$. Da in diesem Fall der Inhibitor chemisch identisch mit dem Substrat ist, gilt $\mathrm{K}_{\mathrm{m}}={ }^{\mathrm{K}_{\mathrm{i}}} \mathrm{K}_{\mathrm{i}}$, und die Gleichung vereinfacht sich $z u v=\frac{v_{\max }\left[\mathrm{S}^{*}\right]}{\mathrm{K}_{\mathrm{m}}+[\mathrm{S}]+\left[\mathrm{S}^{*}\right]}$, wobei $[\mathrm{S}]$ das nicht markierte Substrat und $\left[\mathrm{S}^{*}\right]$ das radioaktiv markierte Substrat ist.

Der nach dieser Methode berechnete $\mathrm{K}_{\mathrm{m}}$-Wert für den PAH-Transport lag mit 7,3 $\pm 1,9 \mu \mathrm{M}$ etwas oberhalb des Wertes, der mit der anderen Methode erhalten wurde. Der Wert für Östronsulfat-Transport war mit 2,8 $\pm 0,3 \mu \mathrm{M}$ identisch mit dem Wert, der nach der ersten Methode berechnet wurde.

In der Literatur werden $\mathrm{K}_{\mathrm{m}}$-Werte von 3,1 bis maximal 112,7 $\mu \mathrm{M}$ für den PAH-Transport durch hOAT1 berichtet. Die $\mathrm{K}_{\mathrm{m}}$-Werte für den Transport von Östronsulfat durch den hOAT3 schwanken mit 2,2 bis 21,2 $\mu \mathrm{M}$ nicht ganz so stark (BURCKHARDT G und BURCKHARDT $B C$ 2011). Die Ursache für die großen Unterschiede sind verschiedene Expressionssysteme und unterschiedliche experimentelle Bedingungen. Die von uns bestimmten $\mathrm{K}_{\mathrm{m}}$-Werte liegen im unteren Bereich der publizierten Werte.

\section{4. $K_{\mathrm{i}}$-Bestimmung und Hemmmechanismen}

Der $\mathrm{IC}_{50}$-Wert gibt an, bei welcher Inhibitor-Konzentration der Transport eines Substrates zu $50 \%$ gehemmt wird. Damit ist der $\mathrm{IC}_{50}$-Wert ein $\mathrm{Ma} ß$ für die Affinität des Inhibitors zum Transporter: Je kleiner der $\mathrm{IC}_{50}$-Wert, desto größer die Affinität des Inhibitors zum 
Ein objektiveres Maß für die Affinität eines Inhibitors zu einem Transporter ist die Hemmkonstante $\mathrm{K}_{\mathrm{i}}$. Der $\mathrm{K}_{\mathrm{i}}$-Wert entspricht der Dissoziationskonstante des Inhibitor-TransporterKomplexes (BISSWANGER 2000). Der $\mathrm{K}_{\mathrm{i}}$-Wert ist also unabhängig von der SubstratKonzentration. Nachteil des $\mathrm{K}_{\mathrm{i}}$-Wertes ist, dass er experimentell nur relativ aufwendig bestimmt werden kann. Nach DIXON (1953) werden $\mathrm{K}_{\mathrm{i}}$-Werte bestimmt, indem man die Hemmung des Transports durch steigende Hemmstoff-Konzentrationen bei zwei verschiedenen Substrat-Konzentrationen bestimmt. Trägt man dann die reziproke Transportrate, also die reziproke Substrataufnahme, gegen die Hemmstoff-Konzentration auf, entstehen zwei Geraden. Diese beiden Geraden schneiden sich in einem Punkt bei der Inhibitorkonzentration, die dem negativen $\mathrm{K}_{\mathrm{i}}$-Wert entspricht.

Gegenüber den $\mathrm{IC}_{50}$-Bestimmungen müssen bei den $\mathrm{K}_{\mathrm{i}}$-Bestimmungen also doppelt so viel Messungen durchgeführt werden. Ein weiterer Nachteil ist, dass bei hohen HemmstoffKonzentrationen die Transportraten nur noch sehr gering sind, die reziproken Transportraten, die im Dixon-Plot aufgetragen werden, daher sehr groß werden. Ungenauigkeiten bei der Messung der geringen aufgenommenen Substratmengen bei hohen HemmstoffKonzentrationen haben daher einen relativ großen Einfluss auf die Lage und Steigung der Geraden im Dixon-Plot und damit auf die Bestimmung des $\mathrm{K}_{\mathrm{i}}$-Wertes.

Daher wurden nur für die beiden Dicarboxylate mit den höchsten Affinitäten zusätzlich zu den $\mathrm{IC}_{50}$-Werten auch die $\mathrm{K}_{\mathrm{i}}$-Werte bestimmt. Wie erwartet waren die $\mathrm{K}_{\mathrm{i}}$-Werte für Glutarat und $\alpha$-Ketoglutarat gegenüber hOAT1 und auch gegenüber hOAT3 jeweils etwas niedriger als die $\mathrm{IC}_{50}$-Werte (Tab. 3).

Die $\mathrm{K}_{\mathrm{i}}$-Werte können aus den $\mathrm{IC}_{50}$-Werten berechnet werden, wenn man den Hemmmechanismus kennt.

Man unterscheidet verschiedene Hemmtypen, je nachdem wo der Hemmstoff am Transporter bindet, und ob sich die Bindung von Substrat und Hemmstoff gegenseitig beeinflussen (BISSWANGER 2000, BERG et al. 2007).

Bei der kompetitiven Hemmung bindet der Hemmstoff an dieselbe Stelle des Transporters an die auch das Substrat bindet. Das heißt, Hemmstoff und Substrat konkurrieren um dieselbe 
Bindungsstelle. Wenn der Hemmstoff bindet, kann nicht gleichzeitig das Substrat binden und kann daher nicht transportiert werden.

Bei der nicht-kompetitiven Hemmung bindet der Hemmstoff an eine andere Stelle. Die Bindung von Hemmstoff und Substrat beeinflussen sich nicht gegenseitig, sie erfolgen völlig unabhängig voneinander. Der Hemmstoff kann sowohl an den Transporter, als auch an den Transporter-Substrat-Komplex binden. Durch die Bindung des Hemmstoffs wird der Transport des Substrats verhindert.

Bei der unkompetitiven Hemmung bindet der Hemmstoff nur an den Transporter-SubstratKomplex. Seine Bindungsstelle wird erst durch die Bindung des Substrats an den Transporter geschaffen. Der Hemmstoff bindet hier also ebenfalls an eine andere Stelle als das Substrat. Die unkompetitive Hemmung kommt wie die nicht-kompetitive Hemmung eher selten vor.

Daneben gibt es noch die gemischte Hemmung, die wieder häufiger vorkommt. Auch hier bindet der Hemmstoff an eine andere Stelle als das Substrat. Wie bei der nicht-kompetitiven Hemmung kann der Hemmstoff an den freien Transporter und an den Transporter-SubstratKomplex binden, aber im Unterschied zur nicht-kompetitiven Hemmung mit unterschiedlicher Affinität. Die Bindung des Substrats beeinflusst die nachfolgende Bindung des Hemmstoffs und umgekehrt. Meistens werden die Bindungen gegenseitig gestört, sie können sich aber auch gegenseitig begünstigen.

Welcher Hemmtyp vorliegt, kann im Prinzip durch den Dixon-Plot festgestellt werden. Bei einer kompetitiven Hemmung schneiden sich die beiden Geraden im zweiten Quadranten, bei der nicht-kompetitiven Hemmung liegt der Schnittpunkt auf der x-Achse. Im Falle einer unkompetitiven Hemmung schneiden die Geraden sich nicht, sondern man erhält zwei parallele Geraden. Wenn eine gemischte Hemmung vorliegt, treffen sich die Geraden im zweiten Quadranten, wenn sich Substrat und Hemmstoff gegenseitig behindern, und im dritten Quadranten, wenn sie sich gegenseitig unterstützen.

Bei den $\mathrm{K}_{\mathrm{i}}$-Bestimmungen der Hemmung von hOAT1 und hOAT3 durch Glutarat und $\alpha$ Ketoglutarat in dieser Arbeit trafen sich die Geraden jeweils im zweiten Quadranten (Abb. 22, 23, 35, 36). Somit liegt eine kompetitive oder gemischte Hemmung vor.

Theoretisch kann man zwischen diesen beiden Möglichkeiten durch eine Auftragung der Werte nach Cornish-Bowden (CORNISH-BOWDEN 1974) unterscheiden. Wenn man das Verhältnis Substratkonzentration zu Transportrate [S]/v, aufträgt gegen die Hemmstoffkonzentration [I], sollte man bei einer kompetitiven Hemmung zwei parallele Geraden erhalten und bei einer gemischten Hemmung einen Schnittpunkt der beiden Geraden links von der $\mathrm{y}$-Achse. Leider ergab die Auftragung unserer Werte nach diesem Schema kein eindeutiges Ergebnis, so dass also auch mit dieser Methode nicht unterschieden werden kann, 
ob eine kompetitive oder gemischte Hemmung durch die Dicarboxylate vorliegt. Dabei ist anzumerken, dass es in der Praxis auch schwierig sein dürfte, zwei Geraden zu erhalten, die tatsächlich parallel sind.

Eine weitere Möglichkeit, um zwischen verschiedenen Hemmtypen unterscheiden zu können, ist die Messung der Hemmung bei verschiedenen Substratkonzentrationen mit mindestens zwei verschiedenen Hemmstoffkonzentrationen. Bei einer kompetitiven Hemmung sollte in Anwesenheit des Hemmstoffs $\mathrm{v}_{\max }$ im Vergleich zu einer Messung ohne Hemmstoff nicht verändert sein, während der $\mathrm{K}_{\mathrm{m}}$-Wert größer werden sollte. Bei einer gemischten Hemmung wird $\mathrm{v}_{\max }$ kleiner, während der $\mathrm{K}_{\mathrm{m}}$-Wert größer oder kleiner wird.

In dieser Arbeit wurde in einem Versuch die Aufnahme von PAH durch den hOAT1 (Abb. 37) und von Östronsulfat durch den hOAT3 (Abb. 40) in An- und Abwesenheit von $\alpha$ Ketoglutarat gemessen. In Anwesenheit von $\alpha$-Ketoglutarat erhöhte sich der $\mathrm{K}_{\mathrm{m}}$-Wert für den PAH-Transport durch hOAT1 von 3,6 $\pm 0,6 \mu \mathrm{M}$ auf 17,4 $\pm 3,0 \mu \mathrm{M}$, während sich $\mathrm{v}_{\max }$ nicht signifikant änderte $(9,3 \pm 0,4 \mathrm{pmol} / \mathrm{min}$ gegenüber $9,2 \pm 0,9 \mathrm{pmol} / \mathrm{min})$. Ähnlich verhielt sich der Östronsulfat-Transport durch den hOAT3. Der $\mathrm{K}_{\mathrm{m}}$-Wert stieg in Anwesenheit von $\alpha$ Ketoglutarat von 3,8 $\pm 1,1 \mu \mathrm{M}$ auf $11,9 \pm 3,1 \mu \mathrm{M}$. Dagegen waren die $\mathrm{v}_{\max }$-Werte in An- und Abwesenheit von $\alpha$-Ketoglutarat wieder nicht signifikant verschieden $(24910 \pm 3986$ $\mathrm{fmol} / \mathrm{min}$ gegenüber $20220 \pm 2216 \mathrm{fmol} / \mathrm{min}$ ). Dies deutet daraufhin, dass die Hemmung sowohl des hOAT1 als auch des hOAT3 zumindest durch $\alpha$-Ketoglutarat kompetitiv ist.

Auch durch die Auftragung der Werte nach der Methode von Lineweaver-Burk, bei der die reziproke Transportrate $(1 / \mathrm{v})$ gegen die reziproke Substratkonzentration (1/[S]) aufgetragen wird, und nach der Methode von Eadie-Hofstee, bei der die Transportrate v gegen v/[S] aufgetragen wird, kann zwischen verschiedenen Hemmtypen unterschieden werden. Wenn z.B. ein kompetitiver Hemmtyp vorliegt, sollten sich die beiden Geraden sowohl bei der Lineweaver-Burk-Auftragung als auch bei der Eadie-Hofstee-Auftragung auf der y-Achse treffen. Bei anderen Hemmtypen findet man andere Schnittpunkte oder parallele Geraden (BISSWANGER 2000). Die Abb. 38, 39 und 41, 42 zeigen, dass sich sowohl bei der Hemmung des hOAT1 als auch bei der Hemmung des hOAT3 durch $\alpha$-Ketoglutarat zumindest die 95\%-Vertrauensintervalle der Regressionsgeraden auf der y-Achse schneiden.

In einem letzten Ansatz, um zwischen den verschiedenen möglichen Hemmmechanismen der Dicarboxylate zu differenzieren, wurden bei den Messungen der Hemmung von hOAT1 und hOAT3 durch $\alpha$-Ketoglutarat die verschiedenen Hemmmodelle mit einem Computerprogramm (SYSTAT SOFTWARE 2008 - Sigma Plot 11 Enzymkinetik Modul) den Messwerten angepasst und statistisch ausgewertet. Das Programm bestimmt dann eine Rangordnung, welches Hemmmodell am besten passt. Ein Kriterium für die Rangordnung ist 
z.B. der Korrelationskoeffizient, ein anderes die Standardabweichungen der Residuen, also der Differenzen zwischen den gemessenen Werten und den vorausgesagten. Das wichtigste Kriterium ist aber Akaikes Informationskriterium (AKAIKE 1973), in das vor allem die Varianzen der Residuen eingehen. Außerdem berücksichtigt das Akaike Informationskriterium auch, wie viele Parameter das Modell benötigt. Bevorzugt werden Modelle mit wenigen Parametern. Der Wert von Akaikes Informationskriterium sollte daher möglichst klein sein. Für die Messungen der hOAT1- und hOAT3-Hemmung durch $\alpha$ Ketoglutarat, die in Abb. 37 und 40 dargestellt sind, hat das Computerprogramm jeweils für das kompetitive Hemmmodell den kleinsten Wert für Akaikes Informationskriterium berechnet.

Zusammenfassend gibt es also mehrere Hinweise darauf, dass die Hemmung des organischen Anionen Transports durch hOAT1 und hOAT3 zumindest durch das Dicarboxylat $\alpha-$ Ketoglutarat kompetitiv ist, $\alpha$-Ketoglutarat also an dieselbe Bindungsstelle bindet wie PAH bzw. Östronsulfat. Dies ist auch nicht verwunderlich, da $\alpha$-Ketoglutarat nicht nur den Transport durch hOAT1 und hOAT3 hemmt, sondern zumindest durch hOAT1 (LU et al. 1999) auch selbst transportiert wird. Die anderen in dieser Arbeit getesteten Dicarboxylate binden wahrscheinlich an die selbe Bindungsstelle wie $\alpha$-Ketoglutarat. Für Glutarat ist nachgewiesen worden, dass es sowohl durch hOAT1 (RIZWAN et al. 2007) als auch durch hOAT3 (BAKHIYA et al. 2003) transportiert wird. Allerdings ist die Tatsache, dass PAH bzw. Östronsulfat und die Dicarboxylate nicht nur ihre Bindung gegenseitig beeinflussen, sondern auch transportiert werden, natürlich kein Beweis, dass es nur eine Bindungsstelle gibt. Für andere Transporter wie den humanen Organischen Kationen Transporter 1 (hOCT1) gibt es z.B. Hinweise, dass es in der Bindungstasche zwei verschiedene Bindungsstellen mit unterschiedlichen Affinitäten zu organischen Kationen gibt, von denen aus die Kationen transportiert werden oder den Transport hemmen können (GORBUNOV et al. 2008). Ein solcher Mechanismus würde eine gemischte Hemmung bewirken und könnte auch eine partielle Hemmung erklären.

Wie kann man nun die $\mathrm{K}_{\mathrm{i}}$-Werte der Dicarboxylate aus den gemessenen $\mathrm{IC}_{50}$-Werten berechnen, und wie unterscheiden sich die $\mathrm{K}_{\mathrm{i}}$-Werte der Dicarboxylate von den $\mathrm{IC}_{50}$-Werten? Das hängt, wie oben schon erwähnt, vom Hemmtyp der Dicarboxylate ab (CHENG und PRUSOFF 1973). Bei kompetitiver Hemmung gibt es folgenden Zusammenhang zwischen $\mathrm{IC}_{50}$-Wert und $\mathrm{K}_{\mathrm{i}}$-Wert: $\mathrm{IC}_{50}=\mathrm{K}_{\mathrm{i}} \cdot\left(1+\frac{[\mathrm{S}]}{\mathrm{K}_{\mathrm{m}}}\right)$. Wenn also die Substratkonzentration deutlich kleiner als der $\mathrm{K}_{\mathrm{m}}$-Wert ist, dann ist der $\mathrm{IC}_{50}$-Wert gleich dem $\mathrm{K}_{\mathrm{i}}$-Wert. Der $\mathrm{K}_{\mathrm{m}}$-Wert für den Transport von PAH durch den hOAT1 wurde in dieser Arbeit zu 7,3 $\mu \mathrm{M}$ bestimmt. Die PAH- 
Konzentration bei den $\mathrm{IC}_{50}$-Bestimmungen war $1,1 \mu \mathrm{M}$. Der $\mathrm{IC}_{50}$-Wert ist also unter diesen Bedingungen 1,15mal größer als der $\mathrm{K}_{\mathrm{i}}$-Wert. Die Abweichung beträgt damit lediglich $15 \%$. Für den Transport von Östronsulfat durch hOAT3 haben wir einen $\mathrm{K}_{\mathrm{m}}$-Wert von 2,8 $\mu \mathrm{M}$ ermittelt, die Östronsulfat-Konzentration betrug in den Hemmversuchen $10 \mathrm{nM}$. Damit ist der $\mathrm{K}_{\mathrm{i}}$-Wert für die Hemmung des Östronsulfat-Transportes unter diesen Bedingungen lediglich um den Faktor 1,004 größer als der $\mathrm{IC}_{50}$-Wert. Das heißt, wenn das Modell der kompetitiven Hemmung zutrifft, dann unterscheiden sich die von uns bestimmten $\mathrm{IC}_{50}$-Werte kaum von den $\mathrm{K}_{\mathrm{i}}$-Werten.

Bei nicht-kompetitiver Hemmung sind $\mathrm{IC}_{50}$-Werte und $\mathrm{K}_{\mathrm{i}}$-Werte identisch, dann ist $\mathrm{IC}_{50}=\mathrm{K}_{\mathrm{i}}$ (CHENG und PRUSOFF 1973). Komplizierter ist die Beziehung zwischen $\mathrm{IC}_{50}$ und $\mathrm{K}_{\mathrm{i}}$, wenn ein gemischter Hemmtyp vorliegt, da wir hier zwei verschiedene Inhibitionskonstanten, $\mathrm{K}_{\mathrm{EI}}$ und $\mathrm{K}_{\mathrm{ESI}}$ haben: $\mathrm{IC}_{50}=\frac{\mathrm{K}_{\mathrm{m}}+[\mathrm{S}]}{\frac{\mathrm{K}_{\mathrm{m}}}{\mathrm{K}_{\mathrm{i}}^{\mathrm{II}}+\frac{[\mathrm{S}]}{\mathrm{K}_{\mathrm{i}}^{\mathrm{ESI}}}} \text {. }}$

\subsection{IC I0 -Werte der Hemmung von hOAT1 und hOAT3 durch die Dicarboxylate}

In dieser Arbeit sind die $\mathrm{IC}_{50}$-Werte verschiedener Dicarboxylate gegenüber dem PAH- und Östronsulfat-Transport in Zellen gemessen worden, die stabil mit den humanen OrganischeAnionen-Transportern hOAT1 bzw. hOAT3 transfiziert waren. Diese Versuche wurden alle unter genau denselben Bedingungen durchgeführt, um so die Affinität der verschiedenen Dicarboxylate gegenüber den Transportern vergleichen zu können. In der Literatur ist dagegen oft nur beschrieben worden, ob ein Dicarboxylat bei einer bestimmten Konzentration hemmt oder nicht. Wenn $\mathrm{IC}_{50}$-Werte der Hemmung durch Dicarboxylate bestimmt wurden, dann sind sie an verschiedenen Systemen, verschiedenen Spezies und unter verschiedenen Bedingungen durchgeführt worden, so dass sie nur schwer vergleichbar sind.

Die in dieser Arbeit getesteten Dicarboxylate haben zwei ionisierbare Carboxylgruppen. Die $\mathrm{pK}_{\mathrm{a}}$-Werte der getesteten Dicarboxylate liegen für die Dissoziation der ersten Carboxylgruppe zwischen 1,8 und 5,8 (s. Tab. 1). Die Transportexperimente wurden in einem Puffer mit einem $\mathrm{pH}$ von 7,4 durchgeführt. Das heißt während der Transportexperimente war die erste Carboxylgruppe zwischen $97,5 \%$ und $99,9 \%$ dissoziiert. Die $\mathrm{pK}_{\mathrm{a}}$-Werte für die zweite Carboxylgruppe werden mit 3,9 bis maximal 6,4 angegeben. Damit war auch die zweite Carboxylgruppe mindestens zu 90\% dissoziiert. Man kann also davon ausgehen, dass in unseren Transportexperimenten die Dicarbonsäuren zwischen 90 - 99\% als zweifach ionisierte Anionen vorlagen. Die unterschiedlichen Hemmaktivitäten der Dicarboxylate 
beruhen also tatsächlich auf Unterschieden in ihrer Affinität zum Transporter und nicht auf unterschiedliche Dissoziationsgrade der Carboxylgruppen.

Abb. 43 zeigt, dass in unseren Versuchen die Hemmstärke der Dicarboxylate gegenüber hOAT1 mit steigender Länge zunächst ansteigt. Das C3-Dicarboxylat Malonat hemmte nicht, die gesättigten und ungesättigten $\mathrm{C} 4$-Dicarboxylate hemmten nur schwach mit $\mathrm{IC}_{50}$-Werten im millimolaren Bereich. Ein deutlicher Sprung zu höheren Affinitäten war dann bei den beiden C5-Dicarboxylaten Glutarat und $\alpha$-Ketoglutarat zu beobachten. Sie waren die potentesten Hemmer mit einer $\mathrm{IC}_{50}$ von 3,3 bzw. 4,7 $\mu \mathrm{M}$. Mit dem weiteren Anstieg der CAtom-Anzahl (C6-Adipat, C7-Pimelat und C8-Suberat) nahm die IC $_{50}$ nur moderat von 6,2 auf 19,3 $\mu \mathrm{M}$ zu. Aus diesem Schema fällt lediglich Citrat heraus. Citrat kann man formal als C5-Dicarboxylat ansehen mit einer zusätzlichen Hydroxyl- und Carboxylgruppe. Als C5Dicarboxylat sollte Citrat eine niedrige $\mathrm{IC}_{50}$ haben, tatsächlich wurde die $\mathrm{IC}_{50}$ aber mit 5,5 $\mathrm{mM}$ bestimmt. Offensichtlich stört hier die zusätzliche negative Ladung der dritten Carboxylgruppe.

Wie Abb. 43 zeigt, ändert sich die Affinität der getesteten Dicarboxylate gegenüber hOAT3 mit der gleichen Tendenz. Auch hier hemmen die C3- und C4-Dicarboxylate nicht oder sehr schlecht, während die C5-Dicarboxylate die besten Hemmer sind. Lediglich Suberat fällt heraus, es hat eine etwas größere Affinität als Pimelat zum Transporter.

In Abb. 44 sind die $\mathrm{IC}_{50}$-Werte der Dicarboxylate gegenüber hOAT1 aufgetragen gegen die $\mathrm{IC}_{50}$-Werte gegenüber hOAT3. Man sieht, dass die Dicarboxylat-Selektivität von hOAT1 und hOAT3 praktisch gleich ist. Der wesentliche Unterschied aber ist, dass die Affinitäten der Dicarboxylate gegenüber hOAT3 immer jeweils etwa 13-mal geringer ist als gegenüber hOAT1.

Die Hemmwirkung der Dicarboxylate, die in der vorliegenden Arbeit bestimmt wurde, ist vergleichbar mit den allerdings meist nur qualitativen Werten aus der Literatur, die in anderen Systemen und Spezies gemessen wurden.

Die ersten Messungen zur Hemmwirkung der Dicarboxylate auf den Transport von organischen Anionen führten ULLRICH et al. 1987b durch. Sie haben die Aufnahme von PAH in in-situ-Experimenten mit Rattennieren gemessen. Sie beschreiben ein sogenanntes „PAH-Transport-System“, das PAH über die basolaterale Membran in die Zellen der proximalen Tubuli mit einer $\mathrm{K}_{\mathrm{m}}$ von $80 \mu \mathrm{M}$ aufnimmt (ULLRICH et al. 1987a). Für die Hemmung dieses Systems durch Dicarboxylate hatten sie folgende $\mathrm{K}_{\mathrm{i}}$-Werte bestimmt: Malonat und Maleat: keine Hemmung, Fumarat: 0,92 mM; Succinat: 1,35 mM, Glutarat: 0,05 $\mathrm{mM}, \alpha$-Ketoglutarat: 0,03 mM, Citrat: 3,5 mM, Adipat: 0,14 mM, Pimelat: 0,35 mM, Suberat: 
0,35 mM. (ULLRICH et al. 1987b). Das ist die gleiche Reihenfolge, die auch wir für die klonierten humanen Transporter bestimmt haben. Absolut sind die Werte höher als von uns für den Transport durch hOAT1 gemessen (außer Succinat), und liegen eher im Bereich für den Transport durch hOAT3.

Mittlerweile weiß man, dass PAH in den proximalen Tubuli der Nieren von mindestens zwei Systemen, OAT1 und OAT3, über die basolaterale Membran transportiert wird. Der $\mathrm{K}_{\mathrm{m}}$-Wert für den PAH-Transport durch den humanen OAT1 wurde in der vorliegenden Arbeit zu 7,3 $\mu \mathrm{M}$ bestimmt, der $\mathrm{K}_{\mathrm{m}}$-Wert für den PAH-Transport durch hOAT3 wurde an Oozyten zu 87,3 $\mu \mathrm{M}$ bestimmt (CHA et al. 2001). Dies deutet daraufhin, dass bei den in-situ-Untersuchungen von ULLRICH et al. (1987a/b) eher der PAH-Transport durch OAT3 und weniger durch OAT1 gemessen wurde.

Ähnliche Ergebnisse wie bei den Untersuchungen an der Rattenniere in situ wurden von SHIMADA et al. (1987) erhalten, die den Einfluss von Dicarboxylaten auf die PAHAufnahme in basolaterale Membranvesikel getestet haben, die aus der Rattenniere isoliert worden waren. Oxalat (C2), Malonat und Succinat hemmten nicht bzw. kaum. Dagegen wurde in Anwesenheit von $5 \mathrm{mM}$ Glutarat und Adipat eine deutliche Hemmung der PAHAufnahme beobachtet.

Auch die Hemmwirkung von Dicarboxylaten auf den endogenen PAH-Transport in OKZellen ist untersucht worden (NAGAI et al. 1995). Dort hemmten in einer Konzentration von $1 \mathrm{mM}$ die C3- und C4-Dicarboxylate sehr schlecht. Am besten hemmten C5- und C6Dicarboxylate. Während die Hemmung von Pimelat (C7) relativ schlecht war, nahm die Potenz mit steigender Länge bis $\mathrm{C} 10$ wieder zu. $\mathrm{IC}_{50}$-Werte wurden nicht bestimmt.

Untersuchungen mit Dicarboxylaten am klonierten OAT1 führten UWAI et al. (1998) durch. Nach Expression des Ratten-OAT1 in Oozyten wurden der PAH durch C3- und C4Dicarboxylate kaum gehemmt, während C5- bis C10-Dicarboxylate bei einer Konzentration von $1 \mathrm{mM}$ eine deutliche Hemmung zeigten.

Bei Messungen der Hemmung des PAH-Transports durch den Maus-OAT1, exprimiert in Oozyten, zeigte Fumarat die geringste Affinität $\left(\mathrm{K}_{\mathrm{i}}=610 \mu \mathrm{M}\right)$ der getesteten Dicarboxylate, während die Affinität von Glutarat $\left(\mathrm{K}_{\mathrm{i}}=6,7 \mu \mathrm{M}\right)$, Adipat $\left(\mathrm{K}_{\mathrm{i}}=0,4 \mu \mathrm{M}\right)$ und auch Suberat $\left(\mathrm{K}_{\mathrm{i}}\right.$ $=34,1 \mu \mathrm{M}$ ) deutlich höher war (KALER et al. 2007).

Die Wirkungen von Dicarboxylaten auf den Östronsulfat-Transport durch den klonierten Ratten-OAT3 nach Expression in Oozyten haben ANZAI et al. (2005) getestet. Sie beobachteten keine bzw. nur sehr geringe Hemmung durch die C2- bis C4-Dicarboxylate, dagegen eine deutliche Hemmung durch C5- bis C9-Dicarboxylate. Getestet wurde nur eine Dicarboxylatkonzentration von $1 \mathrm{mM}$. 


\subsection{Die Bindungstasche der Dicarboxylate in den Organische-Anionen- Transportern}

Über die Bindungstasche der Transporter OAT1 und OAT3 ist bisher wenig bekannt. Nach den Ergebnissen der vorliegenden Arbeit sollte die Bindungstasche von OAT1 strukturell sehr ähnlich der von OAT3 sein, da die Dicarboxylat-Selektivität bei beiden Transportern gleich ist. Allerdings sind die Affinitäten aller Dicarboxylate für hOAT3 deutlich kleiner als für hOAT1. Dies deutet daraufhin, dass die Bindungstasche für die Dicarboxylate im OAT3 schlechter zugänglich ist als im OAT1.

Die Bindungstasche hat wahrscheinlich zwei Aminosäuren mit positiven Ladungen, an die die beiden Carboxylgruppen der Dicarboxylate binden. Für eine effektive Bindung ist der Abstand der beiden positiven Ladungen offensichtlich wichtig, wie die Abhängigkeit der $\mathrm{IC}_{50}$-Werte von der Moleküllänge und damit vom Abstand der negativen Ladung der Carboxylgruppen zeigt. Der niedrigste $\mathrm{IC}_{50}$-Wert und damit die beste Affinität wurde in dieser Arbeit für Glutarat bestimmt ( $\mathrm{IC}_{50}$ hOAT1: 3,3 $\left.\mu \mathrm{M}\right)$. In Glutarat sind nach unseren Berechnungen die Zentren der negativen Ladungen in einem Abstand von 639 pm (s. Tab. 2). Der Abstand der positiven Ladungen in der Bindungstasche sollte also etwas größer als diese 639 pm sein. Sobald die Dicarboxylate kleiner werden, nimmt die Affinität rapide ab. Für das C4-Dicarboxylat Succinat mit einem Ladungsabstand von 514 pm erhöht sich der $\mathrm{IC}_{50}$-Wert gegenüber hOAT1 um mehr als das Tausendfache $(4825 \mu \mathrm{M})$. Das ungesättigte und transkonfigurierte C4-Dicarboxylat Fumarat, bei dem der Ladungsabstand nach unseren Berechnungen mit 523 pm etwas größer sein sollte als im Succinat, hat auch eine etwas größere Affinität $(1733 \mu \mathrm{M})$, während das cis-konfigurierte C4-Dicarboxylat Maleat mit einem größeren Ladungsabstand $(406 \mathrm{pm})$ auch einen deutlich höheren $\mathrm{IC}_{50}$-Wert hat (für hOAT1: $12950 \mu \mathrm{M})$. Wenn der Ladungsabstand dann noch kleiner wird wie im Malonat (383 pm), scheint praktisch keine effektive Bindung mehr möglich zu sein.

Auf der anderen Seite, in Richtung größerem Abstand der Ladungen, sind die Auswirkungen auf die Bindungsfähigkeit nicht so ausgeprägt. Adipat mit einem Ladungsabstand von 764 pm hat im Vergleich zu Glutarat ebenfalls noch einen sehr geringen $\mathrm{IC}_{50}$-Wert. Selbst Suberat, in dem Ladungen einen Abstand von 1015 pm haben, hat noch eine hohe Affinität gegenüber hOAT1 und hOAT3 (IC 50 hOAT1: $19 \mu \mathrm{M}$ ). Der Grund warum größere Ladungsabstände nur einen relativ geringen Einfluss auf die Affinität der Dicarboxylate haben, liegt möglicherweise darin, dass die längeren Dicarboxylate flexibel sind und so gebogen werden können, dass ihre negativen Ladungen den richtigen Abstand haben. 
Ein weiterer Anteil der Bindung der Dicarboxylate durch die Transporter scheint über den mittleren Teil der Dicarboxylate zu erfolgen. Dieser sollte offensichtlich hydrophob oder zumindest nicht geladen sein. So haben Glutarat und Citrat nach unseren Berechnungen denselben Abstand der Carboxylgruppen, aber die Affinität von Glutarat ist deutlich höher $\left(\mathrm{IC}_{50} 3,3 \mu \mathrm{M}\right)$ als die von Citrat $\left(\mathrm{IC}_{50}: 5460 \mu \mathrm{M}\right)$. Der Grund ist wahrscheinlich, dass das mittlere Kohlenstoffatom von Glutarat zwei Wasserstoffatome gebunden hat, während dieses C-Atom im Citrat eine Hydroxygruppe und eine ionisierte, dritte Carboxylgruppe gebunden hat. Auch der allerdings nur geringfügige Unterschied in den $\mathrm{IC}_{50}$-Werten von Glutarat und $\alpha$ Ketoglutarat $(3,3$ gegenüber 4,7 $\mu \mathrm{M})$ könnte so erklärt werden, da $\alpha$-Ketoglutarat eine zusätzliche polare, elektronegative Carbonylgruppe statt einer Methylengruppe enthält.

$\mathrm{Ob}$ diese Bindungstasche nur die Dicarboxylate bindet oder auch die anderen organischen Anionen, die im Austausch gegen die Dicarboxylate von OAT1 und OAT3 transportiert werden, ist nicht sicher zu sagen. Wie oben schon diskutiert, ist die Hemmung des PAH- bzw. Östronsulfat-Transports durch die Dicarboxylate zwar wahrscheinlich, aber nicht sicher kompetitiv. Eine kompetitive Hemmung würde bedeuten, dass es nur eine Bindungstasche für die Dicarboxylate und die anderen organischen Anionen gibt. Es könnte bei den hier beschriebenen Hemmungen aber auch ein gemischter Hemmtyp vorliegen und damit hätten die Transporter zwei verschiedene Bindungstaschen.

ULLRICH et al. (1987a/b) haben bei ihren in-situ-Messungen der basolateralen PAHAufnahme in Ratten nicht nur die Hemmung durch einfache Dicarboxylate untersucht, wie schon oben beschrieben, sondern auch durch verschiedene Dicarboxylat-Derivate. Durch Veresterung einer der beiden Carboxylgruppe in Succinat und Glutarat nahm deren Affinität gegenüber dem „PAH-Transport-System“ deutlich ab. Bei Veresterung beider Carboxylgruppen haben ULLRICH et al. keine Hemmung mehr beobachtet. Bei Einführung einer Oxo-Gruppe in die 2-Position von Glutarat ( $\alpha$-Ketoglutarat) haben ULLRICH et al., im Gegensatz zu den Ergebnissen der vorliegenden Arbeit, eine geringfügige Affinitätssteigerung beobachtet. Dagegen war die Hemmpotenz nach Einführung anderer polarer Gruppen in Succinat und Glutarat, wie Hydroxy-, Amino- oder Carboxylgruppen, deutlich erniedrigt bzw. sogar nicht mehr vorhanden. Die Einführung von unpolaren Gruppen reduzierte die Hemmaktivität nicht. Die Autoren schlossen daraus, dass die Bindungsstelle zwei positiv geladene Amino- und Arginingruppen in einem Abstand von $750 \mathrm{pm}$ hat und dazwischen eine hydrophobe Bindungstasche. Die Substrate des „PAH-Transport-Systems“ sollten daher einen hydrophoben Kern und ein oder zwei elektronegative Gruppen haben, die elektrostatische oder Dipol-Wechselwirkungen eingehen können. 
Aus diesen und aus weiteren in-situ-Untersuchungen und genaueren Berechnungen der Ladungsverteilungen in den Molekülen zogen FRITZSCH et al. 1989 den Schluss, dass Dicarboxylate das „PAH-Transport-System“ am besten hemmen, wenn der Abstand der negativen Ladungen etwa 600 - 700 pm beträgt. Aber auch längere Dicarboxylate können hemmen. Hier erfolgt die Bindung dann möglicherweise über nur eine Carboxylgruppe und über die relativ große, hydrophobe Moleküldomäne zwischen den beiden Carboxylgruppen. Monovalente Anionen interagieren mit dem „PAH-Transport-System“, wenn ihre hydrophobe Domäne mindestens 400 pm groß ist. Dabei liegt die hydrophobe Bindungstasche wahrscheinlich nicht genau auf der Verbindungslinie zwischen den Ladungen, sondern etwas versetzt.

Durch verschiedene Mutagenese-Experimente ist versucht worden, die DicarboxylatBindungsstelle in den Organische-Anionen-Transportern genauer zu lokalisieren.

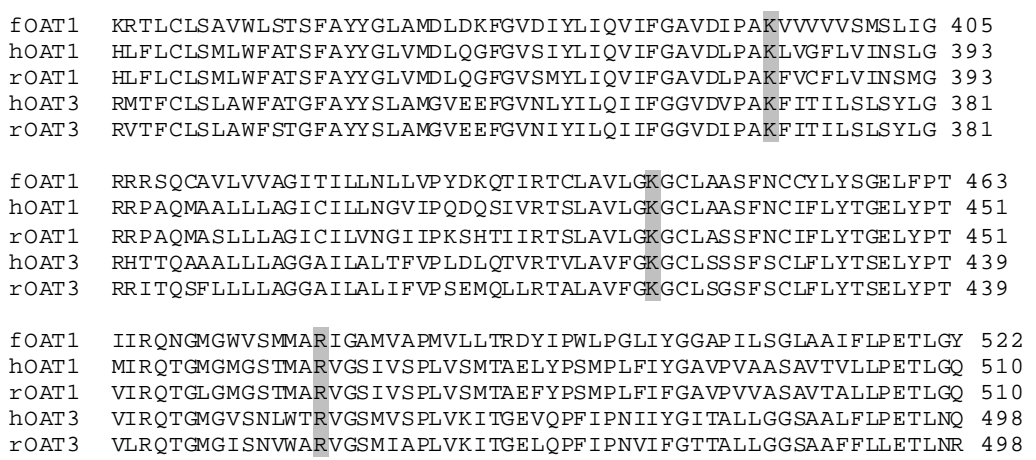

Abb. 46: Alignment von Teilsequenzen von OAT1 und OAT3 aus verschiedenen Spezies. Die im Text erwähnten Aminosäuren sind grau hinterlegt.

Mutation der positiven Aminosäuren Lys394 und Arg478 (s. Abb. 46) in den Transmembrandomänen 8 und 11 im OAT1 aus der Flunder zu der neutralen Aminosäure Ala394 bzw. sauren Aminosäure Asp478 verhindert sowohl die Stimulation des PAHTransports durch Glutarat als auch den Transport von Glutarat (WOLFF et al. 2001). Dies deutet daraufhin, dass die beiden positiven Aminosäuren Lys394 und Arg478 an der Dicarboxylat-Bindung beteiligt sind.

Ebenfalls 2001 zeigten FENG et al. durch Mutagenese-Experimente, dass die Aminosäuren Lys370 und Arg454 im OAT3 aus der Ratte, die den beiden mutierten Aminosäuren im fOAT1 entsprechen, ebenfalls am Transport organischer Anionen beteiligt sind.

RIZWAN et al. (2007) ließen die positive Aminosäure Arg466 in der 11. Transmembrandomäne des humanen OAT1, die der Aminosäure Arg478 im fOAT1 
entspricht, zu der negativen Aminosäure Asp466 mutieren und konnten keine Interaktion des mutierten hOAT1 mehr mit Glutarat in ihren Transportuntersuchungen beobachten.

In dem dreidimensionalen Strukturmodell des humanen OAT1, dass PERRY et al. (2006) aus der bekannten Kristallstruktur des bakteriellen Transporters GlpT entwickelt haben, hat hOAT1 eine große, nach außen sich öffnende Höhlung, die von den Transmembrandomänen 5, 7, 8, 10 und 11 gebildet wird, und die die Bindungstasche für die Substrate enthält. Die Aminosäure Arg466 ist an der Öffnung dieser Tasche lokalisiert. Ebenfalls in der Nähe der Bindungstasche ist eine weitere positive Aminosäure Lys431 lokalisiert. Mutation dieser Aminosäure zu Ala431 erniedrigte den PAH-Transport durch hOAT1. Dieser Aminosäure im hOAT1 entspricht die Aminosäure Lys419 im hOAT3. Mutation dieser Aminosäure verhindert den Transport von Glutarat (SRIMAROENG et al. 2008).

Nach den Mutagenese-Experimenten scheinen also unter anderem die drei folgenden positiven Aminosäuren an der Dicarboxylat-Bindung im hOAT1 und hOAT3 beteiligt zu sein: Lys382 (hOAT1) bzw. Lys370 (hOAT3) in der Transmembrandomäne 8, Lys431 (hOAT1) bzw. Lys419 (hOAT3) in der Transmembrandomäne 10, sowie Arg466 (hOAT1) bzw. Arg454 (hOAT3) in der Transmembrandomäne 11. Zumindest in den Aminosäuresequenzen der beiden Transporter sind die Aminosäuren im hOAT1 und hOAT3 gleich weit voneinander entfernt.

Die gleiche Dicarboxylat-Selektivität von hOAT1 und hOAT3, die in der vorliegenden Arbeit gefunden wurde, deutet darauf hin, dass die positiven Aminosäuren, die für die Bindung der negativ geladenen Carboxygruppen zuständig sind, auch in der dreidimensionalen Struktur der Transportproteine den gleichen Abstand haben. Der Grund für die allgemein geringere Affinität der Dicarboxylate gegenüber OAT3 im Vergleich zu OAT1, könnte darin liegen, dass die Substrate im OAT3 allgemein die Bindungsstelle schlechter erreichen, oder dass ihre hydrophoben Domänen speziell die Bindungsstelle für die hydrophoben Wechselwirkungen über Wasserstoff-Atome schlechter erreichen können, weil diese weiter weg ist von den positiven Ladungen, die gesamte Bindungstasche des OAT3 also größer ist. Dies könnte auch erklären, warum der OAT3 im Vergleich zum OAT1 voluminösere Substrate binden kann. 


\subsection{Physiologie des Dicarboxylat- und Organische-Anionen-Transports durch hOAT1 und hOAT3}

In der vorliegenden Arbeit wurden die höchsten Affinitäten gegenüber hOAT1 und hOAT3 für die Dicarboxylate Glutarat und $\alpha$-Ketoglutarat gemessen. Die Dicarboxylate werden wie oben beschrieben im Austausch gegen organische Anionen von den proximalen Tubuluszellen ins Interstitium abgegeben. Die organischen Anionen werden dann von den Zellen über die luminale Membran ins Tubuluslumen sezerniert und somit ausgeschieden. Die Dicarboxylate können über den $\mathrm{Na}^{+}$-Dicarboxylat-Austauscher NaDC3 in der basolateralen Membran wieder in die Zellen aufgenommen werden. In einer anderen Studie dieser Abteilung, die parallel zu der vorliegenden Arbeit durchgeführt wurde, wurde die Dicarboxylat-Selektivität des hNaDC3, ebenfalls stabil transfiziert in HEK293-Zellen, untersucht. Dabei zeigte sich, dass der hNaDC3 die höchsten Affinitäten gegenüber Succinat, Glutarat und $\alpha$-Ketoglutarat hat (KAUFHOLD et al. 2011).

Die idealen Kandidaten für den Austausch gegen organische Anionen durch OAT1 und OAT3 sind also Glutarat und $\alpha$-Ketoglutarat, da diese Dicarboxylate eine hohe Affinität gegenüber hOAT1 und hOAT3 sowie gegenüber hNaDC3 haben. Die Konzentrationen in den Tubuluszellen sind nicht bekannt, doch sollte zumindest $\alpha$-Ketoglutarat als Tricarbonsäurezyklus und Aminosäurestoffwechsel-Intermediat in ausreichend hohen Konzentrationen vorliegen. Da die Plasmakonzentration von $\alpha$-Ketoglutarat größer ist als die von Glutarat (s. unten) und außerdem die Affinität des NaDC3 gegenüber $\alpha$-Ketoglutarat größer ist als gegenüber Glutarat (KAUFHOLD et al. 2011), kann wahrscheinlich auch mehr $\alpha$-Ketoglutarat als Glutarat in die Zelle durch NaDC3 transportiert werden. Dies deutet daraufhin, dass physiologisch die Aufnahme organischer Anionen durch OAT1 und OAT3 eher über den Austausch mit $\alpha$-Ketoglutarat als über den Austausch mit Glutarat erfolgt.

Die Plasmakonzentration von $\alpha$-Ketoglutarat liegt beim Menschen bei $8,6 \mu \mathrm{M}$ (ROCCHICCIOLI et al. 1984), die von Glutarat bei 0,6 - 2,9 $\mu \mathrm{M}$ (BARIC et al. 1999). Bei diesen Konzentrationen sollte der OAT3 bei Weitem noch nicht durch extrazelluläres $\alpha$ Ketoglutarat und Glutarat gesättigt sein, da die $\mathrm{K}_{\mathrm{i}}$-Werte der beiden Dicarboxylate nach der vorliegenden Arbeit 92 bzw. $79 \mu \mathrm{M}$ betragen. Es sollten also noch genügend nicht besetzte OAT3-Transporter vorliegen, die andere organische Anionen in die Tubuluszellen aufnehmen können. Dagegen ist die extrazelluläre Konzentration von $\alpha$-Ketoglutarat etwa siebenmal größer als der von uns gemessene $\mathrm{K}_{\mathrm{i}}$-Wert $(1,2 \mu \mathrm{M})$ gegenüber OAT1. OAT1 sollte also weitgehend durch extrazelluläres $\alpha$-Ketoglutarat gesättigt sein und kann damit weniger andere organische Anionen in die Zelle aufnehmen. Möglicherweise spielt daher der OAT3 bei der renalen Ausscheidung von organischen Anionen, die von beiden Transportern in die Tubuluszellen aufgenommen werden können, eine größere Rolle als bisher angenommen. 


\section{Zusammenfassung}

In der vorliegenden Arbeit wurde die Interaktion verschiedener Dicarboxylate mit den Organische-Anionen-Transportern hOAT1 und hOAT3 untersucht. Dadurch sollten mehr Informationen über die Rolle der Dicarboxylate bei der renalen Sekretion von organischen Anionen durch die Organische-Anionen-Transporter und gleichzeitig über die Struktur der Bindungstasche der Organische-Anionen-Transporter für die Dicarboxylate gewonnen werden.

Dazu wurden die $\mathrm{IC}_{50}$-Werte der Hemmung des Transports der Modellsubstrate PAH bzw. Östronsulfat über die humanen Transporter hOAT1 und hOAT3 durch die Dicarboxylate bestimmt. Zur besseren Vergleichbarkeit wurden alle Untersuchungen unter den gleichen Bedingungen und im gleichen System durchgeführt. Alle Messungen erfolgten an HEK293Zellen, die stabil mit den Transportern transfiziert waren.

Getestet wurden verschiedene Dicarboxylate mit drei bis acht Kohlenstoffatomen (C3 bis C8). Die $\mathrm{IC}_{50}$-Werte der Dicarboxylate gegenüber hOAT1 und hOAT3 änderten sich mit der Kettenlänge der Dicarboxylate. Sowohl gegenüber hOAT1 als auch gegenüber hOAT3 nahm die Affinität mit steigender Kettenlänge, und damit mit dem Abstand der beiden Carboxylgruppen voneinander, zunächst sehr drastisch zu und erreichte ihr Maximum bei den C5-Dicarboxylaten $\alpha$-Ketoglutarat und Glutarat. Mit weiter steigender Kettenlänge nahmen die Affinitäten wieder moderat ab. Absolut waren die $\mathrm{IC}_{50}$-Werte gegenüber hOAT3 immer um etwa den Faktor 13 größer als gegenüber hOAT1. Die gleiche Selektivität lässt vermuten, dass die Bindungstaschen von hOAT1 und hOAT3 ähnliche Strukturen aufweisen. Die unterschiedlichen Affinitäten der untersuchten Dicarboxylate deuten darauf hin, dass diese Bindungstasche bei beiden Transportern zwei positiv geladene Aminosäuren in einem Abstand von etwa $700 \mathrm{pm}$ hat. Die absolut höheren $\mathrm{IC}_{50}$-Werte gegenüber OAT3 haben ihre Ursache möglicherweise darin, dass die Dicarboxylate die Bindungsstelle im OAT3 schlechter erreichen können als im OAT1.

Physiologisch werden die Dicarboxylate im Austausch gegen organische Anionen von OAT1 und OAT3 aus der Tubuluszelle sezerniert. Die organischen Anionen werden nach ihrer Aufnahme in die Zelle in das Tubuluslumen sezerniert und ausgeschieden. Die von den Tubuluszellen benötigten Dicarboxylate werden von dem $\mathrm{Na}^{+}$-Dicarboxylat-Transporter NaDC3 aufgenommen. In einer zu der vorliegenden Arbeit parallel und unter den gleichen Bedingungen im gleichen Expressionssystem durchgeführten Untersuchung wurde gezeigt, dass der NaDC3-Transporter mit den höchsten Affinitäten C4- und C5-Dicarboxylate transportiert. Das heißt, dass physiologisch wahrscheinlich Glutarat und $\alpha$-Ketoglutarat an der 
renalen Sekretion organischer Anionen beteiligt sind, da diese beiden Dicarboxylate von allen beteiligten Transportern gut transportiert werden und vor allem $\alpha$-Ketoglutarat auch in ausreichend hohen Konzentrationen zur Verfügung stehen sollte. 


\section{Literaturverzeichnis}

Akaike $\mathrm{H}$ : Information theory and extension of the maximum likelihood principle. In: Proceeding of the second international symposium on information theory. Akademiai Kiado, Budapest 1973, 267-281

Alebouyeh M, Takeda M, Onozato ML, Tojo A, Noshiro R, Hasannejad H, Inatomi J, Narikawa S, Huang XL, Khamdang S, Anzai N, Endou H (2003): Expression of human organic anion transporters in the choroid plexus and their interactions with neurotransmitter metabolites. J Pharmacol Sci 93, 430-436

Anzai N, Miyazaki H, Noshiro R, Khamdang S, Chairoungdua A, Shin HJ, Enomoto A, Sakamoto S, Hirata T, Tomita K, Kanai Y, Endou H (2004): The multivalent PDZ domaincontaining protein PDZK1 regulates transport activity of renal urate-anion exchanger URAT1 via its C terminus. J Biol Chem $\underline{279}, 45942-45950$

Anzai N, Jutabha P, Enomoto A, Yokoyama H, Nonoguchi H, Hirata T, Shiraya K, He X, Cha SH, Takeda M, Miyazaki H, Sakata T, Tomita K, Igarashi T, Kanai Y, Endou H (2005): Functional characterization of rat organic anion transporter 5 (Slc22a19) at the apical membrane of renal proximal tubules. J Pharmacol Exp Ther $\underline{315}$, 534-544

Asif AR, Steffgen J, Metten M, Grunewald RW, Müller GA, Bahn A, Burckhardt G and Hagos Y (2005): Presence of organic anion transporters 3 (OAT3) and 4 (OAT4) inhuman adrenocortical cells. Pflügers Arch $\underline{450}, 88-95$

Babu E, Takeda M, Narikawa S, Kobayashi Y, Enomoto A, Tojo A, Cha SH, Sekine T, Sakthisekaran D and Endou H (2002): Role of human organic anion transporter 4 in thetransport of ochratoxin A. Biochim Biophys Acta 1590, 64-75

Bahn A, Prawitt D, Buttler D, Reid G, Enklaar T, Wolff NA, Ebbinghaus C, Hillemann A, Schulten HJ, Gunawan B (2000): Genomic structure and in vivo expression of the human organic anion transporter 1 (hOAT1) gene. Biochem Biophys Res Commun 275, 623-630 
Bahn A, Ebbinghaus C, Ebbinghaus D, Ponimaskin EG, Füzesi L, Burckhardt G, Hagos Y (2004): Expression studies and functional characterization of renal human organic anion transporter 1 isoforms. Drug Metab Dispos 32, 424-430

Bakhiya N, Bahn A, Burckhardt G, Wolff N (2003): Human organic anion transporter 3 (hOAT3) can operate as an exchanger and mediate secretory urate flux. Cell Physiol Biochem $\underline{13}, 249-256$

Bakhiya N, Stephani M, Bahn A, Ugele B, Seidel A, Burckhardt G, Glatt H (2006): Uptake of chemically reactive, DNA-damaging sulfuric acid esters into renal cells by human organic anion transporters. J Am Soc Nephrol 17, 1414-1421

Baric I, Wagner L, Feyh P, Liesert M, Buckel W, Hoffmann GF (1999): Sensitivity and specificity of free and total glutaric acid and 3-hydroxyglutaric acid measurements by stableisotope dilution assays for the diagnosis of glutaric aciduria type I. J Inherit Metab Dis $\underline{22}$, 867-681

Berg JM, Stryer L, Tymoczko JL: Stryer Biochemie. 6. Auflage Spektrum Akademischer Verlag, Heidelberg 2007, 209-248

Bisswanger H. Enzymkinetik: Theorie und Methoden. 3. Auflage Wiley-VHC Verlag, Weinheim 2000

Bradford MM (1976): A rapid and sensitive method for the quantitation of microgram quantities of protein utilizing the principle of protein-dye binding. Anal Biochem $\underline{72}, 248-254$

Brady KP, Dushkin H, Fornzler D, Koike T, Magner F, Her H, Gullans S, Segre GV, Green RM, Beier DR (1999): A novel putative transporter maps to the osteosclerosis (oc) mutation and is not expressed in the oc mutant mouse. Genomics $\underline{56}, 254-261$

Burckhardt BC, Burckhardt G (2003): Transport of organic anions across the basolateral membrane of proximal tubule cells. Rev Physiol Biochem Pharmacol 146, 95-158

Burckhardt G, Burckhardt BC (2011): In vitro and in vivo evidence of the importance of organic anion transporters (OATs) in drug therapy. Handb Exp Pharmacol 201, 29-104 
Burckhardt G, Koepsell H: Organic anion and cation transporters in renal elimination of drugs. In: Alpern RJ, Seldin DW, Giebisch GH (Hg.) Seldin and Giebisch's the Kidney: Physiology and Pathophysiology. Elsevier Verlag, Amsterdam 2008, 2045-2080

Burckhardt G, Bahn A, Wolff NA (2001): Molecular physiology of renal p-aminohippurate secretion. News Physiol Sci $\underline{16}, 114-118$

Cha SH, Sekine T, Kusuhara H, Yu E, Kim JY, Kim DK, Sugiyama Y, Kanai Y, Endou H (2000): Molecular cloning and characterization of multispecific organic anion transporter 4 expressed in the placenta. J Biol Chem $\underline{275}, 4507-4512$

Cha SH, Sekine T, Fukushima JI, Kanai Y, Kobayashi Y, Goya T, Endou H (2001): Identification and characterization of human organic anion transporter 3 expressing predominantly in the kidney. Mol Pharmacol $\underline{59}, 1277-1286$

ChemIDplus 2011 advanced NLM: http://chem.sis.nlm.nih.gov/chemidplus/chemidheavy.jsp

Chen X, Tsukaguchi H, Chen XZ, Berger UV, Hediger MA (1999): Molecular and functional analysis of SDCT2, a novel rat sodium-dependent dicarboxylate transporter. J Clin Invest $\underline{103}$, 1159-1168

Cheng Y, Prusoff WH (1973): Relationship between the inhibition constant (K1) and the concentration of inhibitor which causes 50 per cent inhibition (I50) of an enzymatic reaction. Biochem Pharmacol 22, 3099-3108

Cihlar T, Lin DC, Pritchard JB, Fuller MD, Mendel DB, Sweet DH (1999): The antiviral nucleotide analogs cidofovir and adefovir are novel substrates for human and rat renal organic anion transporter 1. Mol Pharmacol $\underline{56}, 570-580$

Cornish-Bowden A (1974): A simple graphical method for determining the inhibition constants of mixed, uncompetitive and non-competitive inhibitors. Biochem J 137, 143-144

Cox MM, Nelson DL: Lehninger Biochemie 3. Auflage, Springer Verlag, Berlin 2001 
De Lean A, Munson PJ, Rodbard D (1978): Simulataneous analysis of families of sigmoidal curves: application to bioassay, radioligand assay, and physiological dose-response curves. Am J Physiol 235, E97-E102

Dixon M (1953): The Determination of Enzym Inhibitor Constants. Biochem J $\underline{55}$, 170-171

Enomoto A, Takeda M, Shimoda M, Narikawa S, Kobayashi Y, Kobayashi Y, Yamamoto T, Sekine T, Cha SH, Niwa T (2002a): Interaction of human organic anion transporters 2 and 4 with organic anion transport inhibitors. J Pharmacol Exp Ther 301, 797-802

Enomoto A, Wempe MF, Tsuchida H, Shin HJ, Cha SH, Anzai N, Goto A, Sakamoto A, Niwa T, Kanai Y, Anders MW, Endou H (2002b): Molecular identification of a novel carnitine transporter specific to human testis. Insights into the mechanism of carnitine recognition. J Biol Chem 277, 36262-36271

Eraly SA, Vallon V, Vaughn DA, Gangoiti JA, Richter K, Nagle M, Monte JC, Rieg T, Truong DM, Long JM, Barshop BA, Kaler G, Nigam SK (2006): Decreased renal organic anion secretion and plasma accumulation of endogenous organic anions in OAT1 knock-out mice. J Biol Chem 281, 5072-5083

Feng B, Dresser MJ, Shu Y, Johns SJ, Giacomini KM (2001): Arginine 454 and lysine 370 are essential for the anion specificity of the organic anion transporter, rOAT3. Biochemistry $\underline{40}, 5511-5520$

Feng B, Shu Y, Giacomini KM (2002): Role of aromatic transmembrane residues of the organic anion transporter, rOAT3, in substrate recognition. Biochemistry $\underline{41}, 8941-8947$

Fritzsch G, Rumrich G, Ullrich KJ (1989): Anion transport through the contraluminal cell membrane of renal proximal tubule. The influence of hydrophobicity and molecular charge distribution on the inhibitory activity of organic anions. Biochem Biophys Acta $\underline{978}, 249-256$

Gorbunov D, Gorboulev V, Shatskaya N, Mueller T, Bamberg E, Friedrich T, Koepsell H (2008): High-affinity cation binding to organic cation transporter 1 induces movement of helix 11 and blocks transport after mutations in a modeled interaction domain between two helices. Mol Pharmacol $\underline{73}$, 50-61 
Graham FL, Smiley J, Russell WC, Nairn R (1977): Characteristics of a human cell line transformed by DNA from human adenovirus type 5. J Gen Virol. $\underline{36}, 59-74$

Hagos Y, Stein D, Ugele B, Burckhardt G, Bahn A (2007): Human renal organic anion transporter 4 operates as an asymmetric urate transporter. J Am Soc Nephrol 18, 430-439

Hasegawa M, Kusuhara H, Sugiyama D, Ito K, Ueda S, Endou H, Sugiyama Y (2002): Functional involvement of rat organic anion transporter 3 (rOat3; Slc22a8) in the renal uptake of organic anions. J Pharmacol Exp Ther $\underline{300}$, 746-753

Hentschel H, Burckhardt BC, Schölermann B, Kühne L, Burckhardt G, Steffgen (2003): Basolateral localization of flounder Na+-dicarboxylate cotransporter ( $\mathrm{fNaDC}-3)$ in the kidney of Pleuronectes americanus. Pflügers Arch 446, 578-584

Hong M, Zhou F, You G (2004): Critical amino acid residues in transmembrane domain 1 of the human organic anion transporter hOAT1. J Biol Chem $\underline{279}$, 31478-31482

Hong M, Zhou F, Lee K, You G (2007): The putative transmembrane segment 7 of the human organic anion transporter hOAT1 dictates transporter substrate binding and stability. J Pharmacol Exp Ther $\underline{320}$, 1209-1215

Hosoyamada M, Sekine T, Kanai Y, Endou H (1999): Molecular cloning and functional expression of a multispecific organic anion transporter from human kidney. Am J Physiol Renal Physiol 276, F122-F128

Hosoyamada M, Ichida K, Enomoto A, Hosoya T, Endou H (2004): Function and localization of urate transporter 1 in mouse kidney. J Am Soc Nephrol 15, 261-268

Kaler G, Truong DM, Khandelwal A, Nagle M, Eraly SA, Swaan PW, Nigam SK (2007): Structural variation governs substrate specificity for organic anion transporter (OAT) homologs. Potential remote sensing by OAT family members. J Biol Chem $\underline{282}$, 23841-23853 
Kaufhold M, Schulz K, Breljak D, Gupta S, Henjakovic M, Krick W, Hagos Y, Sabolic I, Burckhardt BC, Burckhardt G (2011): Differential interaction of dicarboxylates with human sodium-dicarboxylate cotransporter $3(\mathrm{NaDC} 3)$ and organic anion transporters 1 and 3 (OAT1 and OAT3). Am J Physiol Renal Physiol 301, F1026-F1034

Kekuda R, Wang H, Huang W, Pajor AM, Leibach FH, Devoe LD, Prasad PD, Ganapathy V (1999): Primary structure and functional characteristics of a mammalian sodium-coupled high affinity dicarboxylate transporter. J Biol Chem $\underline{274}$, 3422-3429

Klinke R, Silbernagl S: Lehrbuch der Physiologie. 4. Auflage, Thieme Verlag, Stuttgart 2005

Koepsell H, Endou H (2004): The SLC22 drug transporter family. Pflügers Arch 447, 666676

Kojima R, Sekine T, Kawachi M, Cha SH; Suzuki Y, Endou H (2002): Immunolocalization of multispecific Organic Anion Transporters, OAT1, OAT2, and OAT3, in Rat Kidney. Am Soc Nephrol $\underline{13}, 848-857$

Kusuhara H, Sekine T, Utsunomiya-Tate N, Tsuda M, Kojima R, Cha SH, Sugiyama Y, Kanai Y, Endou H (1999): Molecular cloning and characterization of a new multispecific organic anion transporter from rat brain. J Biol Chem 274, 13675-13680

Ljubojević M, Balen D, Breljak D, Kusan M, Anzai N, Bahn A, Burckhardt G, Sabolić I (2007): Renal expression of organic anion transporter OAT2 in rats and mice is regulated by sex hormones. Am J Physiol Renal Physiol 292, F361-F372

Lopez-Nieto CE, You G, Bush KT, Barros EJ, Beier DR, Nigam SK (1997): Molecular cloning and characterization of NKT, a gene product related to the organic cation transporter family that is almost exclusively expressed in the kidney. J Biol Chem $\underline{272}$, 6471-6478

Lu R, Chan BS, Schuster VL (1999): Cloning of the human kidney PAH transporter: Narrow substrate specificity and regulation by protein kinase c. Am J Physiol Renal Physiol 276, F295-F303 
Malo C, Berteloot A (1991): Analysis of kinetic data in transport studies: new insights from kinetic studies of $\mathrm{Na}(+)$-D-glucose cotransport in human intestinal brush-border membrane vesicles using a fast sampling, rapid filtration apparatus. J Membr Biol 122, 127-141

Motohashi H, Sakurai Y, Saito H, Masuda S, Urakami Y, Goto M, Fukatsu A, Ogawa O, Inui $\mathrm{K}$ (2002): Gene expression levels and immunolocalization of organic ion transporters in the human kidney. J Am Soc Nephrol 13, 866-874

Nagai J, Takano M, Hirozane K, Yasuhara M, Inui K (1995): Specificity of p-aminohippurate transport system in the OK kidney epithelial cell line. J Pharmacol Exp Ther 274, 1161-1166

Pajor AM (1996): Molecular cloning and functional expression of a sodium-dicarboxylate cotransporter from human kidney. Am J Physiol 270, F642-F648

Pajor AM (2006): Molecular properties of the SLC13 family of dicarboxylate and sulfate transporters. Pflügers Arch $\underline{451}$, 597-605

Pajor AM, Sun N (1996): Characterization of the rabbit renal $\mathrm{Na}(+)$-dicarboxylate cotransporter using antifusion protein antibodies. Am J Physiol 271, C1808-C1816

Perry JL, Dembla-Rajpal N, Hall LA, Pritchard JB (2006): A three-dimensional model of human organic anion transporter 1: aromatic amino acids required for substrate transport. $\mathrm{J}$ Biol Chem 28, 38071-38079

Pritchard JB (1988): Coupled transport of p-aminohippurate by rat kidney basolateral membrane vesicles. Am J Physiol 255, F597-F604

Projekt 2002: http://www.bbc.co.uk/dna/h2g2/A791246

Race JE, Grassl SM, Williams WJ, Holtzman EJ (1999): Molecular cloning and characterization of two novel human renal organic anion transporters (hOAT1 and hOAT3). Biochem Biophys Res Commun 255, 508-514

Reid G, Wolff NA, Dautzenberg FM, Burckhardt G (1998): Cloning of a human renal paminohippurate transporter, hROAT1. Kidney Blood Press Res 21, 233-237 
Rizwan AN: The importance of charged amino acids in the human organic anion transporter 1. Med. Diss. Göttingen 2006

Rizwan AN, Burckhardt G (2007): Organic anion transporters of the SLC22 family: biopharmaceutical, physiological, and pathological roles. Pharm Res $\underline{24}$, 450-470

Rizwan AN, Krick W, Burckhardt G (2007): The chloride dependence of the human organic anion transporter 1 (hOAT1) is blunted by mutation of a single amino acid. J Biol Chem $\underline{282}$, 13402-13409

Rocchiccioli F, Leroux JP, Cartier PH (1984): Microdetermination of 2-ketoglutaric acid in plasma and cerebrospinal fluid by capillary gas chromatography mass spectrometry; application to pediatrics. Biomed Mass Spectrom 11, 24-28

Schmidt RF, Thews G, Lang F: Physiologie des Menschen. 29.Auflage Springer-Verlag Berlin 2005

Sekine T, Watanabe N, Hosoyamada M, Kanai Y, Endou H (1997): Expression cloning and characterization of a novel multispecific organic anion transporter. J Biol Chem $\underline{272}$, 1852618529

Sekine T, Cha SH, Tsuda M, Apiwattanakul N, Nakajima N, Kanai Y, Endou H (1998a): Identification of multispecific organic anion transporter 2 expressed predominantly in the liver. FEBS Lett $\underline{429}, 179-182$

Sekine T, Cha SH, Hosoyamada M, Kanai Y, Watanabe N, Furuta Y, Fukuda K, Igarashi T, Endou H (1998b): Cloning, functional characterization, and localization of a rat renal Na+dicarboxylate transporter. Am J Physiol 275, F298-F305

Shimada H, Moewes B, Burckhardt G (1987): Indirect coupling to $\mathrm{Na}^{+}$of p-aminohippuric acid uptake into rat renal basolateral membrane vesicles. Am J Physiol 253, F795-F801

Simonson GD, Vincent AC, Roberg KJ, Huang Y, Iwanij V (1994): Molecular cloning and characterization of a novel liver-specific transport protein. J Cell Sci 107, 1065-1072 
Srimaroeng C, Perry JL, Pritchard JB (2008): Physiology, structure, and regulation of the cloned organic anion transporters. Xenobiotica $\underline{38}, 889-935$

Sweet DH, Wolff NA, Pritchard JB (1997): Expression cloning and characterization of ROAT1: The basolateral organic anion transporter in rat kidney. J Biol Chem $\underline{272}$, 3008830095

Sweet DH, Miller DS, Pritchard JB, Fujiwara Y, Beier DR, Nigam SK (2002): Impaired organic anion transport in kidney and choroid plexus of organic anion transporter 3 (Oat3 (Slc22a8)) knockout mice. J Biol Chem 277, 26934-26943

Systat Software: Sigma: Plot 11 user's guide. 1. Auflage Systat Software San Jose, Ca, USA 2008

Ueo H, Motohashi H, Katsura T, Inui KI (2007): $\mathrm{Cl}^{-}$-dependent up-regulation of human organic anion transporters: different effects on transport kinetics between hOAT1 and hOAT3. Am J Physiol Renal Physiol 293, F391-F397

Ullrich KJ: Affinity of drugs to the different renal transporters of organic anions and organic cations: in situ Ki values. In: Membrane transporters as drug targets. 1. Auflage Kluwer Academic/Plenum Publishers, New York 1999, 159-179

Ullrich KJ, Rumrich G, Fritzsch G, Klöss S (1987a): Contraluminal para-aminohippurate (PAH) transport in the proximal tubule of the rat kidney. I. Kinetics, influence of cations, anions, and capillary preperfusion. Pflügers Arch $\underline{409}$, 229-235

Ullrich KJ, Rumrich G, Fritzsch G, Klöss S (1987b): Contraluminal para-aminohippurate (PAH) transport in the proximal tubule of the rat kidney. II. Specificity: aliphatic dicarboxylic acids. Pflügers Arch $\underline{408}, 38-45$

Uwai Y, Okuda M, Takami K, Hashimoto Y, Inui K (1998): Functional characterization of the rat multispecific organic anion transporter OAT1 mediating basolateral uptake of anionic drugs in the kidney. FEBS Lett $\underline{438}, 321-324$ 
Vollhardt KPC, Schore NE: Organische Chemie. 2. Auflage. Wiley-VCH Verlag, Weinheim 1995

Wang H, Fei YJ, Kekuda R, Yang-Feng TL, Devoe LD, Leibach FH, Prasad PD, Ganapathy V (2000): Structure, function, and genomic organization of human $\mathrm{Na}(+)$-dependent highaffinity dicarboxylate transporter. Am J Physiol Cell Physiol 278, C1019-C1030

Wang X, Poole RC, Halestrap AP, Levi AJ (1993): Characterization of the inhibition by stilbene disulphonates and phloretin of lactate and pyruvate transport into rat and guinea-pig cardiac myocytes suggests the presence of two kinetically distinct carriers in heart cells. Biochem J 290, 249-258

Weast RC, Astle MJ: CRC Handbook of chemistry and physics. 60th Edition CRC Press, Boca Raton, Florida, USA 1979

Wolff NA, Werner A, Burkhardt S, Burckhardt G (1997): Expression cloning and characterization of a renal organic anion transporter from winter flounder. FEBS Lett 417 , $287-291$

Wolff NA, Grunwald B, Friedrich B, Lang F, Godehardt S and Burckhardt G (2001): Cationic amino acids involved in dicarboxylate binding of the flounder renal organic anion transporter. J Am Soc Nephrol 12, 2012-2018

Wolff NA, Thies K, Kuhnke N, Reid G, Friedrich B, Lang F and Burckhardt G (2003): Protein kinase $\mathrm{C}$ activation downregulates human organic anion transporter 1-mediated transport through carrier internalization. J Am Soc Nephrol 14, 1959-1968 


\section{Abkürzungsverzeichnis}

\begin{tabular}{|c|c|}
\hline$\AA$ & Ångström \\
\hline ATP & Adenosintriphosphat \\
\hline${ }^{\circ} \mathrm{C}$ & Grad Celsius \\
\hline cAMP & zyklisches Adenosinmonophosphat \\
\hline C-Atom & Kohlenstoffatom \\
\hline $\mathrm{Da}$ & Dalton \\
\hline HEK-293 & human embryonic kidney cell line \\
\hline hOAT & humaner Organische-Anionen-Transporter \\
\hline $\mathrm{IC}_{50}$ & Inhibitorkonzentration bei $50 \%$ Hemmung \\
\hline $\mathrm{K}_{\mathrm{m}}$ & Michaelis-Menten-Konstante \\
\hline $\mathrm{K}_{\mathrm{i}}$ & Hemmkonstante \\
\hline $\mathrm{M}$ & molar (Mol pro Liter) \\
\hline mRNA & messenger-Ribonukleinsäure \\
\hline $\mathrm{NaDC}$ & Natrium-Dicarboxylat-Cotransporter \\
\hline NKT & novel kidney transporter \\
\hline NPT & Na-Phosphat-Cotransporter \\
\hline NSAIDs & non-steroidal anti-inflammatory drugs \\
\hline OAT & Organische-Anionen-Transporter \\
\hline OCT & Organische-Kationen-Transporter \\
\hline OTA & Ochratoxin A \\
\hline $\mathrm{PAH}$ & para-Aminohippurat \\
\hline PBS & phosphate-buffered saline \\
\hline PKC & Protein-Kinase $\mathrm{C}$ \\
\hline SEM & Standardabweichung (standard error of the mean) \\
\hline TDM & Transmembrandomäne \\
\hline$v_{\max }$ & maximale Transportrate \\
\hline$\underline{V_{\min }}$ & nicht-hemmbare Transportrate \\
\hline Alanin & Ala \\
\hline Arginin & Arg \\
\hline Aspartat & Asp \\
\hline Histidin & His \\
\hline Lysin & Lys \\
\hline Phenylalanin & Phe \\
\hline Threonin & Thr \\
\hline Tryptophan & $\operatorname{Trp}$ \\
\hline
\end{tabular}




\section{Danksagung}

An erster Stelle möchte ich PD Dr. rer. nat. W. Krick dafür danken, mir dieses spannende Promotionsthema überlassen zu haben, und für die sehr zeitintensive Betreuung. Mit viel Geduld führte er mich durch diesen speziellen Fachbereich und stand mir, wenn nötig, mit Hilfestellungen und Anregungen zur Seite.

Ich danke Sören Petzke, der mich während des experimentellen Teils meiner Dissertationsarbeit sehr unterstützt hat, und mir mit viel Geduld und Geschick die nötigen praktischen Fertigkeiten vermittelte. 


\section{Lebenslauf}

Am 30.12.1982 wurde ich, Marcel Kaufhold, Sohn von Peter und Elke Kaufhold, in Mühlhausen (Thüringen) geboren. Von 1989 bis 1993 besuchte ich die Grundschule in Struth. Anschließend besuchte ich von 1993 bis 2001 das Käthe-Kollwitz-Gymnasium in Lengenfeld unterm Stein und erwarb dort das Abitur.

Den folgenden Wehrdienst von 2001 bis 2002 absolvierte ich in Halle und Bad Frankenhausen als Sanitätssoldat und Militärkraftfahrer. Von August 2002 bis März 2003 durchlief ich ein mehrmonatiges zahntechnisches Praktikum in Eisenach. Im Sommer 2002 begann ich das Studium der Zahnheilkunde an der Georg-August-Universität Göttingen und bestand im September 2005 die zahnärztliche Vorprüfung. Im Rahmen meines Studiums famulierte ich mehrwöchig in der zahnärztlichen Abteilung des Marangu Lutheran Hospital (Tansania). Im Juni 2008 beendete ich im Alter von 25 Jahren das Studium der Zahnheilkunde mit der zahnärztlichen Prüfung und dem Gesamtergebnis „gut“. Im Anschluss absolvierte ich den experimentellen Teil dieser Promotionsarbeit.

Im Februar 2009 begann ich in der Zahnarztpraxis Dr. Müllhofer \& Kollegen in Osterode meinen Beruf als zahnärztlicher Ausbildungsassistent. Seit dem Abschluss meiner Assistenzzeit im Februar 2011 gehe ich an gleicher Stelle meiner Tätigkeit als angestellter Zahnarzt nach. Am 5. August 2011 ging ich den Bund der Ehe mit meiner Frau, Cornelia Kaufhold, geborene Ziegenspeck, ein. Kurze Zeit später am 26.09.2011 wurden wir glücklich Eltern von unserer gemeinsamen Tochter Marlene. 